\title{
- RADIATION DAMAGE AT THE ROTATING \\ - TARGET NEUTRON SOURCE (RTNS-I) FACILITY AT LAWRENCE LIVERMORE LABORATORY
}

C. H. Logan
E. W. Ruaeell
Augubt 9, 1976

\section{MASTER}

Prepared for U.3. Energy Research \& Development

Administration under contract No. W-7405-Fng-48

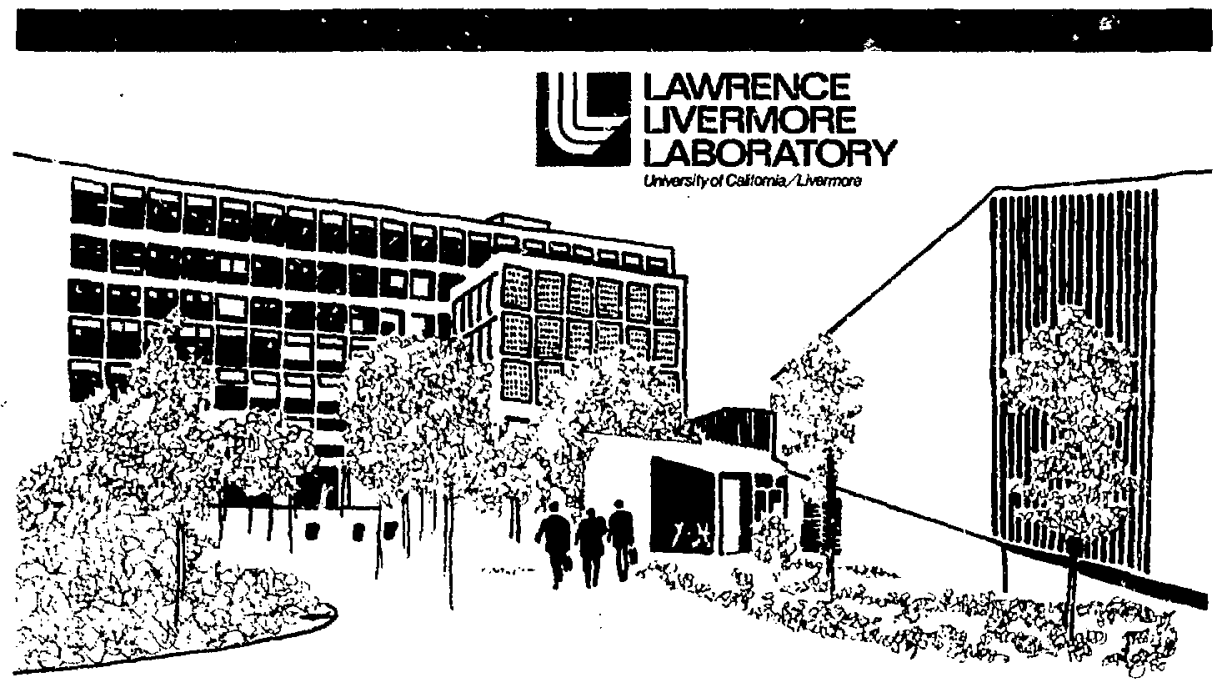




\section{NOTKE}

"This report was propared as an sccount of work sponsored by tho United States Government. Nolther the United Stotes nor the United Sinte Enerty Remarch a Development Admiabtration. nor eny of their employeet, nor any of their contractors, nubcontraciors, is thets nmployees, mekes eny wareanty, expeese on implied, or asumes any lefol liablity or raspondbility for the accurtecy. complotenes or urafulnes of eny information, apperatus, product or proceu iteclosed, of reprecents that lits use would not taffinge privately rowned thats."

Printed in the United States of America Avaliable from

National Technical Information Service

U.S. Department of Commerce

5285 Port Royal Road

Springfield, VA 221EI

Price: Printed Copy 5 ; Microfiche $\$ 2.25$

\begin{tabular}{|c|c|c|c|}
\hline Poj Rens & $\begin{array}{c}\text { Domestic } \\
\text { Price }\end{array}$ & Pan Rans & $\begin{array}{c}\text { Domeate } \\
\text { Price }\end{array}$ \\
\hline $001-025$ & $\$ 3.50$ & $326-3>0$ & 10.60 \\
\hline $026-050$ & 4.00 & $351-375$ & 10.50 \\
\hline $051-075$ & 4.50 & $376-400$ & 10.75 \\
\hline $076-100$ & 5.00 & $401-425$ & 11.00 \\
\hline $101-125$ & 5.25 & $226-450$ & 11.75 \\
\hline i26-150 & 5.50 & $451-475$ & 12.00 \\
\hline $151-175$ & 6.00 & $476-500$ & 12.50 \\
\hline $176-200$ & 7.50 & $501-525$ & 12.75 \\
\hline $201-225$ & 7.75 & $526-550$ & 13.00 \\
\hline $226-250$ & 8.00 & $551-575$ & 13.50 \\
\hline $251-275$ & 9.00 & $576-600$ & 13.75 \\
\hline $276-300$ & 9.25 & $601-u p$ & $\bullet$ \\
\hline $301-325$ & 9.75 & & \\
\hline
\end{tabular}

Add $\$ 2.50$ for each additional 100 page increment from $\$ 01$ to 1,000 pages: add 54,50 for each additional 100 pase, therement over 1,000 pages. 


\title{
노 \\ LAWRENCE LNERMOFE LABOFATORY

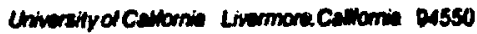

\section{UCRL-52093 \\ RADIATION DAMAGE AT THE ROTATING TARGET NEUTRON SOURCE (RTNS-I) FACUITY AT LAWRENCE UVERMORE LABORATORY}

\author{
C. 11. Logan
}

E. V. Russell

MS. date: Auguet 9, 1976

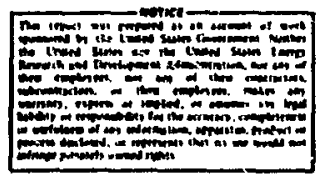




\section{Contents}

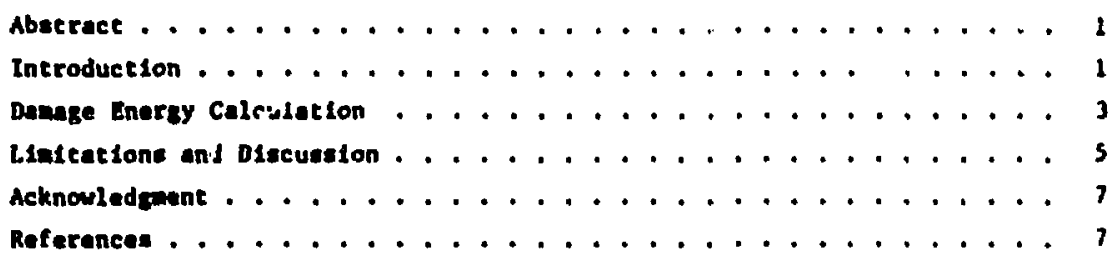




\section{RADIATION DAMAGE AT THE ROTATING TARGET NEUTRON SOURCE (RTNS-I) FACILITY AT LA WRENCE LIVERMORE LABORATORY}

\section{Abstract}

Sowe of the banic computational fentures of a computer program used for nodeling radiation damage at Lbi."s Rotating Target Neutron Source (HTHS-I) are presented. Input Itens required are material cross-section and angular digtribution dat $n$, such as used for blo neutron cransport calculations, along with one particular neutron spectrum of incerest. The nuclear reactions consldered are clastic, neutron-emitting, and charged"particleculteing. Claselcal and relativietic aechanice are used as required to calculate the resulting primary-recoli energy spectra and danuge enerzy spectra. Calculative results are presented Ior the RTNS-I neutron spectra on aluninum, titanlum, vaoadium, iron, nickel, copper, zirconium, nioblum, molybdesum, silver, cin, cantalum, tungsten, gold, and lead.

\section{Introduction}

In the carly days of reactor technolopy and radiation damage, neutron rluence was used as a measure of radiarion exposure. Radiation environments will continue to Increase in conplexity, especially as fusion reactors become a reality. The understanding of the fundamental characteriatics of materials has advanced to a state where hetcer weasurewents of radiation dasage can be deteraned. To understand the response of a waterial to neutron exposure, it is necessary to calculate the damage-enzrgy deltvered to the matertal.

The Rotating Target Neutron Source (RTNS-I) facility conalats of a high Intensity neutron source and a rotat.Ing, water-cooled carget (see FIg. 1). The Insulated core transfotwer (ICT)-accelerator used In RTWS-I presently delivers a 15- to 25-ah deuteron bea collimated to a diameter of $1.6 \mathrm{~cm}$. Most of the current is concentrated to within less than half this diameter. 15-MeV neutrons are produced by deuteron 
bombardment of the tritlun absorbed in the titanlue target. The target is rotated at bigh speeds and is watercooled to dissipate the large asount of power in the deuteron beam. Table 1 summarizes the main parameters of RTNS-I and ulso of RTIS-II, whIch wI11 become operational about July 1,3978 .

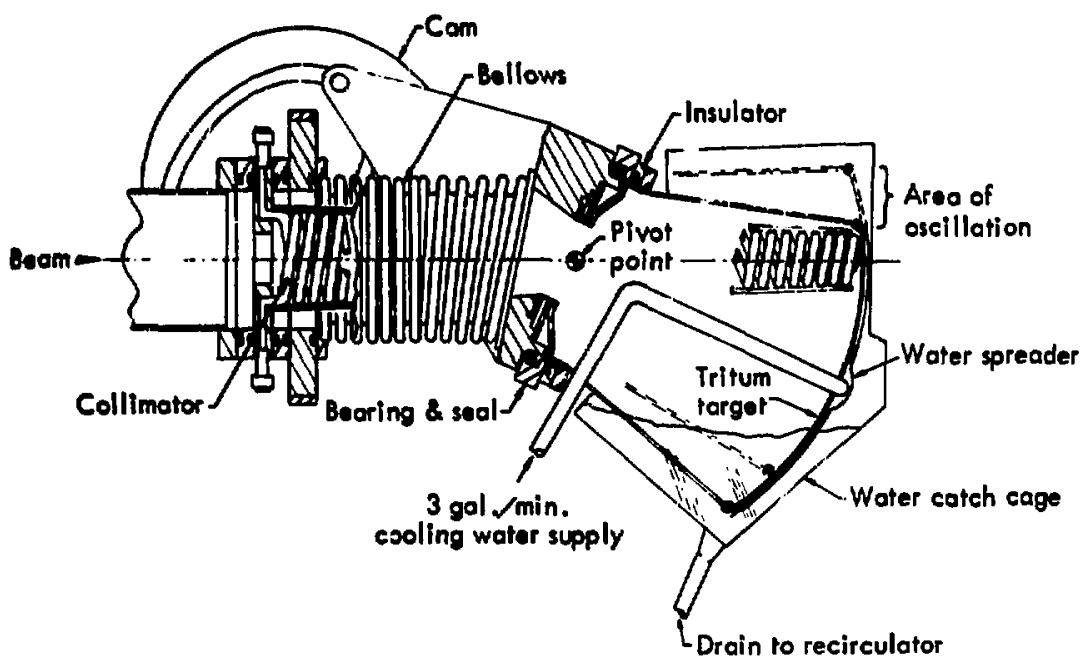

F1g. 1. Target system of RTNS-I.

Table 1. Lawrence Liverwore Laboratory $14-\mathrm{MeV}$ neutron sources.

\begin{tabular}{|c|c|c|c|}
\hline \multirow[b]{2}{*}{ Sarameter } & \multirow[b]{2}{*}{ RTNS-I } & \multicolumn{2}{|c|}{ RTNS-II } \\
\hline & & $\begin{array}{c}\text { Injtial } \\
\text { operation }\end{array}$ & $\begin{array}{l}\text { Upgraded } \\
\text { operation }\end{array}$ \\
\hline Supply, wA,kv & 60,400 & 300,500 & 500,500 \\
\hline Target current, in & 20 & $40-160$ & 400 \\
\hline Bean diamter, cil & 0.6 & $0.6-1.0$ & 1.0 \\
\hline Power density, $\mathrm{kw} / \mathrm{cm}^{2}$ & 30 & $60-80$ & 200 \\
\hline Target dianeter, im & 23 & $48-70$ & 70 \\
\hline Rotation speed, rpin & 1100 & $5000-10000$ & 10000 \\
\hline Source strength, $10^{12} \mathrm{n} / \mathrm{sec}$ & 5 & $10-40$ & 100 \\
\hline Sanil sasple flux, $10^{12} \mathrm{n} / \mathrm{cm}^{2} \mathrm{sec}$ & 2 & $4-16$ & $?$ \\
\hline $\begin{array}{l}\text { Target lifetime, hr } \\
\text { (20z yield drop) }\end{array}$ & 100 & 100 & $?$ \\
\hline
\end{tabular}




\section{Damage Energy Calculation}

The computer program input requires materlal cross-section and angular distribution data for a particular material, along with the incident neutron spectrum of interest. The energy-dependent cross-section and elastic distribution data are taken from the Livemor: Bvaluated Neutron Crosu-Section Libramy. These data are also used for ILL neutron transport calculations. The neutron spectrum and group boundary structure is defined by the user (e.g., see FIg. 2). Isotopic data

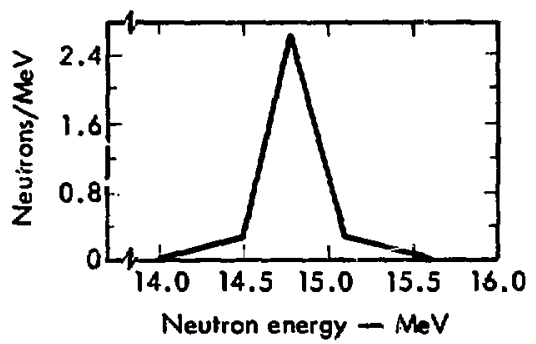

F1g. 2. Neutron spectrum of RTNS-I.

and the threshold energy for displacement in the primary event are also required as input data. Linear Interpolation is used in matching input flux, cross sections, and energy values and also in subsequent calculations.

The calculative procedure basically utilizes the Input data, com- bined with classical and relativistic mechanics, to obtain the primaryrecol1 energy and damage-energy spectra for the material of interest. The main nurlear reactions considered are elastic, $\left(n, n^{\prime}\right),(n, 2 n)$, and $(n,+)$. For RTNS, the $(n, y)$ reaction is not important in damage production and is not included. For elastic reactions, we use input angular distributlons, and for nonelastic reactions we assume 1sotropic scattering. For nonelastic reactions In which the $E$ scondary particles consist of one or more neutrons, the energy distribution of the secondacy particles is chosen from a nuclear temperature plus a pre-equijibrium component. Only the firat particle out is considered. For outgoing charged particles, we assume that the energy spectrum is Gaussian, centered at the Coulomb energy, dropping to 17 of the maximum value for zeroemitted energy.

The following is a summary of the principal steps in the calculations.

1. The Input spectrum is plotied.

2. The Input flux is paritioned, and average energles and cross sections are calculated for each group. A11 neutrons within a group are now assumed to be of the calculated average energy and cross section. 
3. A matrix containing fluxweighted cross sections for each reaction type and each neutron energy group is calculated.

4. The normallzed "prinary knock-on atom" (PKA) spectrum for elastin recolls is calculated for each group.

5. The nuclear temperature is Interpolated from tabular values $^{2}$ (see $\mathrm{FIg}$. 3).

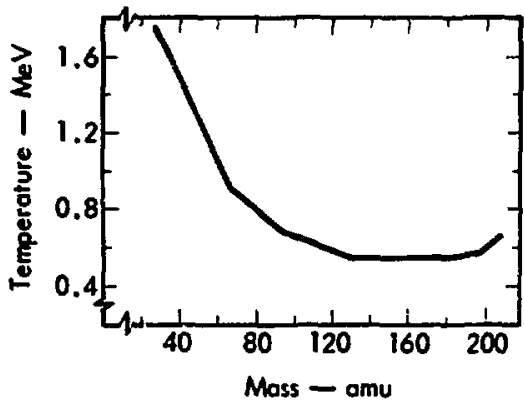

F18. 3. Nuclear temperature as a function of atomic mass.

6. The normalized PKA spectrum resulting from Inelastic collisions is calculated and plotted for each group.

7. The normal1zed PKA- opectrum for charged-particle recolls is calculated and plotted for each group.

8. All spectra are collapsed into a single primary-recoll spectrum. Plots are made of the resulting primary-recoll spectrum as we 11 as the normallzed Integral of the spectrum.

9. The primary recoil spectrum is now converted to a damageenergy spectrum by using theoretical expressions derived (by Lindhard et $a 1 .{ }^{3}$ and Roíinson "; for damage efficlency of creating atom displacements in materials. Plots are made of the damage-energy spectrum as well as the normalIzed Integral of the spection.

The Integral of the drmage-energy spectrum is a measure of the damage effectiveness of the input neutron spectrum. This parameter is proportional to the rate of atom displacement and is the product of (a) the cross section for producing a primary recoll and (b) the uverage damageenergy per primary recoll. Table 2 lists the calculated results of the RTNS-I neutron spe;rrum on aluminum, Iron, copper, and niobium. The spectrum-averaged cross sections Iisted were calculated from the LLL cross-section library data. 
Table 2. S-ectrum-averaged cross sections for RTNS-I (figures in barns unless otherwise noted).

\begin{tabular}{|c|c|c|c|c|}
\hline Nuclear reaction & Aluminum & Iron & Copper & Niobium \\
\hline Elastic & $6.5 \times 10^{-1}$ & $1.1 \times 10^{0}$ & $1.5 \times 10^{0}$ & $2.2 \times 10^{0}$ \\
\hline$\left(n, n^{\prime}\right)$ & $6.6 \times 10^{-1}$ & $7.8 \times 10^{-1}$ & $5.1 \times 10^{-1}$ & $4.1 \times 10^{-1}$ \\
\hline$(n, 2 n)$ & $1.0 \times 10^{-1}$ & $4.7 \times 10^{-1}$ & $7.3 \times 10^{-1}$ & $1.2 \times 10^{0}$ \\
\hline$\left(n, n^{\prime} p\right)$ & - & - & $1.3 \times 10^{-1}$ & - \\
\hline$\left(n, n^{\prime} \alpha\right)$ & $\rightarrow$ & - & - & $2.6 \times 10^{-3}$ \\
\hline$(n, p)$ & $7.1 \times 10^{-2}$ & $1.1 \times 10^{-1}$ & $7.6 \times 10^{-2}$ & $4.0 \times 10^{-2}$ \\
\hline$(n, d)$ & $3.0 \times 10^{-2}$ & - & - & - \\
\hline$(n, t)$ & $6.0 \times 10^{-4}$ & - & - & - \\
\hline$(n, x)$ & $1.2 \times 10^{-1}$ & $2.9 \times 10^{-2}$ & $2.5 \times 10^{-2}$ & $9.2 \times 10^{-3}$ \\
\hline$(n, \gamma)$ & $2.1 \times 10^{-4}$ & $6.2 \times 10^{-5}$ & $5.6 \times 10^{-4}$ & $7.8 \times 10^{-4}$ \\
\hline Tctal & 1.63 & 2.50 & 2.94 & 3.93 \\
\hline$\sigma_{\text {recoll }}$ & 1.63 & 2.50 & 2.94 & 3.92 \\
\hline $\begin{array}{c}\text { Damage energy, } \\
\text { barns - kev }\end{array}$ & 162 & 272 & 277 & 263 \\
\hline
\end{tabular}

\section{Limitations and Discussion}

The computer progran described here can be applled to most neutron spectra with the following limitations:

- The present omission of $(n, Y)$ limits application to cases where this reaction is not important.

- The Lindhard expression used for electron-excitation losses is only appropriate for pure metals.

- The nonelastic and Lindhard theories used are invalid for elements Iighter than aluminum. A number of safeguards built into the program protect the user from some of the more common pitfalls. Messages are printed out, and In sicme cases the calculation is stopped when the following problems are discovertd:

- The material of interest does not match the cross section and angular distribution input data.

- The defilied group boundaries do not fall within the input neutron spectrum.

- The energy entries are not sequential.

- The Input data exceeds the dimensioned storage space. 
- Either the angular or the energy distributlons fall to Integrate tc one.

Also, a warning is printed if the user attempts calculations that are outglde the mass range where the nuclear temperaturc model is appropriate.

In addition to the above, an option to avallable for determining the amount of information output. When other Input error is suspected, this option allows the user to request the maximum output for thecking varlous stages of the calculation.
Calculations wert made for the RTiS-I neutron spectrum on aluminum, titanium, vanadium, :ron, nickel, copper, zircontum, nlobium, molybdenum, silver, tin, tantalim, tungsten, gold, and lead. Table 3 summarizes our damag-energy calculations and compares them to similar calculations made by others. ${ }^{5-9}$ The remaining 11lugtrations - Figs. 4 tisrough 63 ahow graphical computer out?ut for:

- The primary recoll spectrum both In log-1inear (e.g. Fig. 4) and $\log -10 \mathrm{~g}$ form (e.g., FIB. 5).

Table 3. Summary of results of damage-energy calculations and comparison with results of others (damage energy given in barns - keV).

\begin{tabular}{|c|c|c|c|c|c|c|c|}
\hline \multirow[b]{2}{*}{ Element } & \multicolumn{6}{|c|}{ Data source } & \multirow[b]{2}{*}{$\begin{array}{l}\text { Omar } \\
\text { et al. } 9\end{array}$} \\
\hline & $\begin{array}{l}\text { This } \\
\text { work }\end{array}$ & $\begin{array}{l}\text { Doran and } \\
\text { Yosh Ikewa, }\end{array}$ & Eds. & $\begin{array}{l}\text { Park } \pm n_{6} \\
\text { et al. }\end{array}$ & $\begin{array}{l}\text { Robert.o } \\
\text { et al. } 7\end{array}$ & $\begin{array}{l}\text { Parkin and } \\
\text { Goland } 8\end{array}$ & \\
\hline A1 & 163 & 189 & & 164 & & 173 & \\
\hline $\mathbf{T} \mathbf{1}$ & 259 & & & & & & \\
\hline$V$ & $24 i$ & & & 237 & & & \\
\hline $\mathrm{Fe}$ & 272 & & & & & & 278 \\
\hline$N 1$ & 312 & 253 & & & & & 254 \\
\hline Cu & 277 & 273 & & & 301. & 272 & 267 \\
\hline $\mathrm{Zr}$ & 236 & 240 & & & & & 200 \\
\hline $\mathrm{Nb}$ & 263 & & & 273 & 266 & 274 & 266 \\
\hline$M_{0}$ & 246 & & & & & & \\
\hline $\mathbf{A g}$ & 228 & & & & & & \\
\hline $\mathrm{Sn}$ & 229 & & & & & & \\
\hline $\mathbf{T a}$ & 212 & & & & & & \\
\hline$W$ & 201 & 201 & & & & & \\
\hline $\mathrm{Au}$ & 183 & & & & 212 & 194 & 188 \\
\hline $\mathrm{Pb}$ & 193 & $\therefore 10$ & & & & & \\
\hline
\end{tabular}


- The normalized Integral of the recoil spectrum (e.s., Fig. 6).

- The normalized integraj of the damage energy spectrum (c.g., Fig. 7 j.

\section{Acknowledgment}

The authors wish to acknowledge the wurk of D. J. Huber, now with Combustion Engineering, Physics Division, Windsor, Connectlcut, in the development of this computer program.

\section{References}

1. R. I. Howerton, R. J. Doyas, T. C. Michels, and S. T. Perkine, Livernore Evaluated licutron Crose Section Litray, Lawrence Livermore Laborato:y, Rept. UCRL-50400 (1976).

2. S. N. Grimes, lawrence Livernore Laboratory, private communication (1976).

3. J. LIndhard, V. Nielgon, M. Scharff, and P. V. Thomse, KgZ. Danske Videnskab. Selsikab, Mat.-Fys. Medd. 33(10), 1-42 (1963).

4. M. T. Robinson, "The Energy Dependence of Reutron Radiation Damage in Sollds," in Proc. Brit. Nuci. Erergy Soc. Conf. Nucl. Fusion Reactors, Abingion, 1969 (UKAFA Culham Laboratory, Abingdon, Fingland, 1970), Vol. 1, PP. 364-378.

5. D. G. Doran and H. H. Yosh1kawa, Eds., ControiZed Themonuclear Research

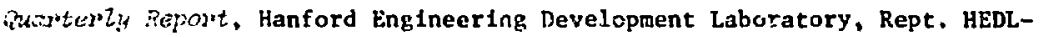
TME-75-90 (1975), p. 20 .

6. D. H. Park1n, A. N. Goland, and H. C. Berry, "Damage Energy Cross Sectlon and Primary Recoll Spectra for CTR-Re'ated Neutron Surces," In Prec. First Topical intg. Tech. Controlled Muclear Fusion (San Diego, Callf., 1974), Vol. 1, Pp. 339-349.

7. J. B. Roberto, M. T. Robinson, and C. Y. FU, "Neutron Drmage Calculations In $\mathrm{Cu}, \mathrm{Mb}$, and $\mathrm{Au}$ to $32 \mathrm{MeV}$ : Application to Sputtering and DeuteronBreakup Neutron Sources," in Proc. Intemat'l Conf. Stroface Effects Controzzed Fusion Devices (San Francisco, Cal1f,, 1976), in press.

8. D. M. Parkin and A. N. Goland, "Calculation of Radiation Effects as a Function of Incident Neutron Spectrum," Radiation Effects 28(1-2), 31-42 (1976).

9. A. M. Omar, J. E. Robinson, and E. A. Thompson, "Calculation of Scattering and Radiation Damage Parameters for MeV Neutrons and Protons on $\mathrm{Fe}, \mathrm{N} 1$, Cu, Zr, Nb, and Au," J. Muct. Mater., In press (1976). 


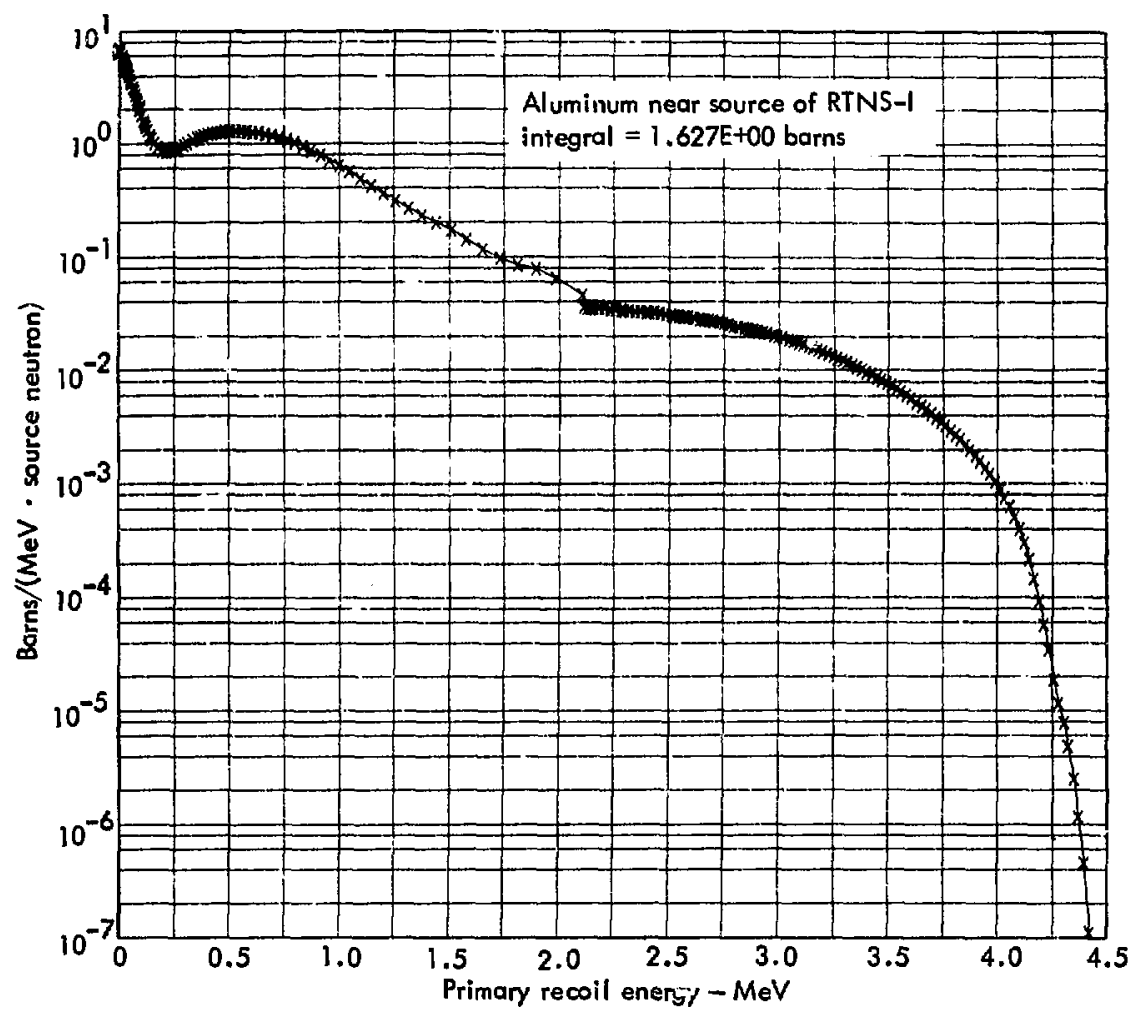

Fig. 4. The primary recoll spectrum (semi-log). 


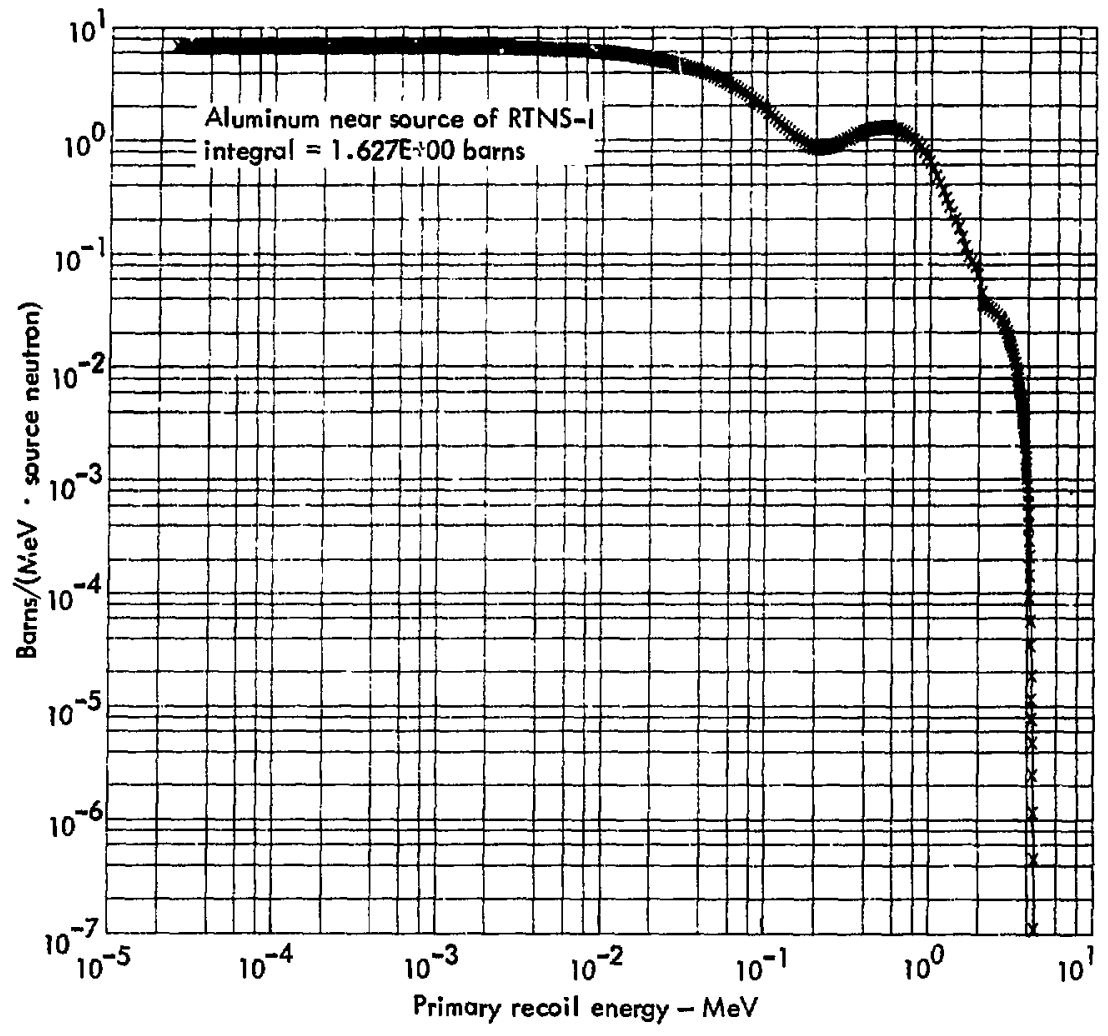

Fig. 5. The primary recoll spectrum (log-1og). 


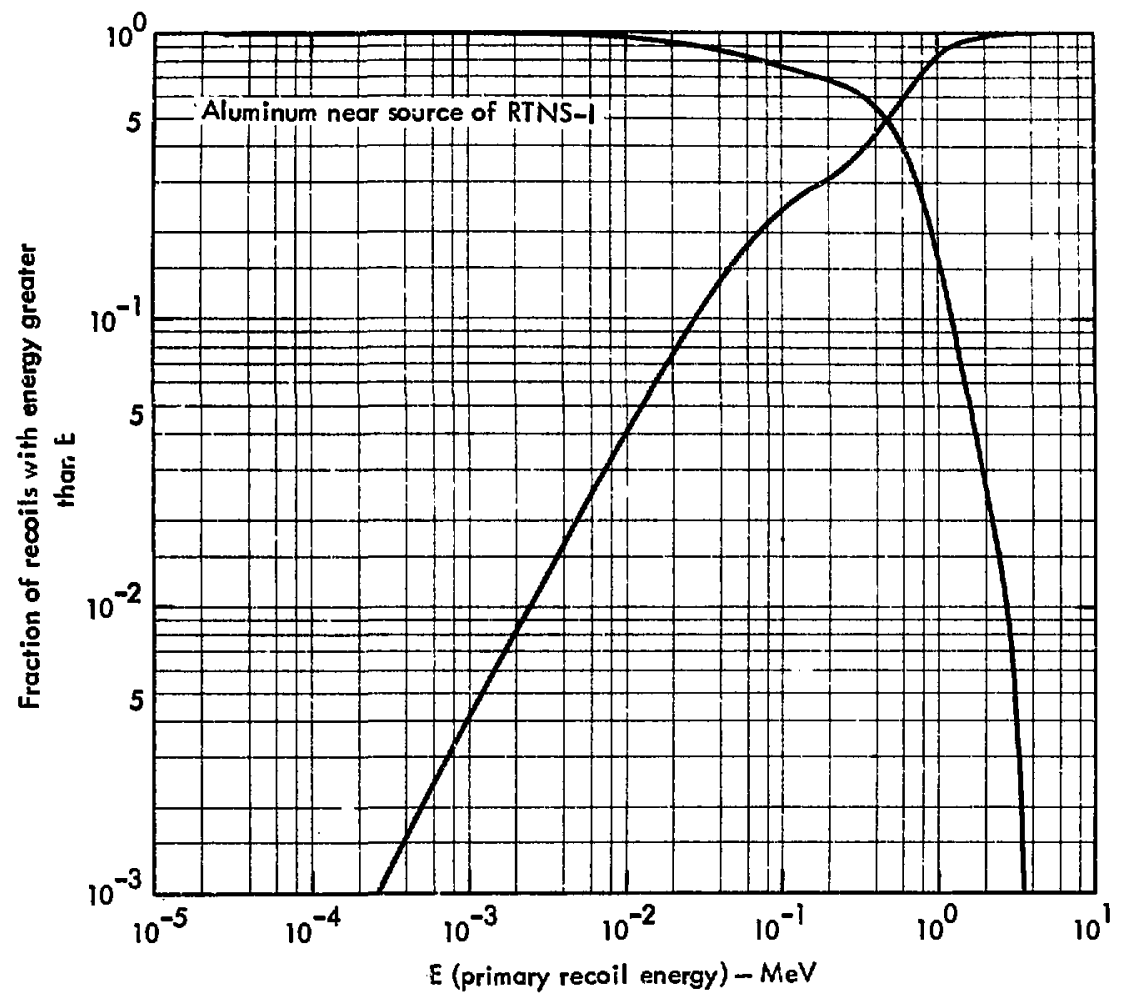

Fig. 6. The normalized Integral of the recoil spectrum. 


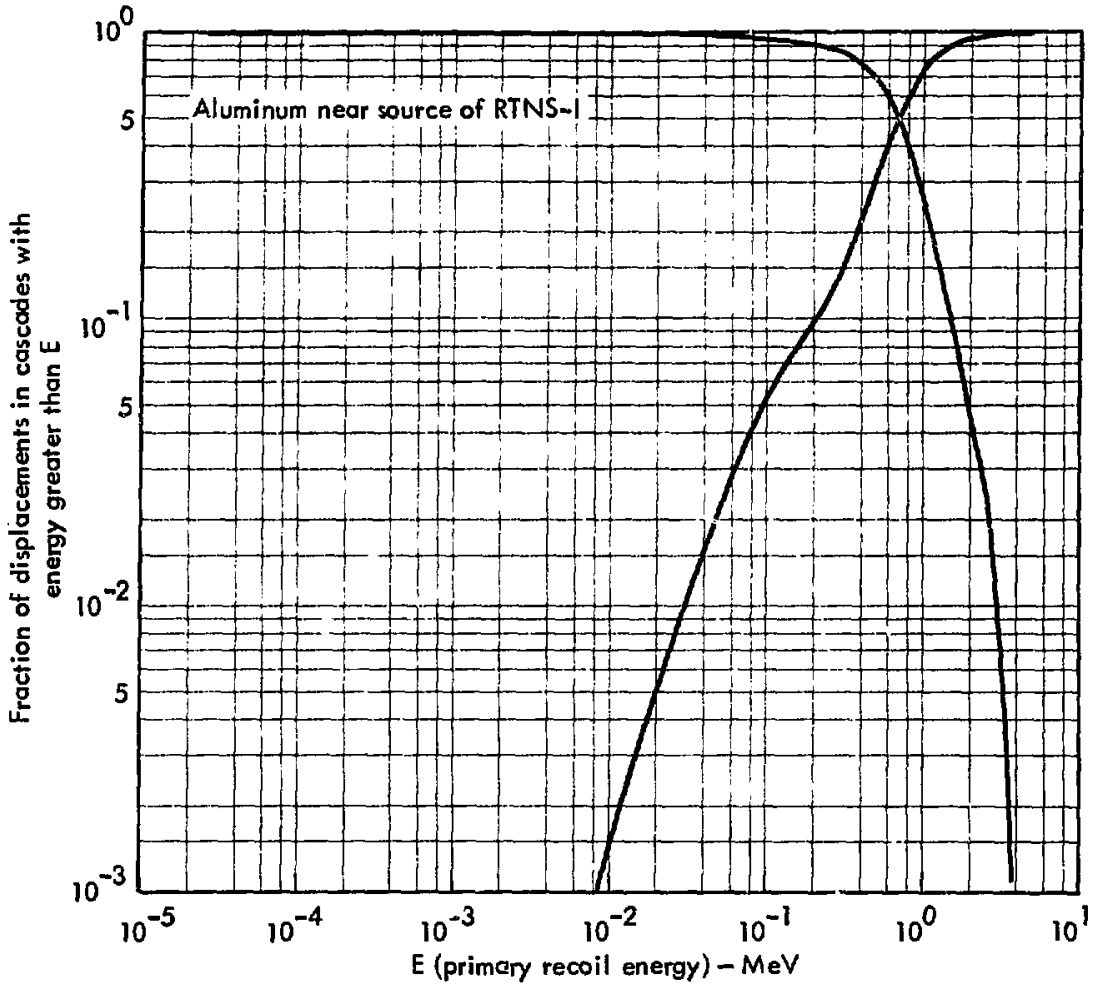

Fig. 7. The normalized integral of the damage energy spectrum. 


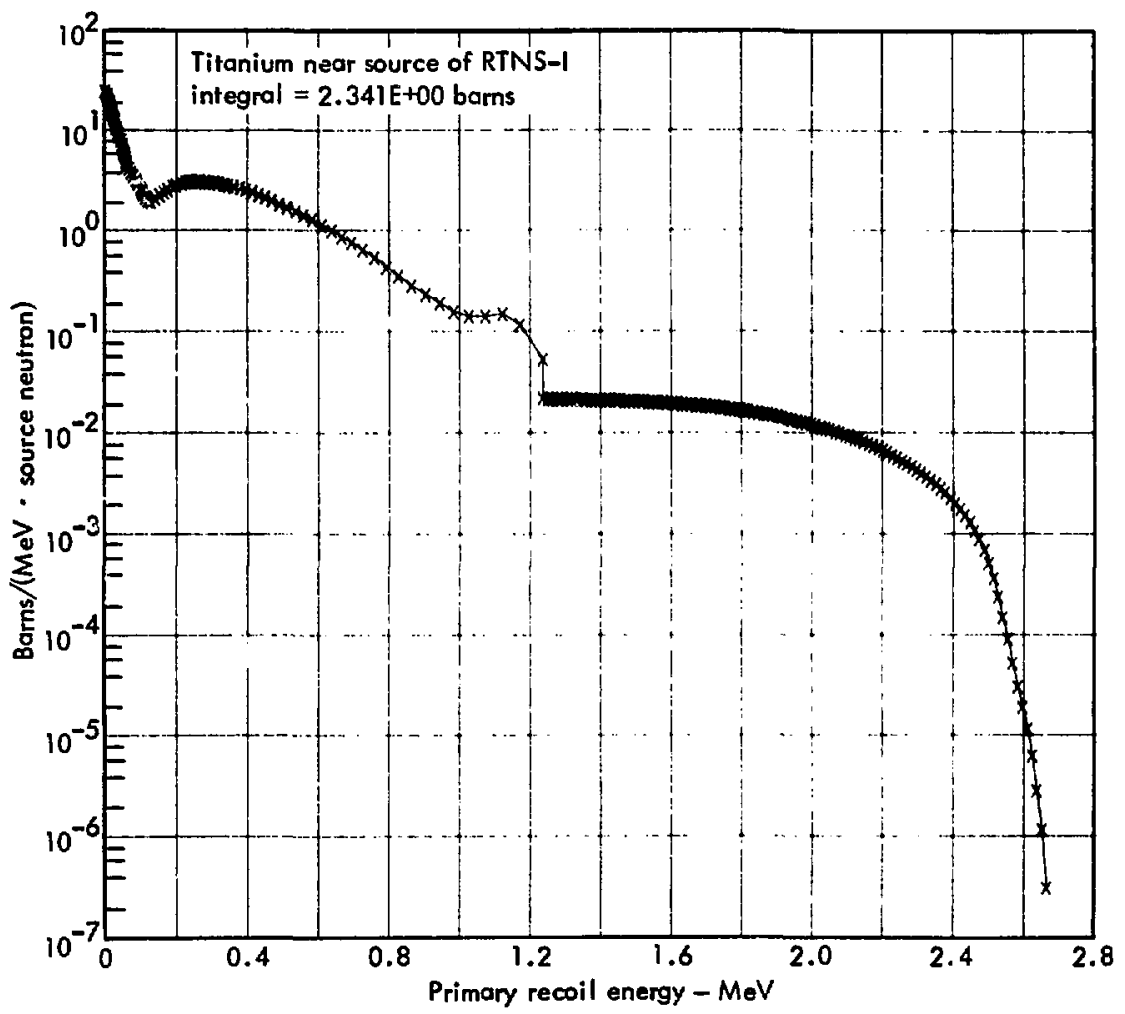

Fig. 8. The primary recoil spectrum (semi-log). 


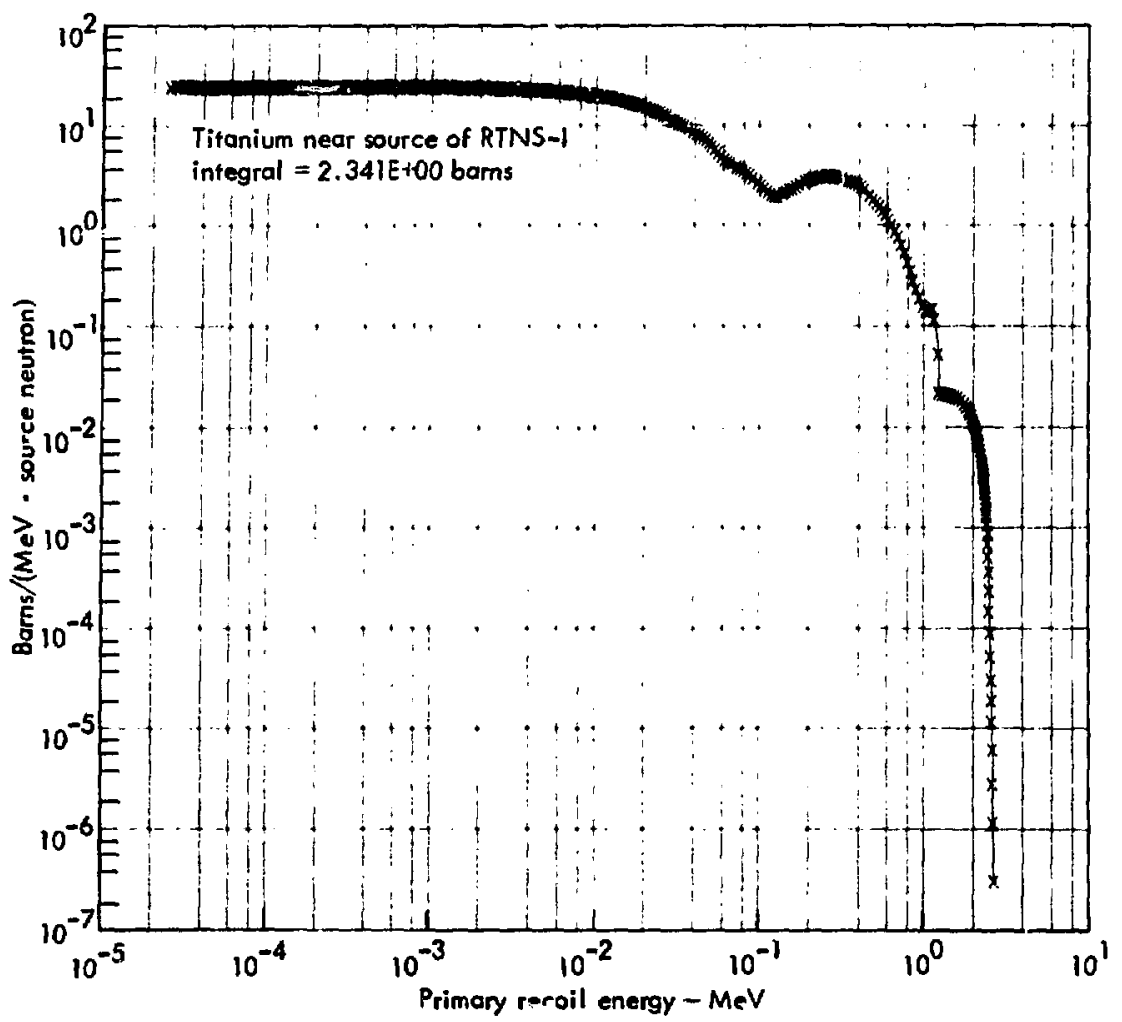

Fig. 9. The primary recoll spectrum (log-log). 


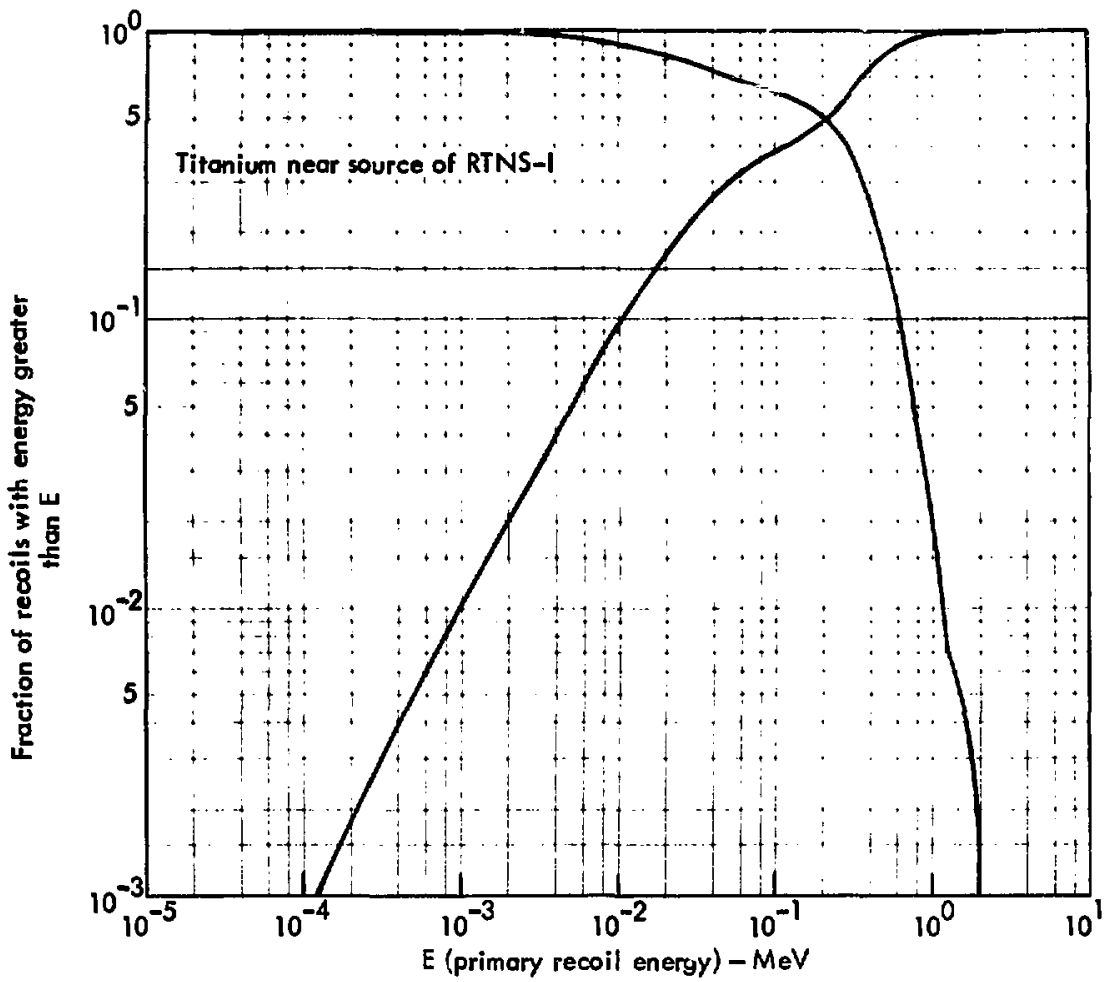

F1g. 10. The normalized integral of the recoll spectrum. 


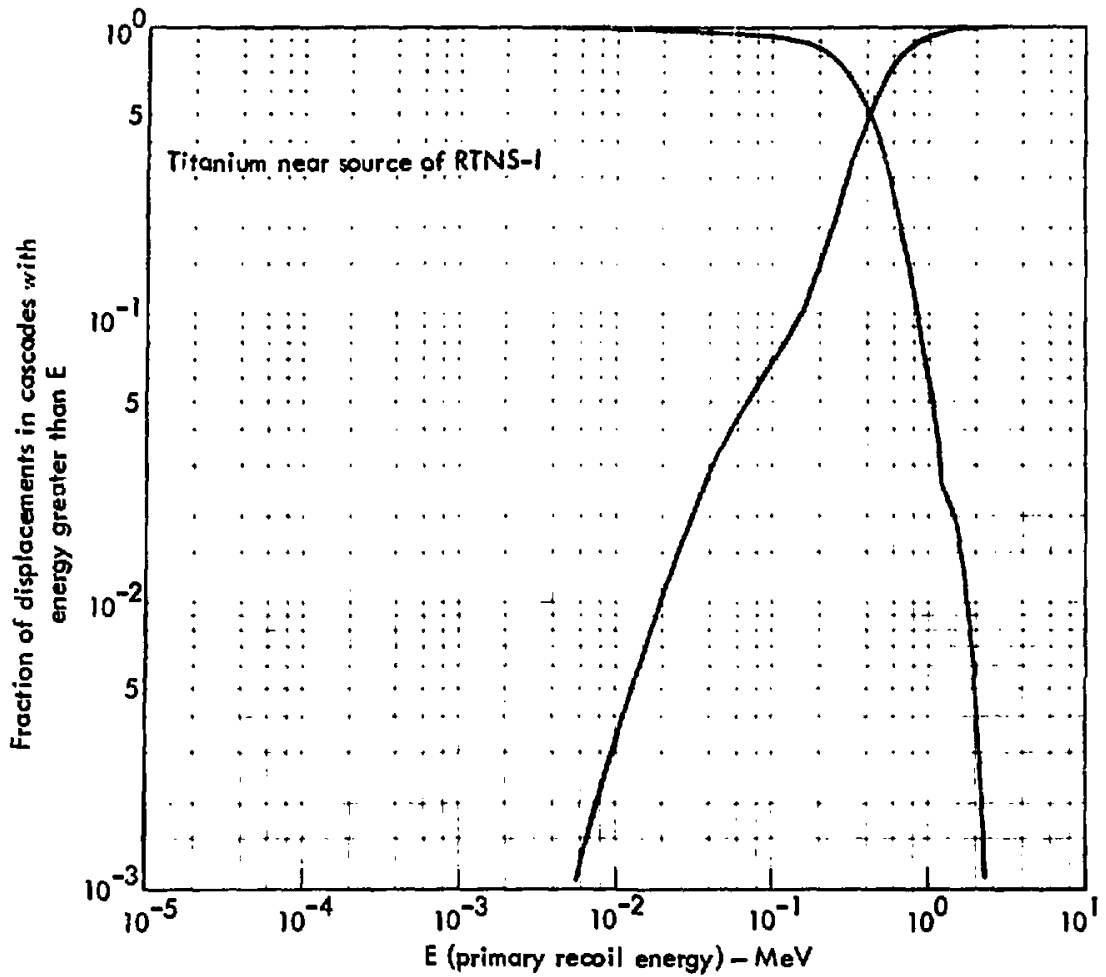

Fig. 11. The normalized integral of the damage energy spectrum. 


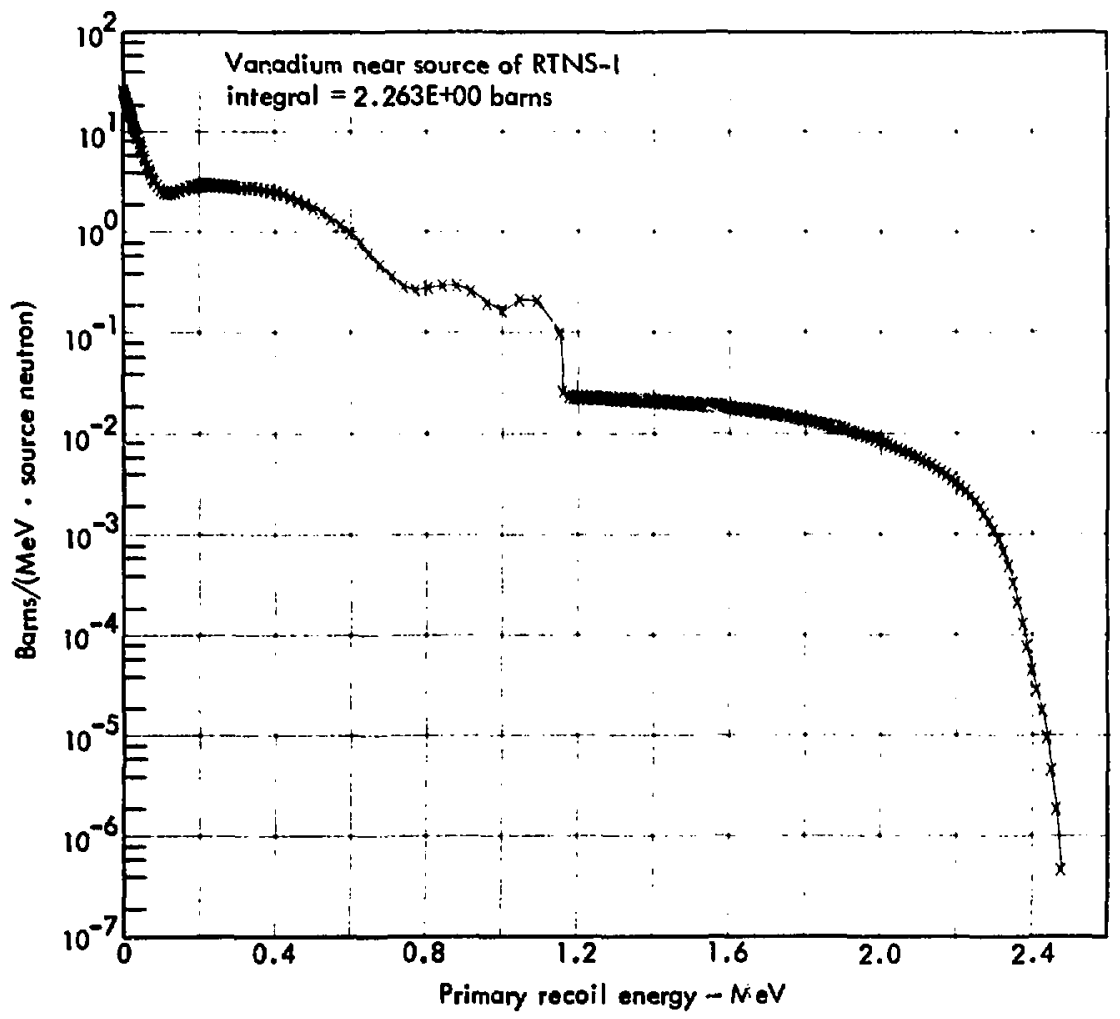

Fig. 12. The primary recoll spectrum (semi-1cg). 


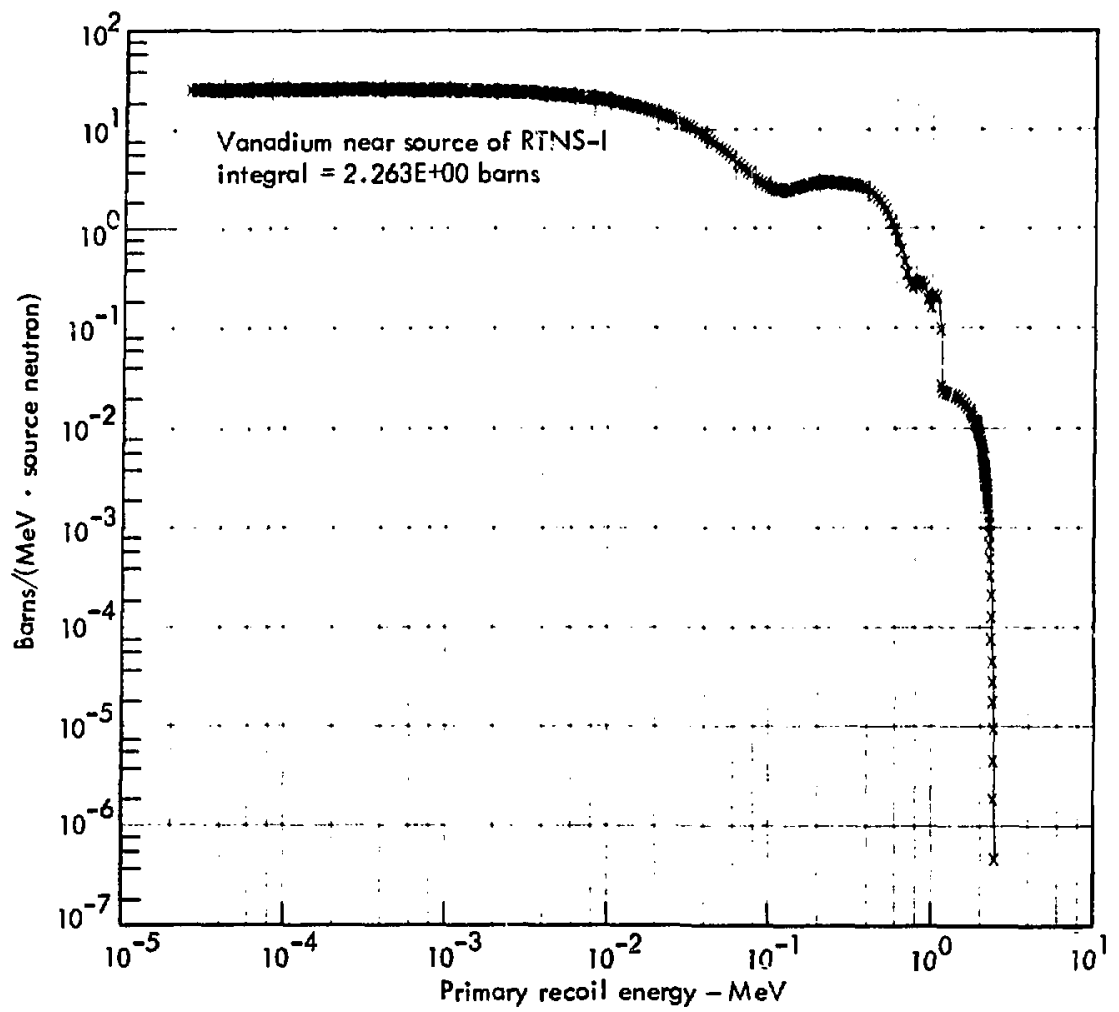

Fig. 13. The primary recoll spectrum (log-10g). 


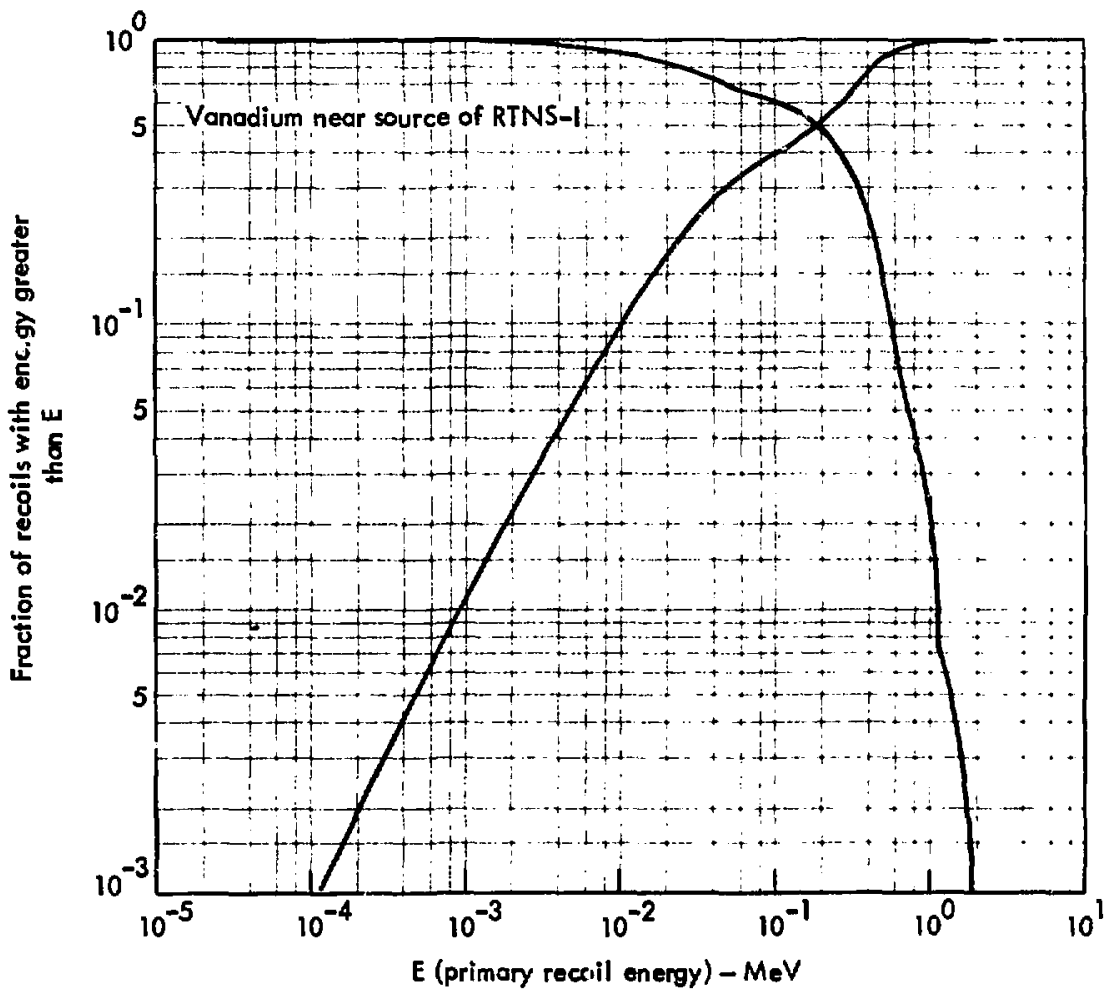

Fig. 14. The normallzed Integral of the recoll spectrum. 


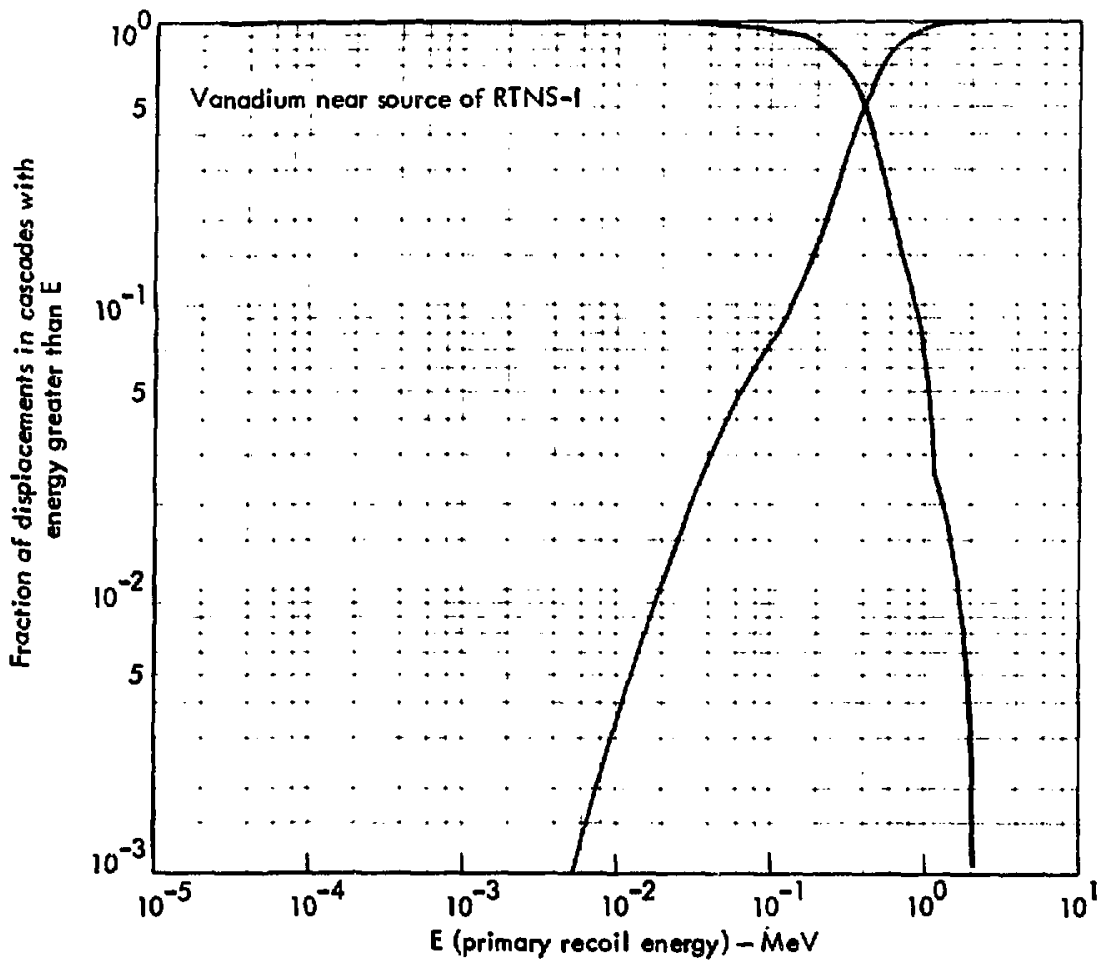

Fig. 15. The notmalized integral of the damage energy spectrum. 


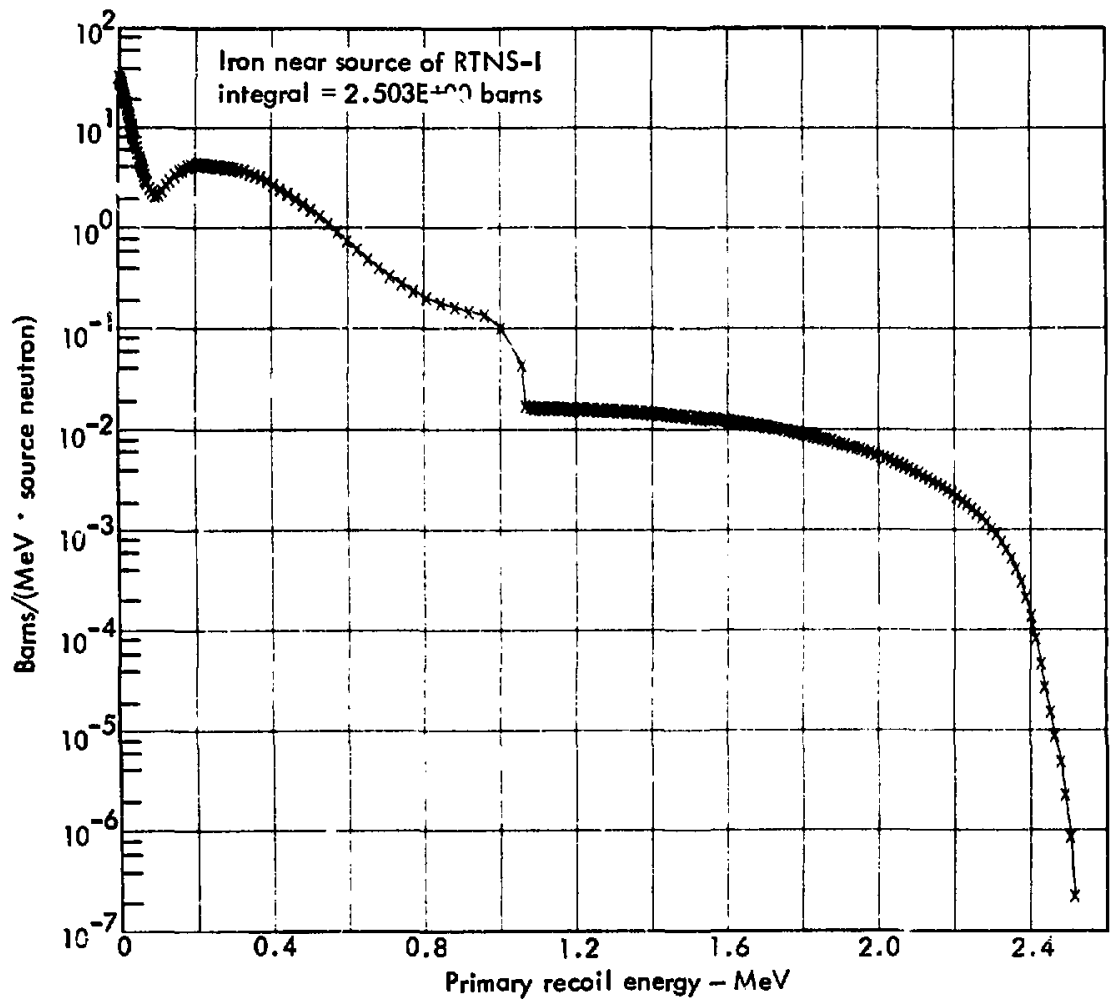

Iig. 16. The primary recoll spectrum (seni-log). 


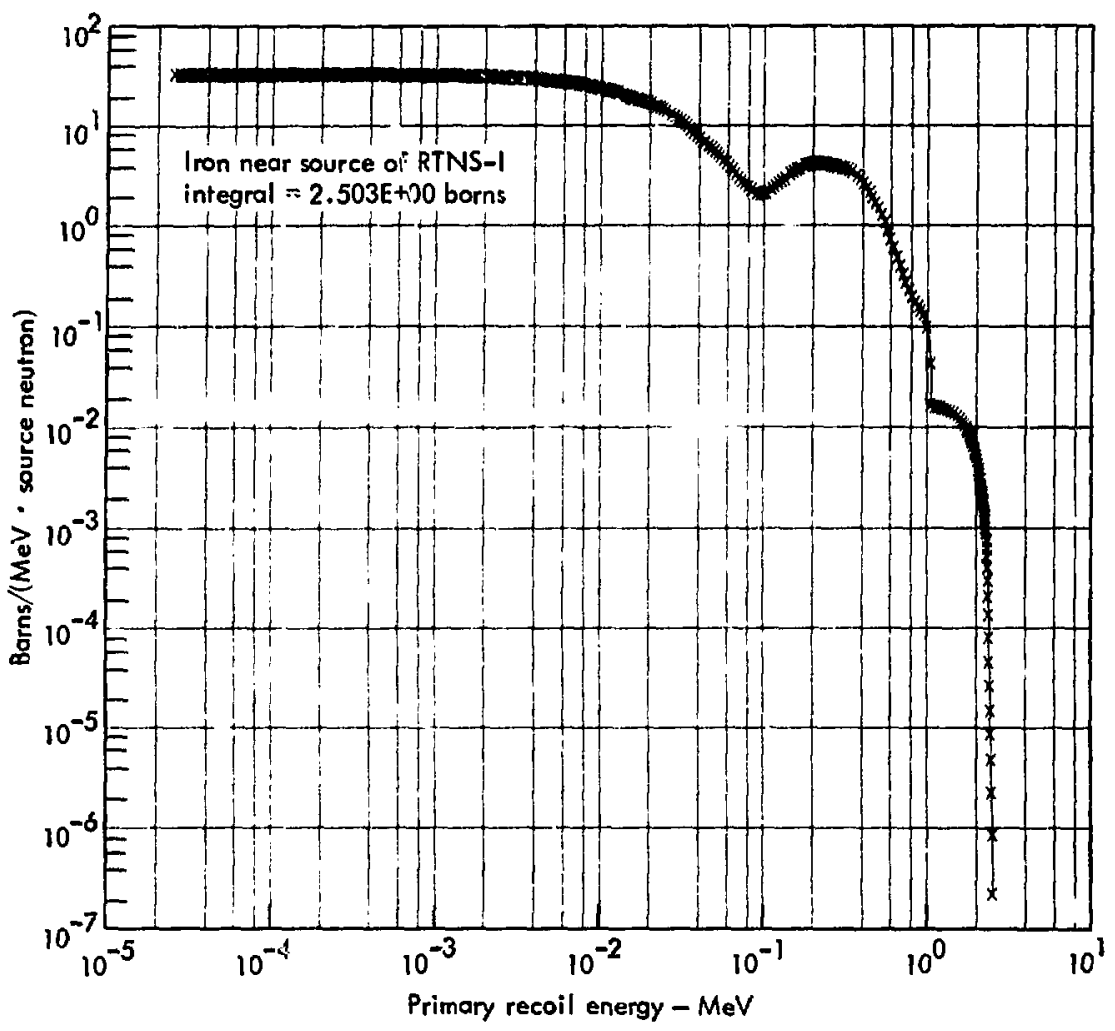

Fig. 17. The primary recoil spectrum $(\log -\log )$. 


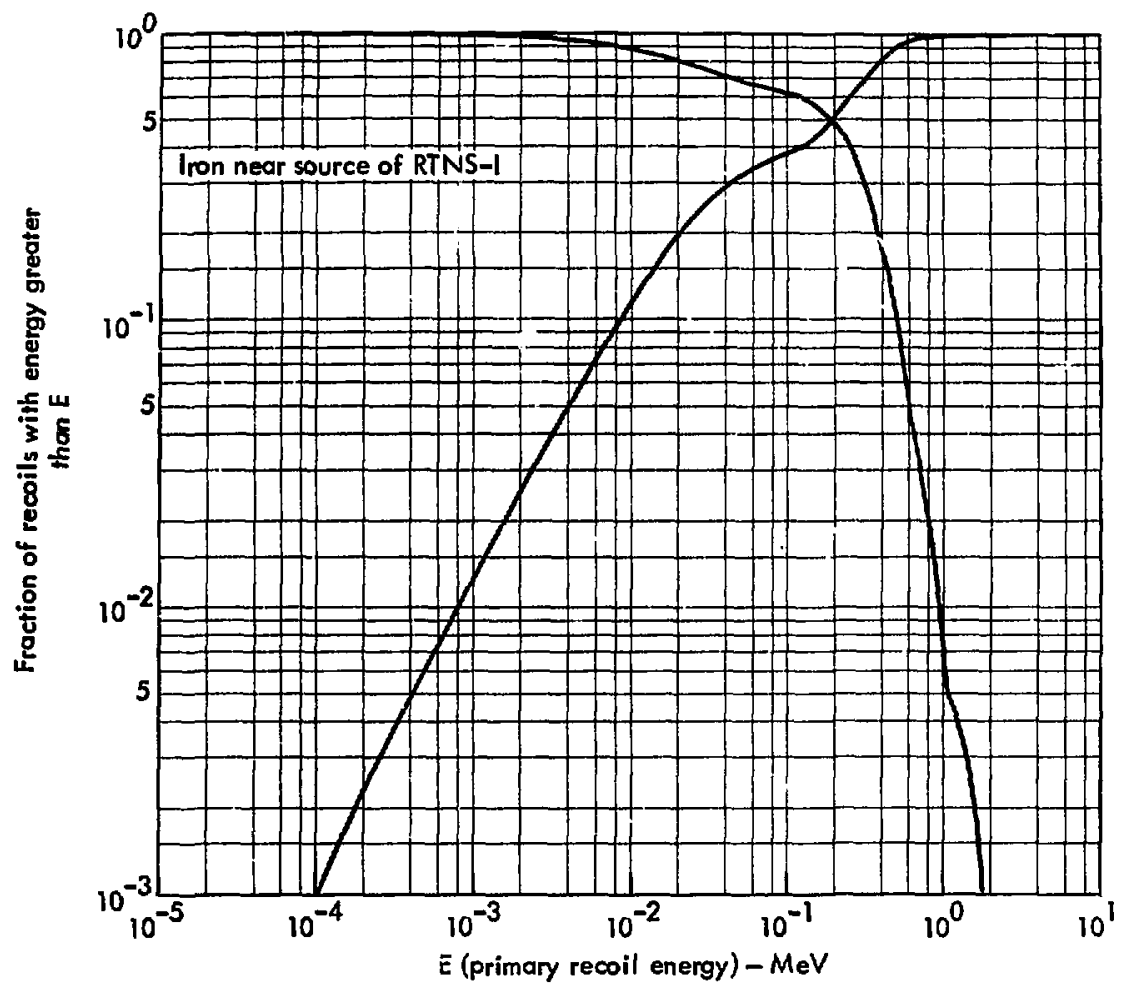

FIg. 18. The normalized integral of the recoll spectrum. 


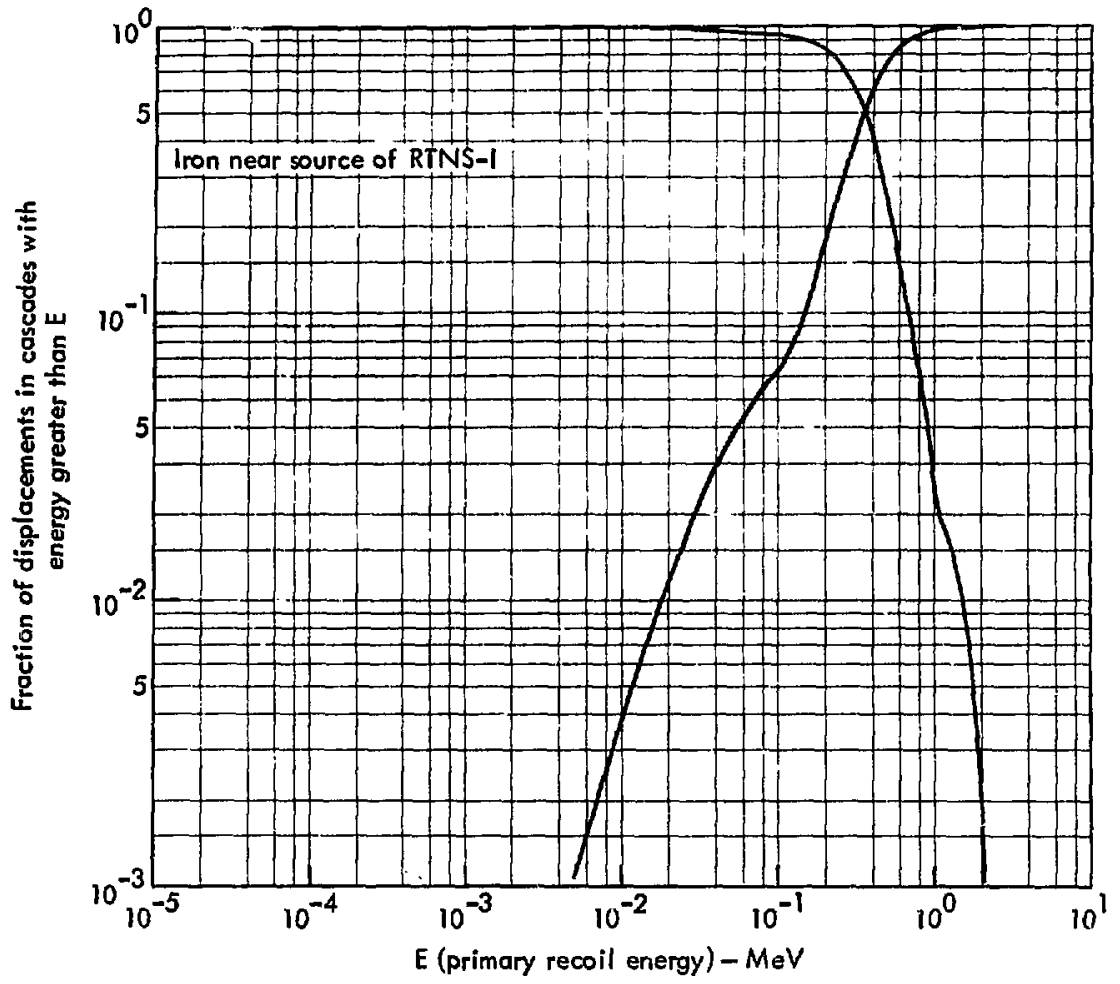

Fig. 19. The normalized integral of the damage energy spectrum. 


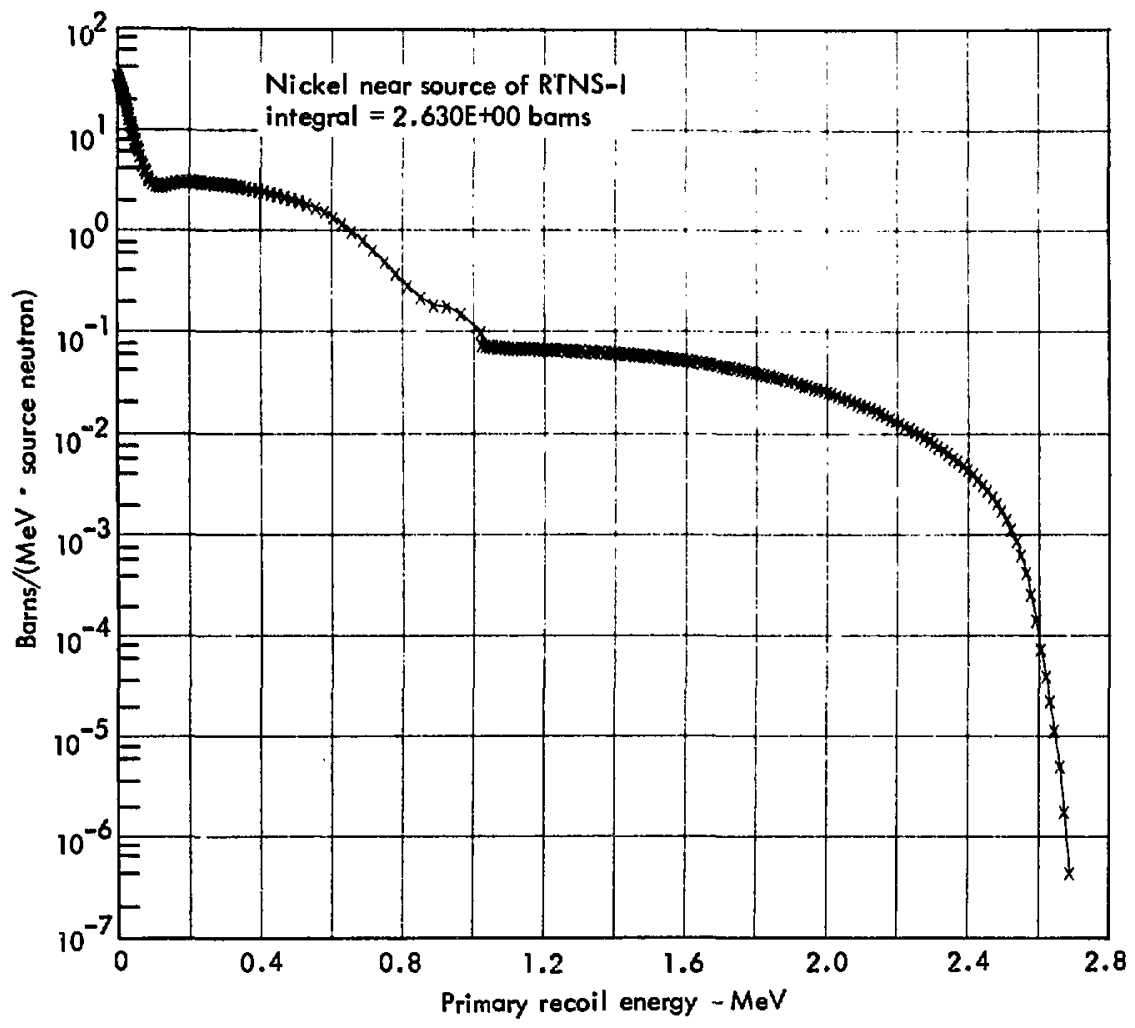

Fig. 20. The primary recoil spectrum (semi-log). 


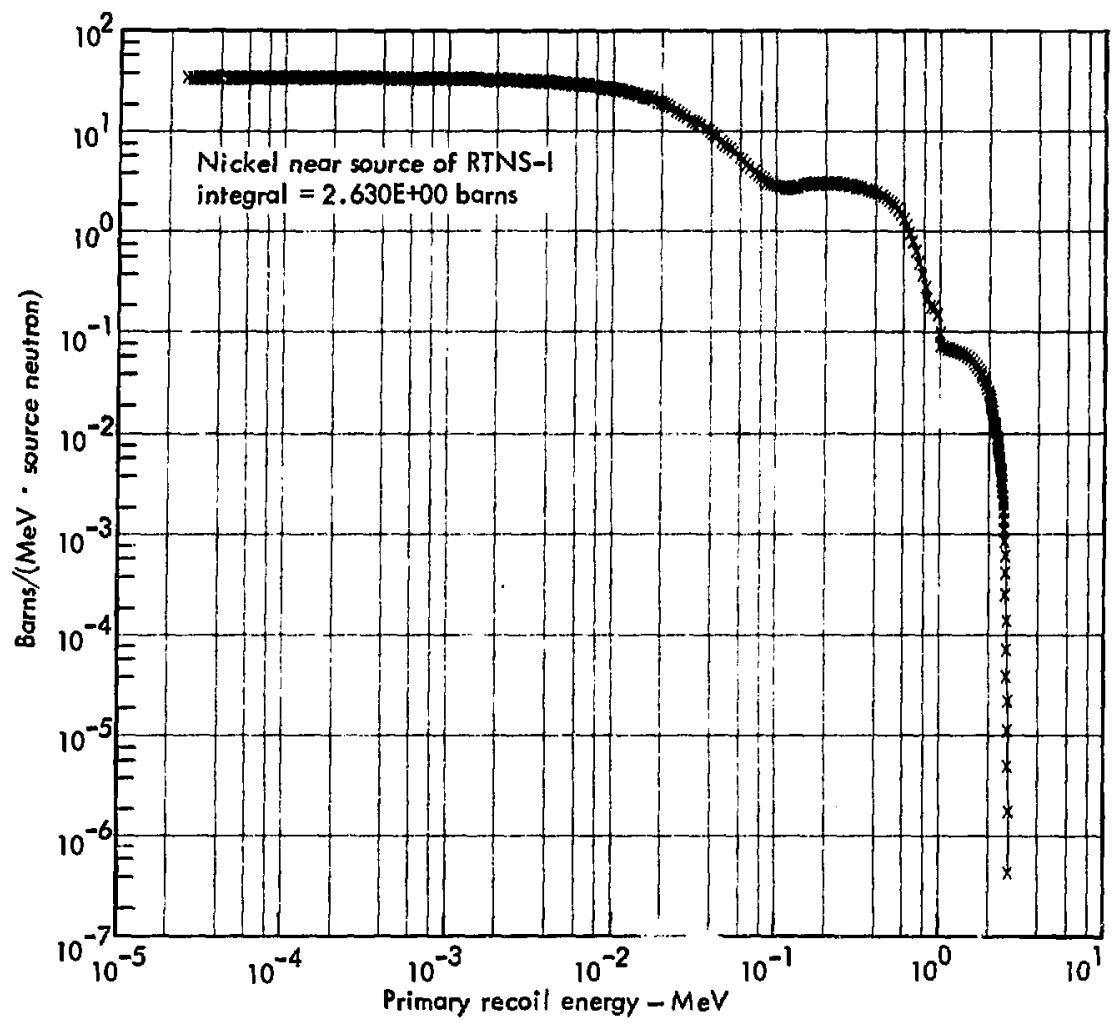

Fig. 21. The primary recoll spectrum $(\log -\log )$. 


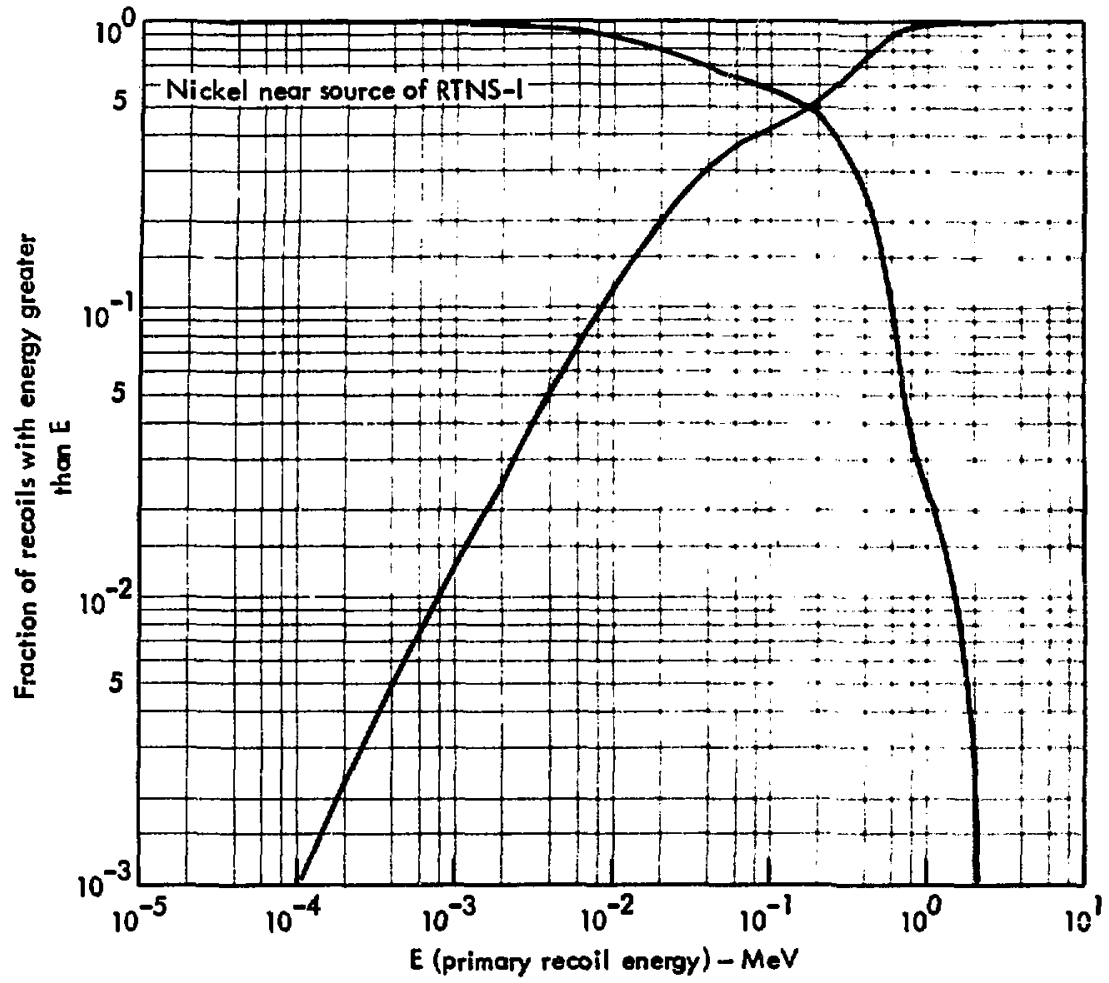

Fig. 22. The normalized integral of the recoll spectrum. 


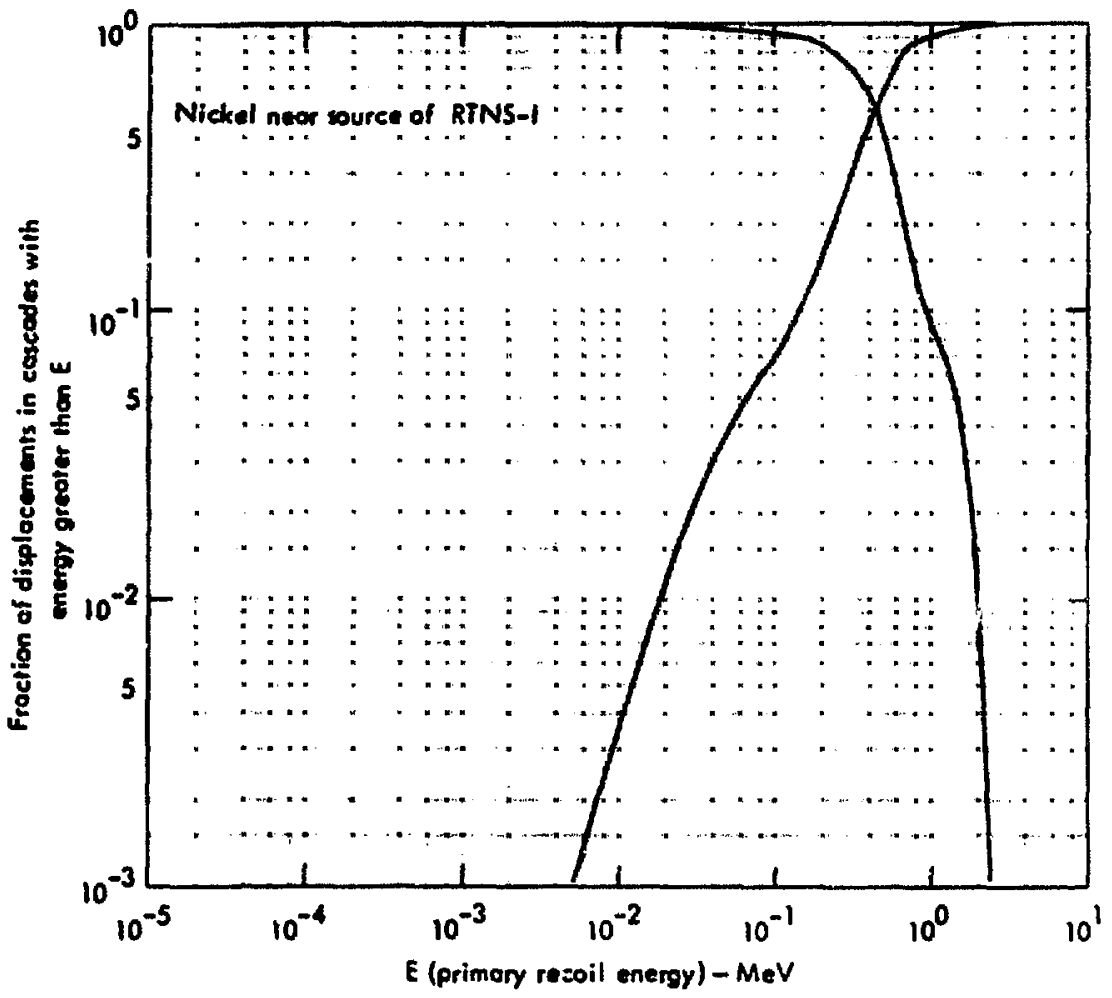

Fig. 23. The normalized intogral of the damage cnergy spectrum. 


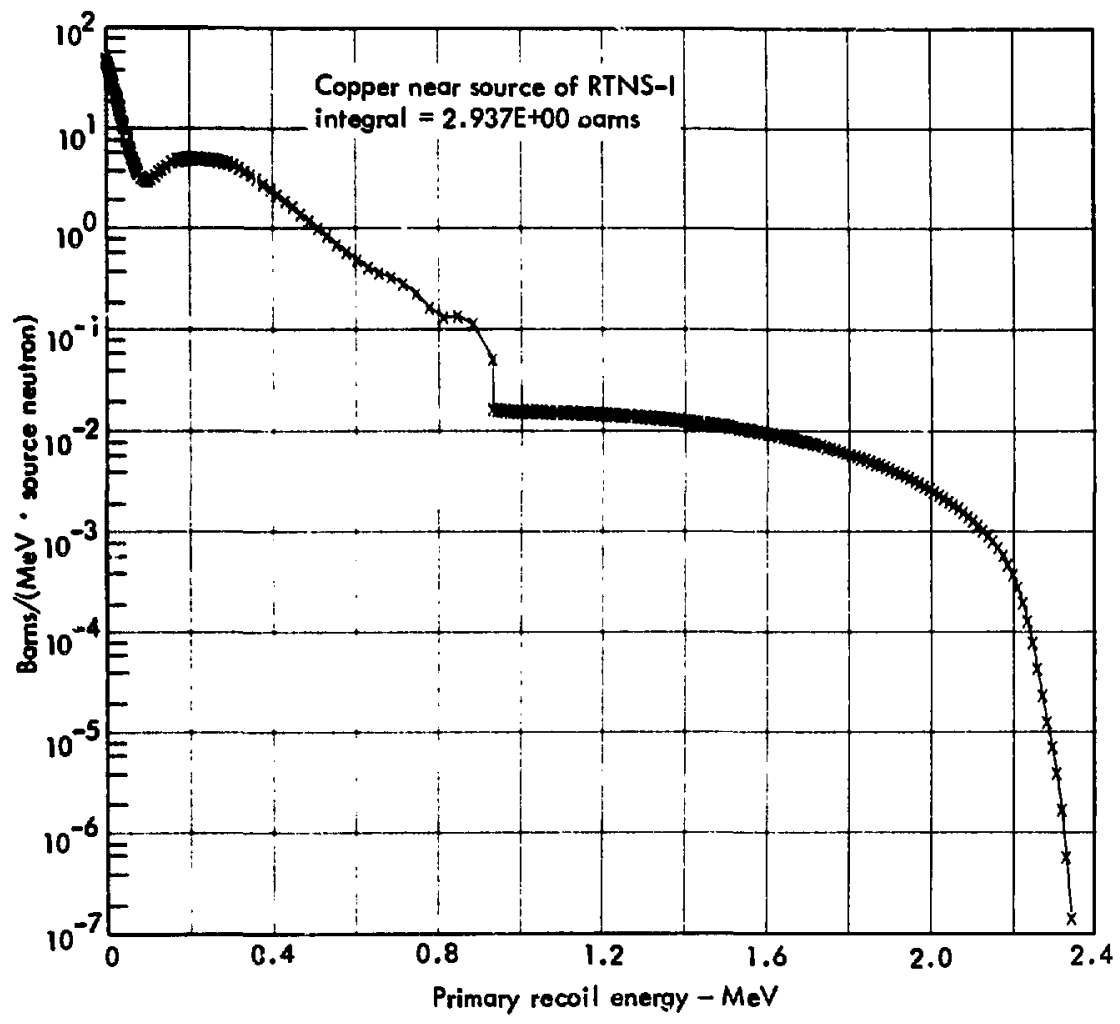

F1g. 24. The primary recoll spectrum (semi-log). 


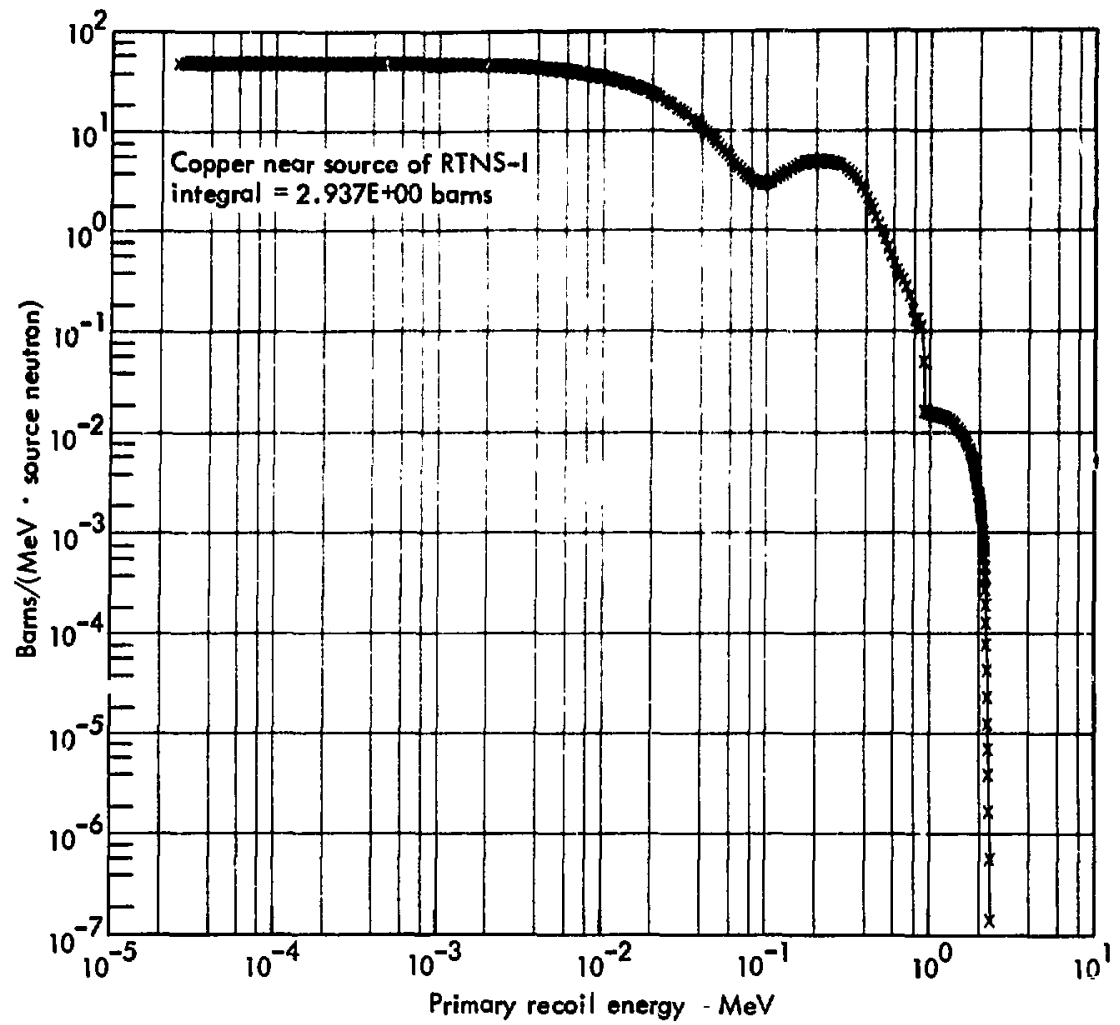

Fig. 25. The primary recoil spectrum (log-log). 


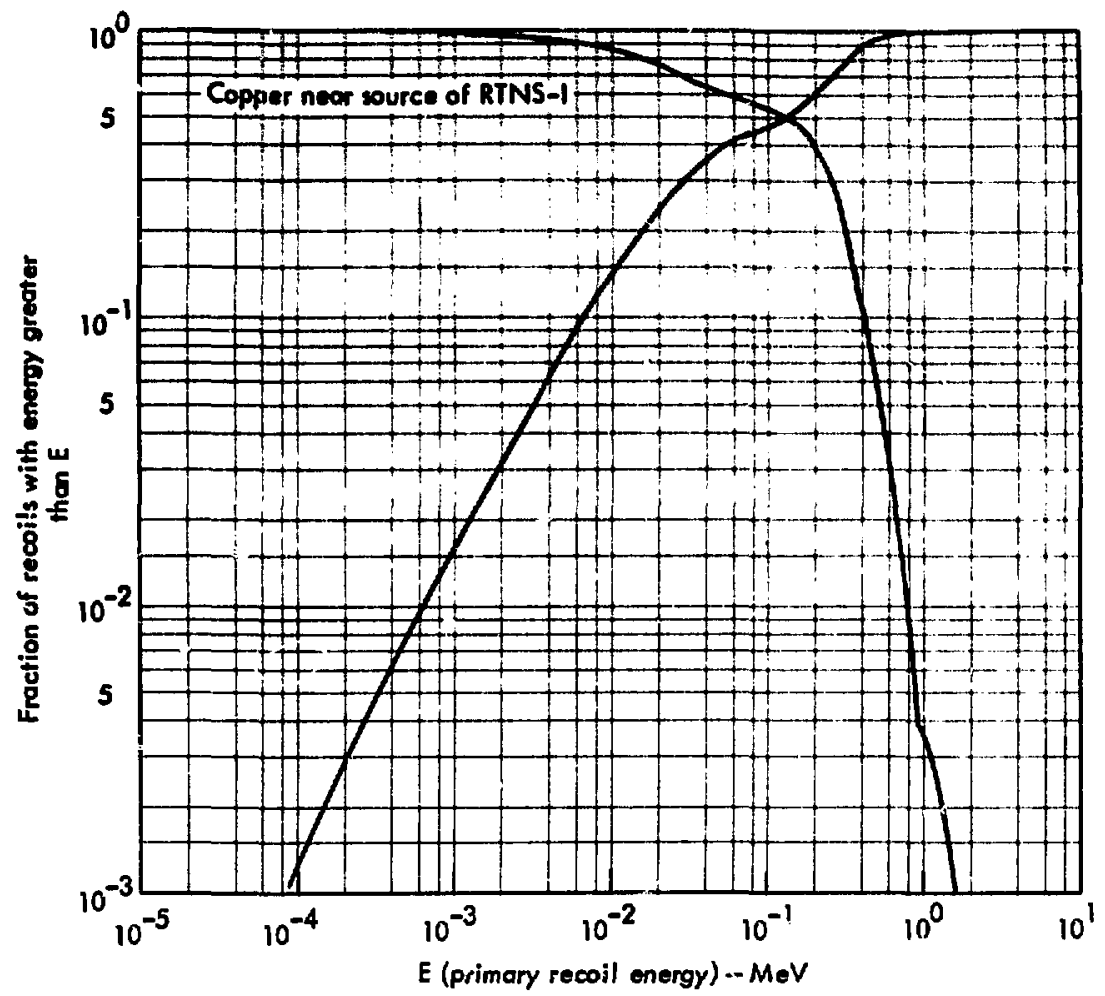

F1g. 26. The normalized Integra1 of the recoll spectrum. 


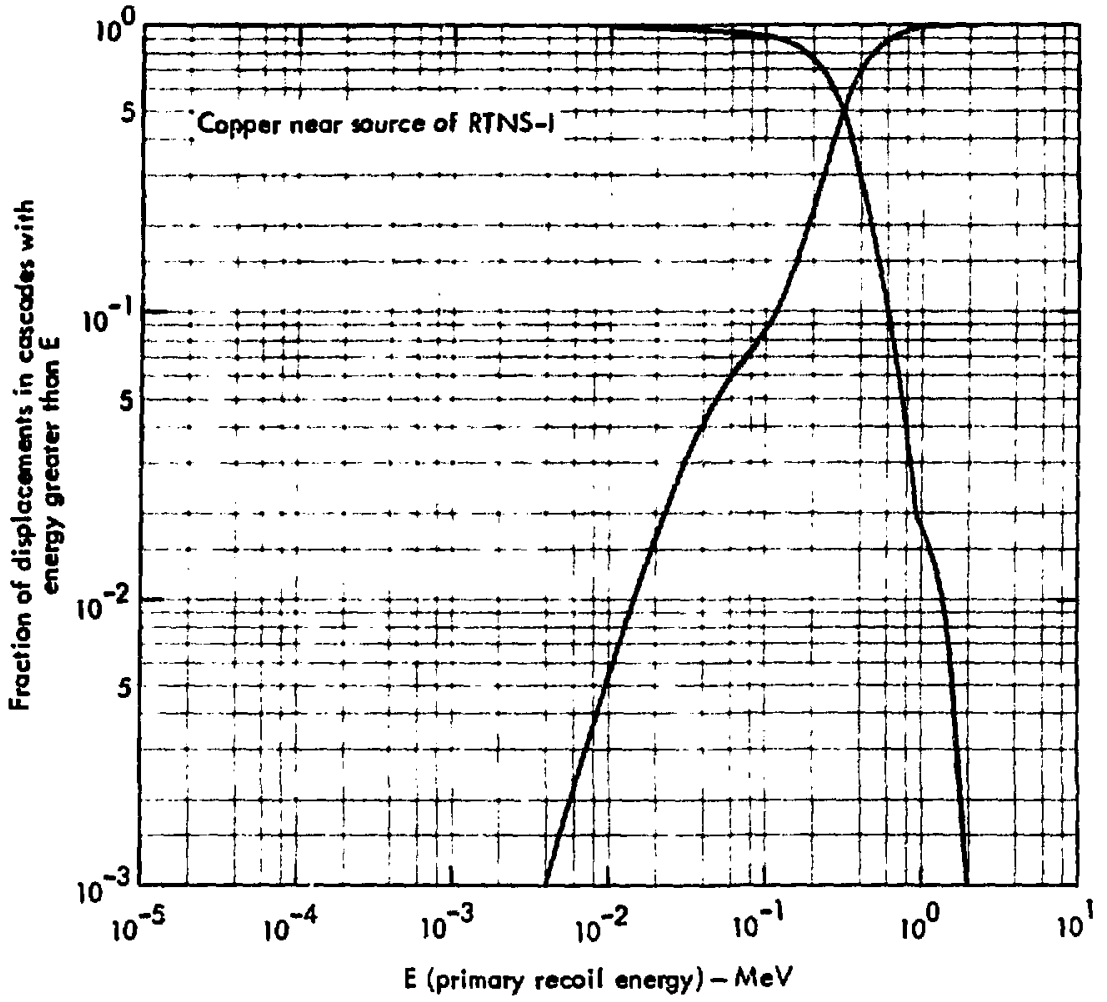

Fig. 27. The normalized integral of the damage energy spectrum. 


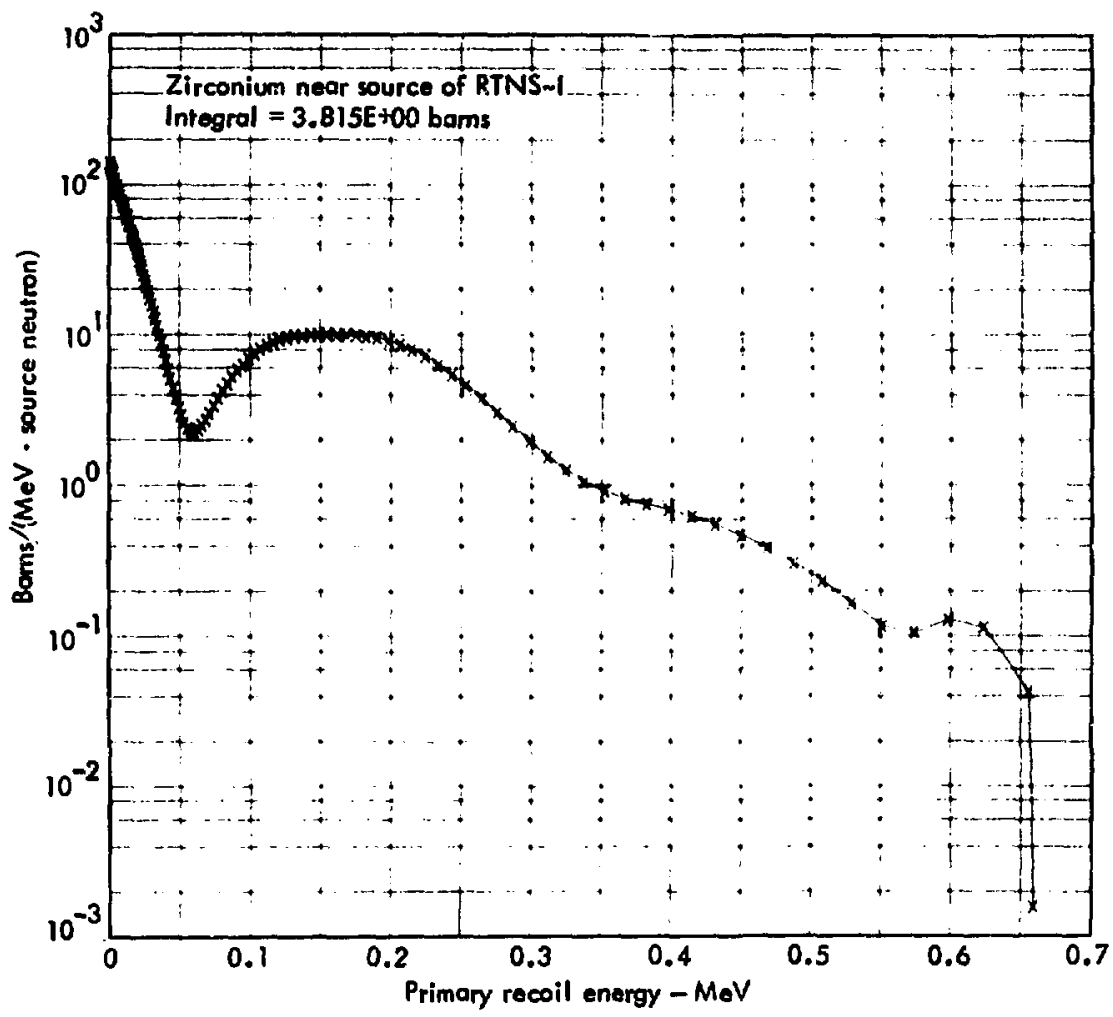

Fig. 28. The primary recoll spectrum (semi-log). 


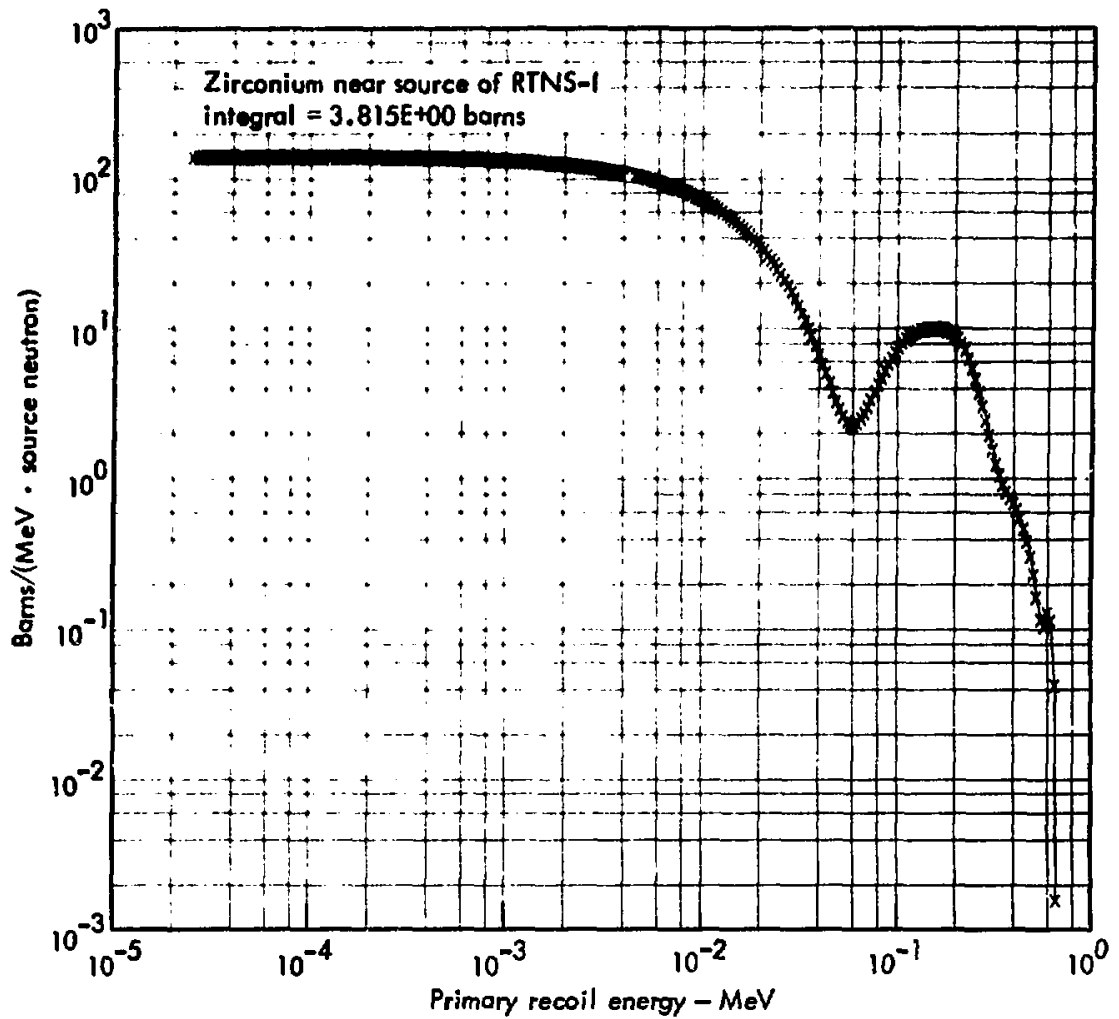

$\mathrm{Fi}_{13}$. 29. The primary recoll spectrum (log-log). 


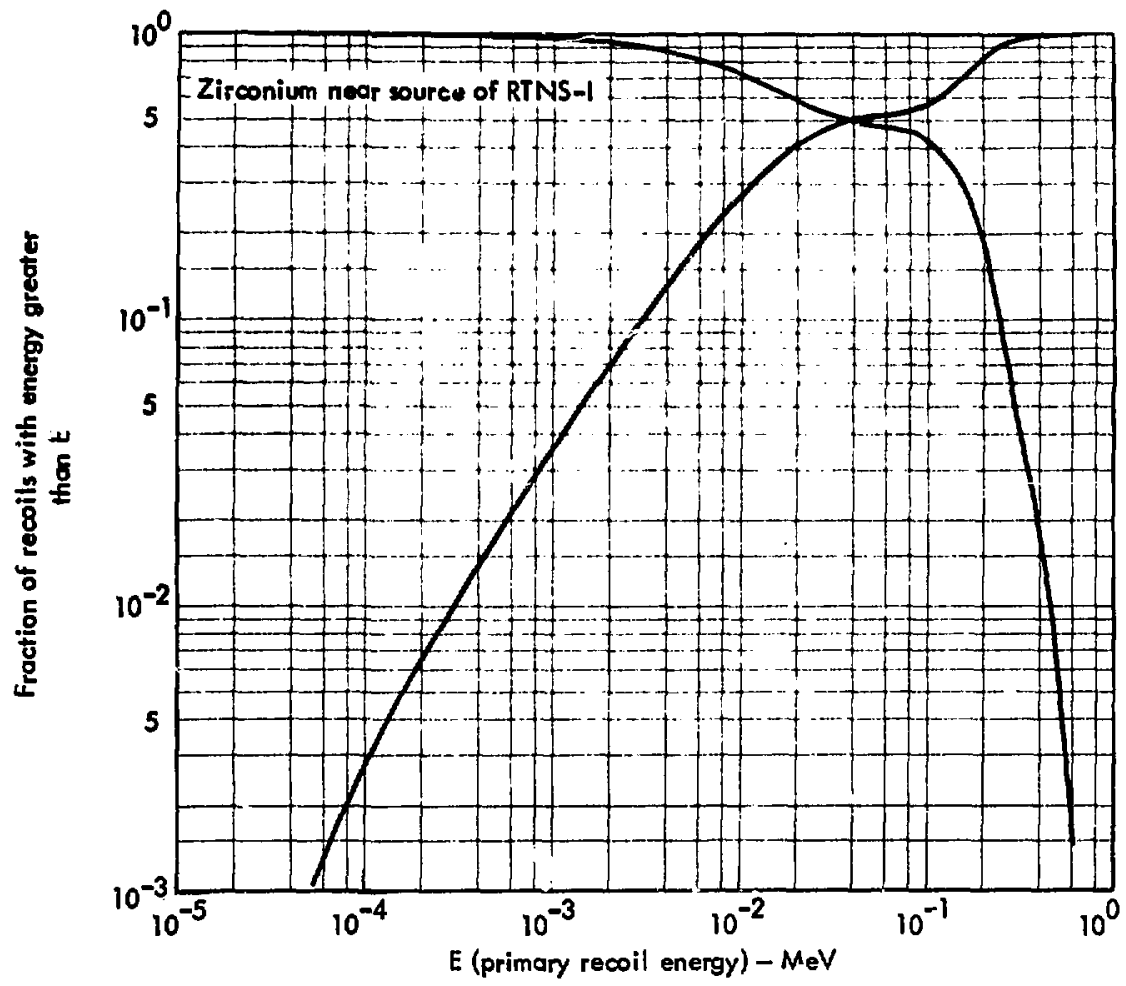

Fig. 30. The normalized integral of the recoil spectrum. 


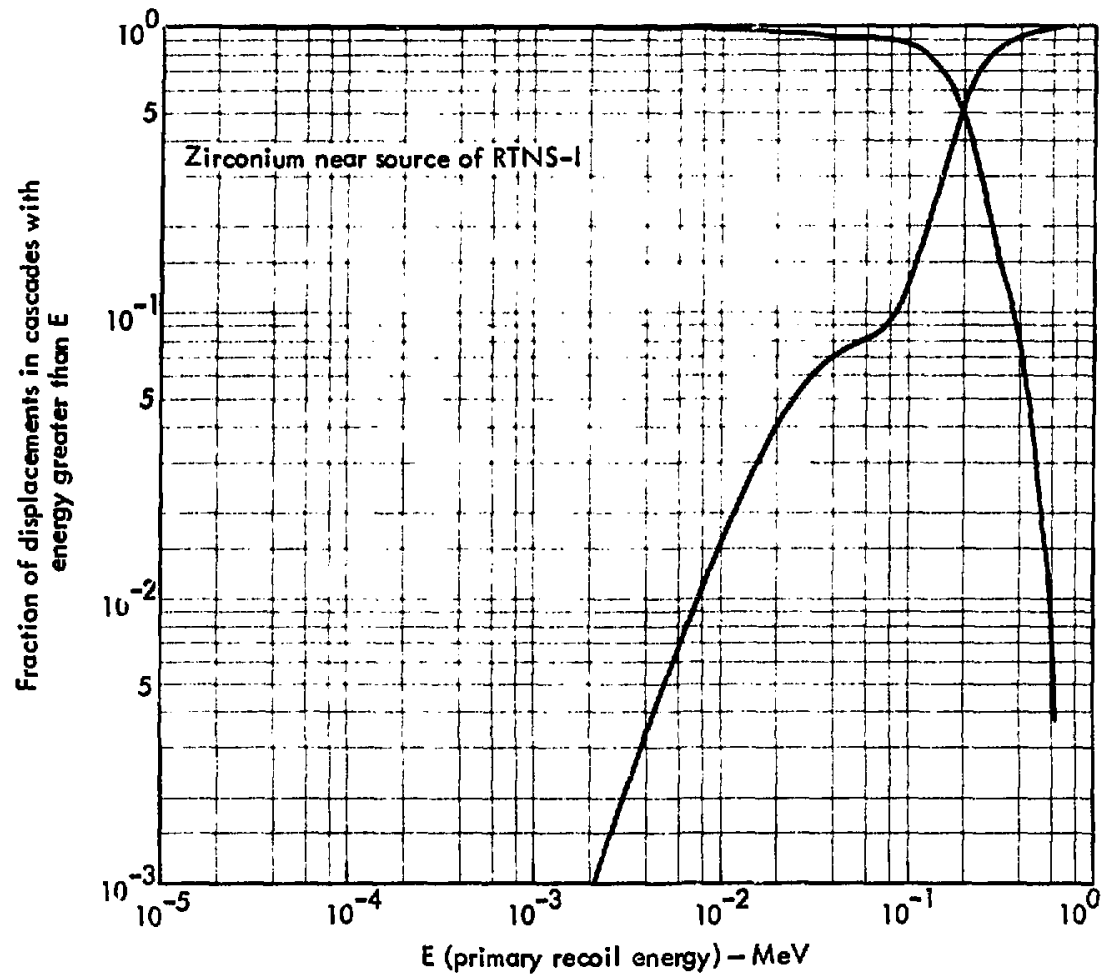

Fig. 31. The normalized integral of the damage energy spectrum. 


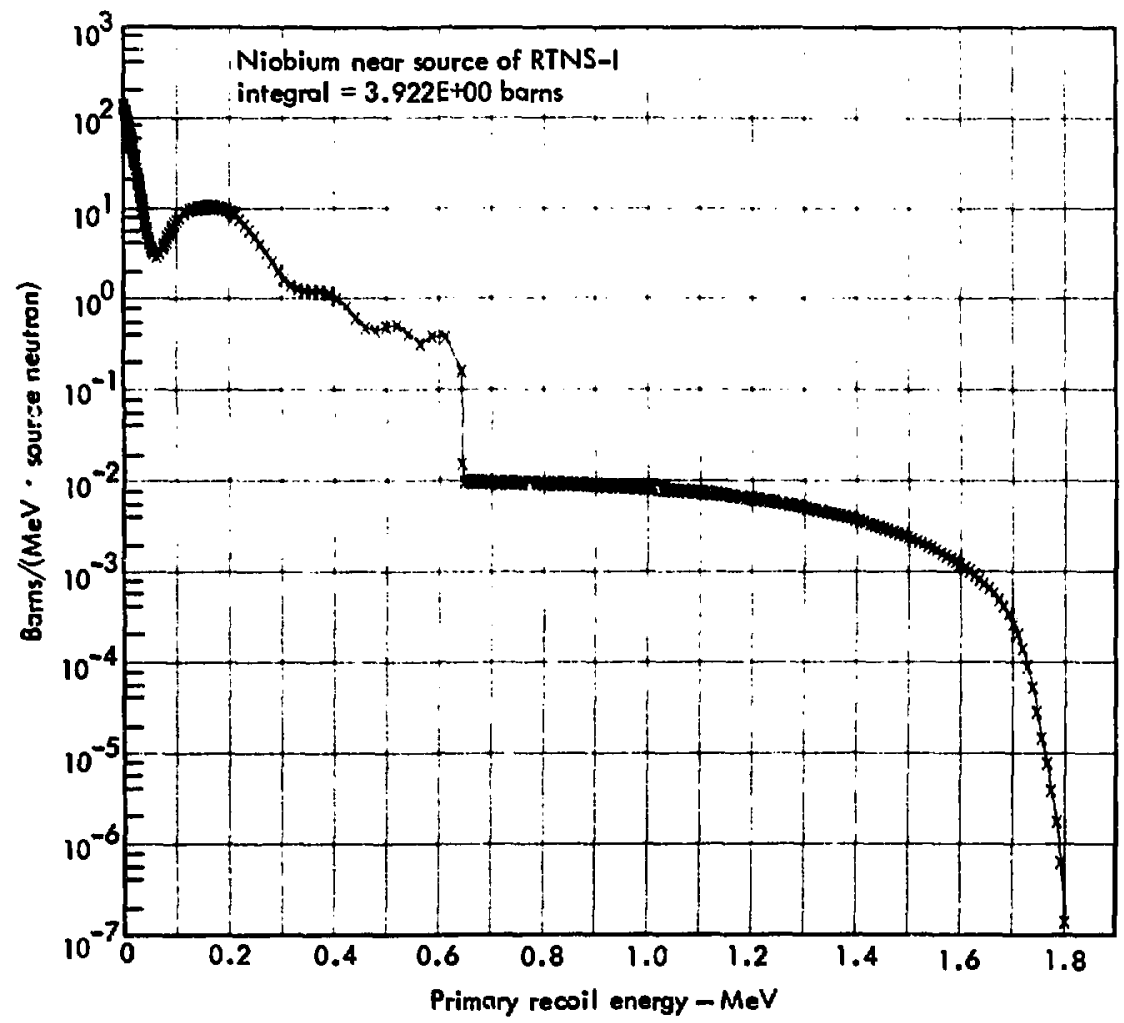

F13. 32. The primary recoil spectrum (semi-log). 


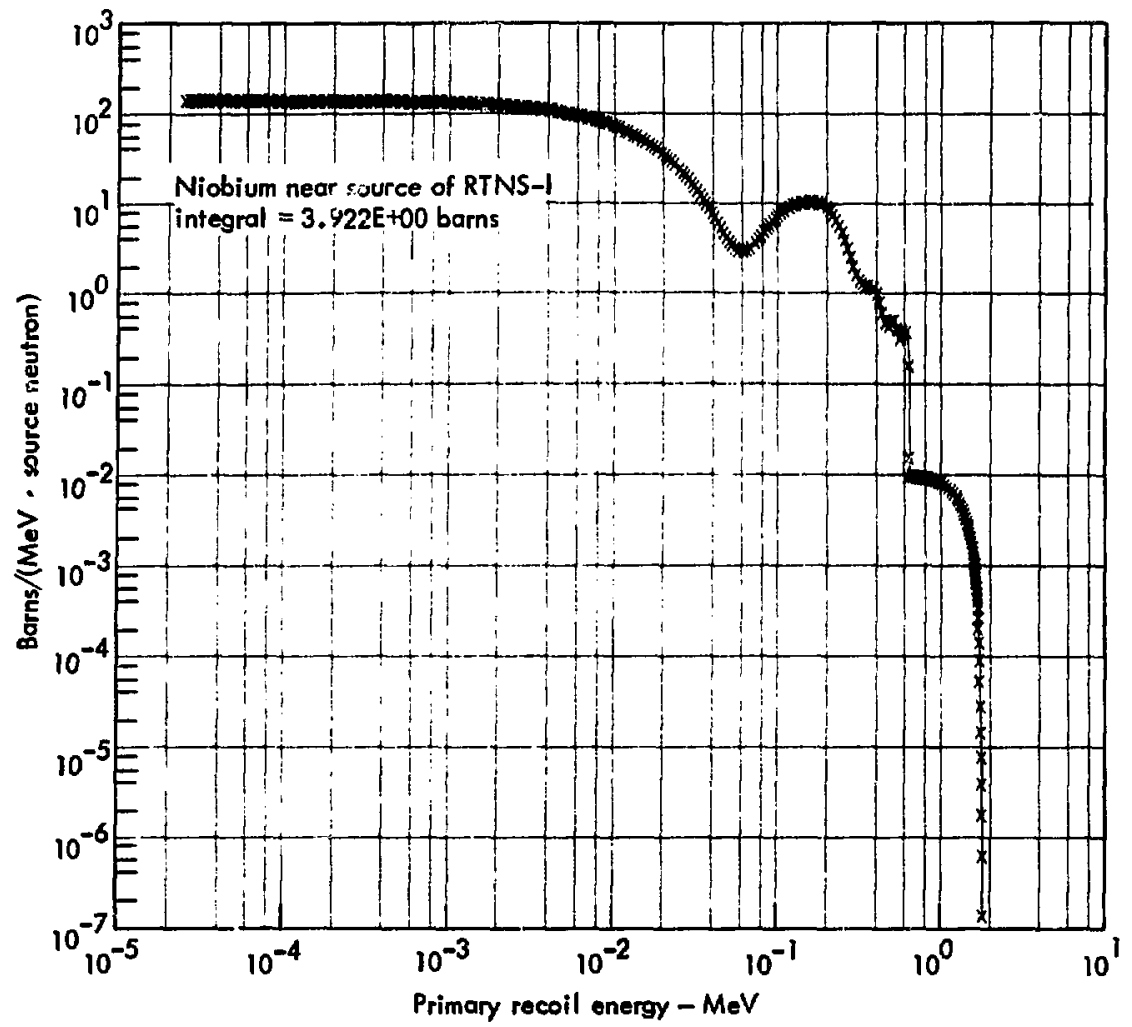

Fig. 33. The primary recoll opectrum (log-log). 


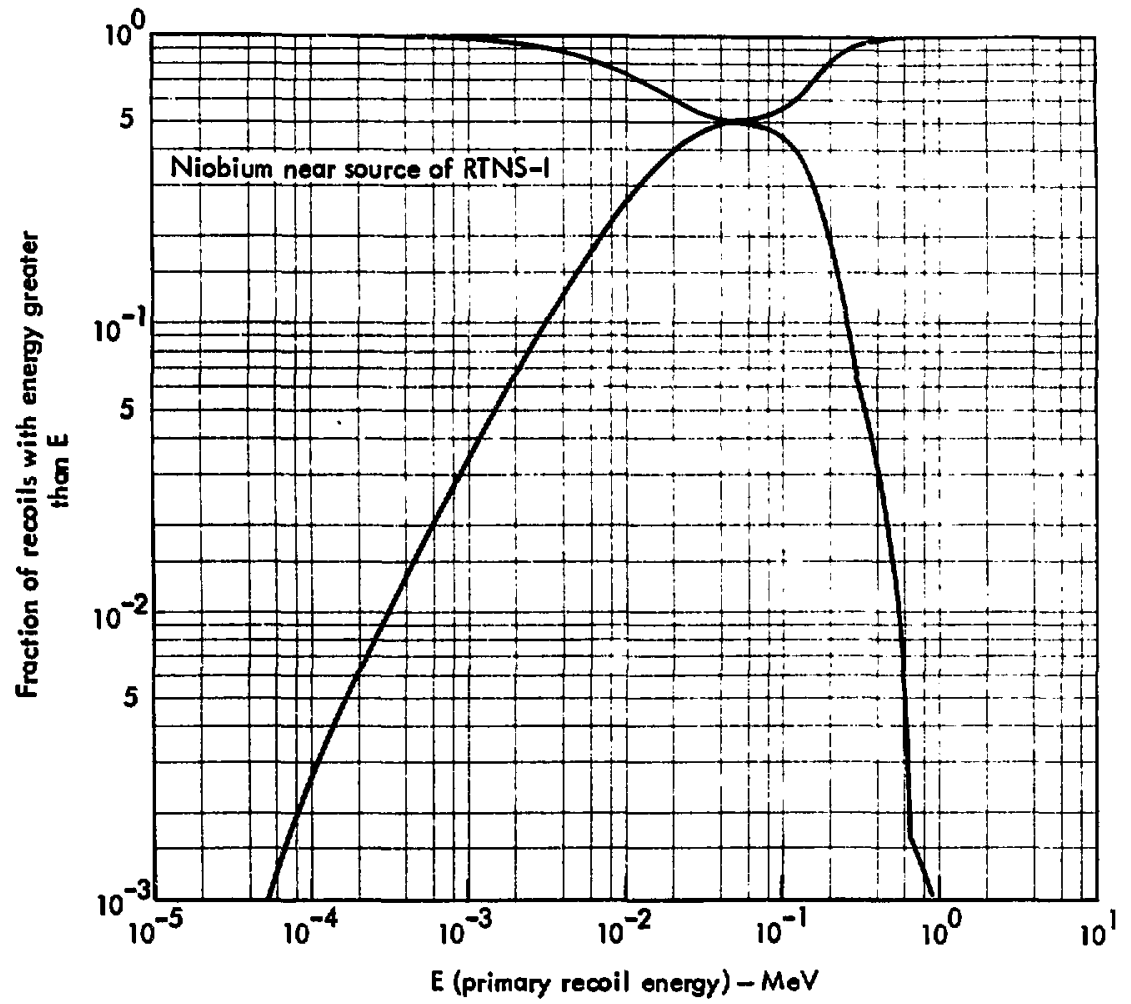

Fig. 34. The normalized integral of the recoil spectrum. 


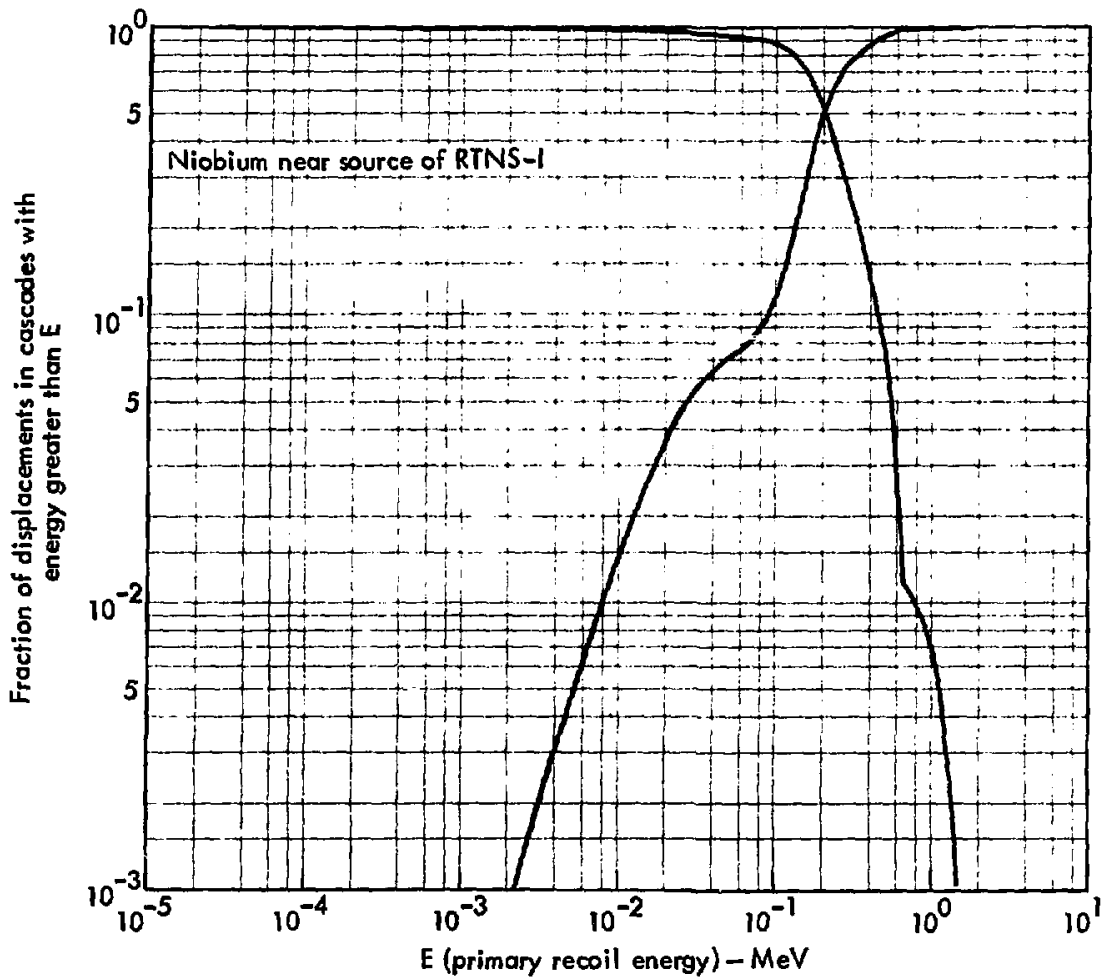

F1g. 35. The normallzed Integral of the damage energy spectrum. 


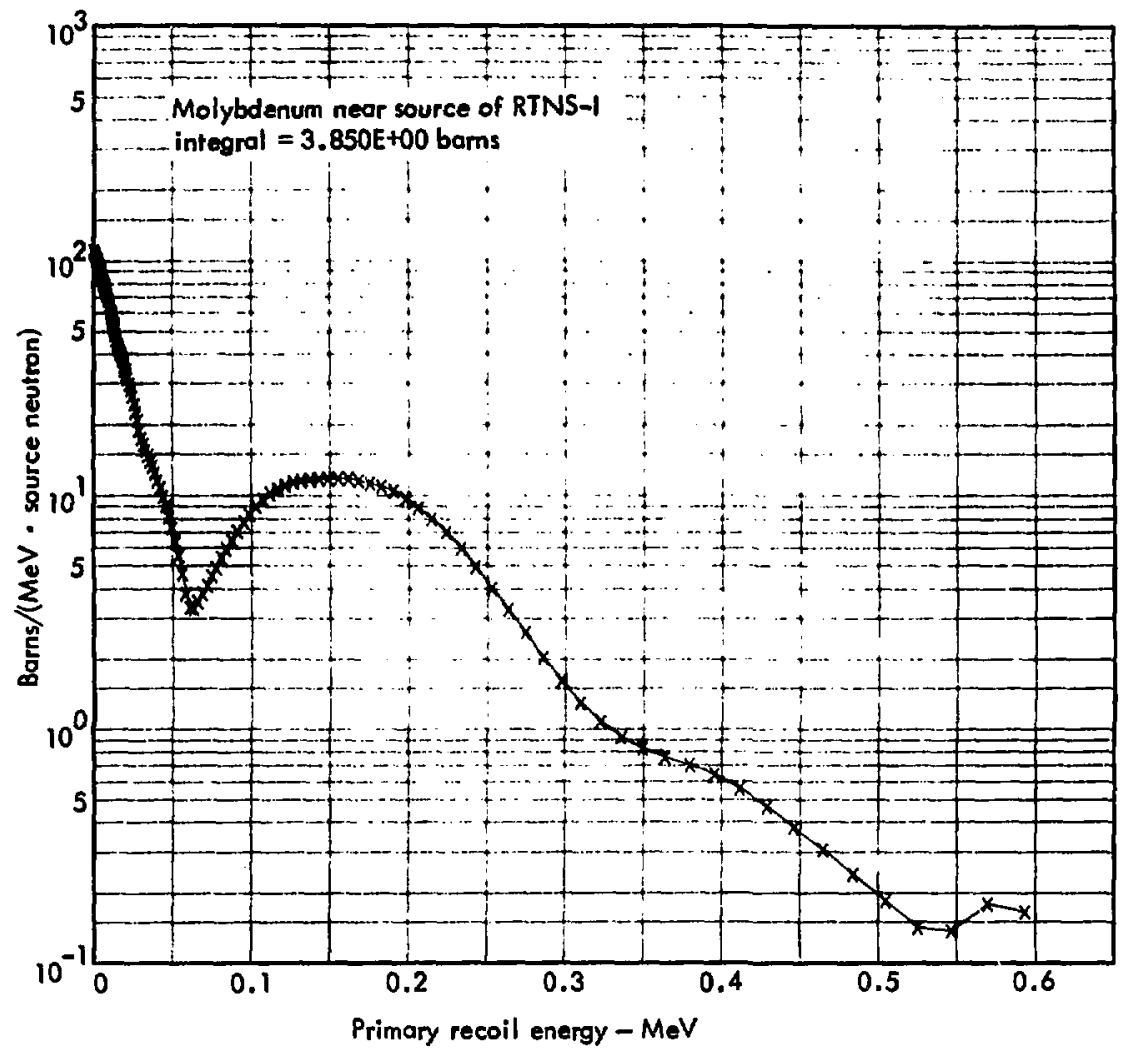

Fig. 36. The primary recoll spectrum (semi-1og). 


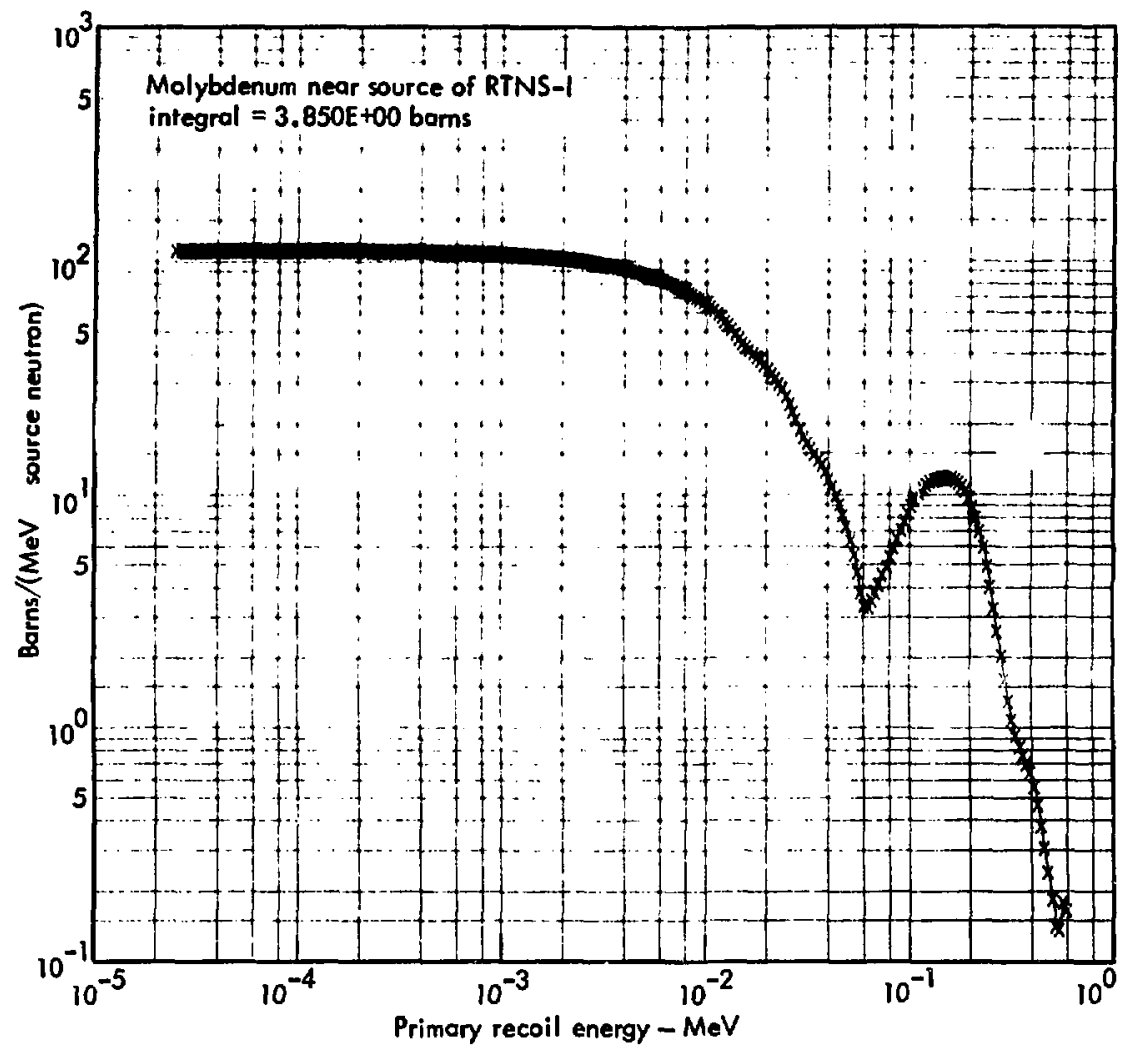

Fig. 37. The primary recoll spectrum (log-1og). 


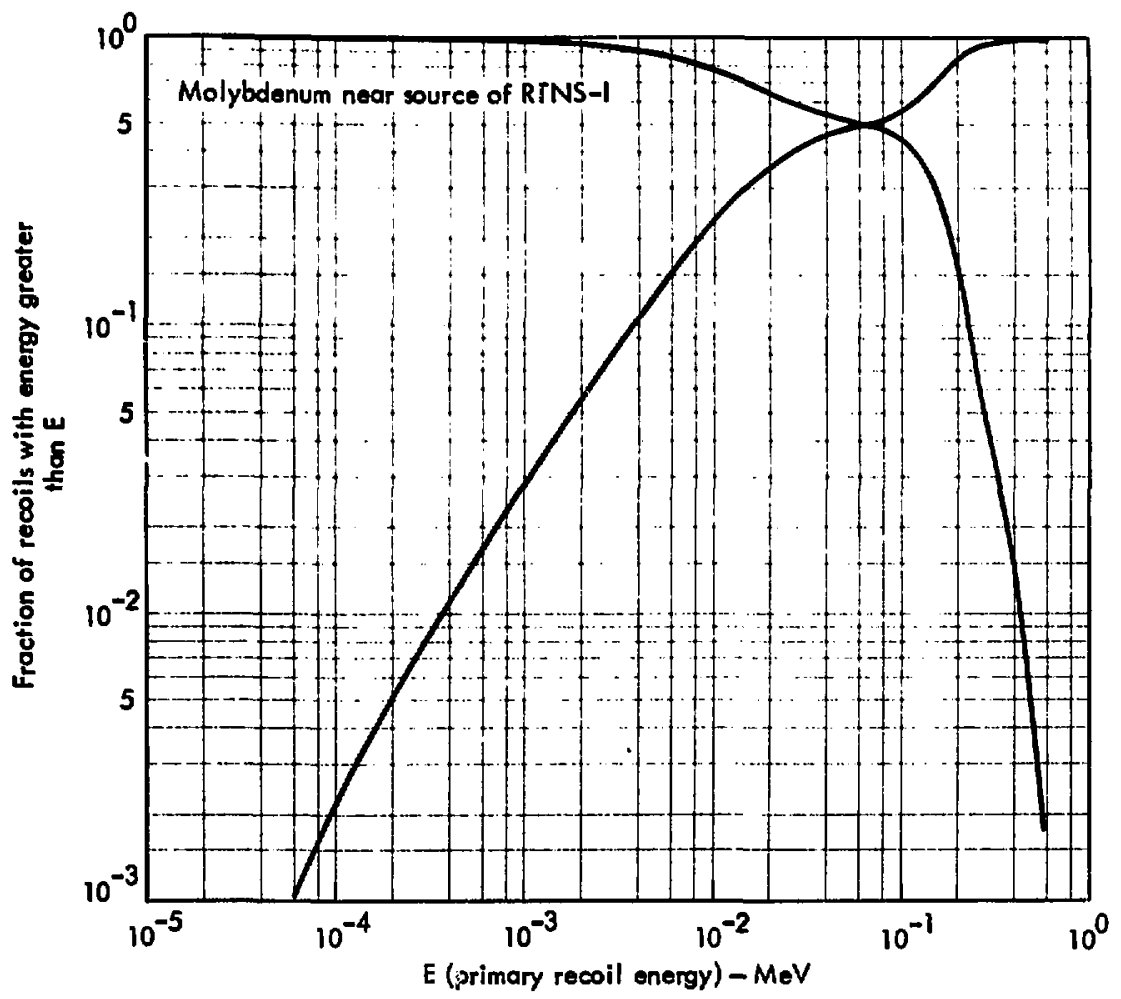

Fig. 38. The normalized Integral of the recoll spectrum. 


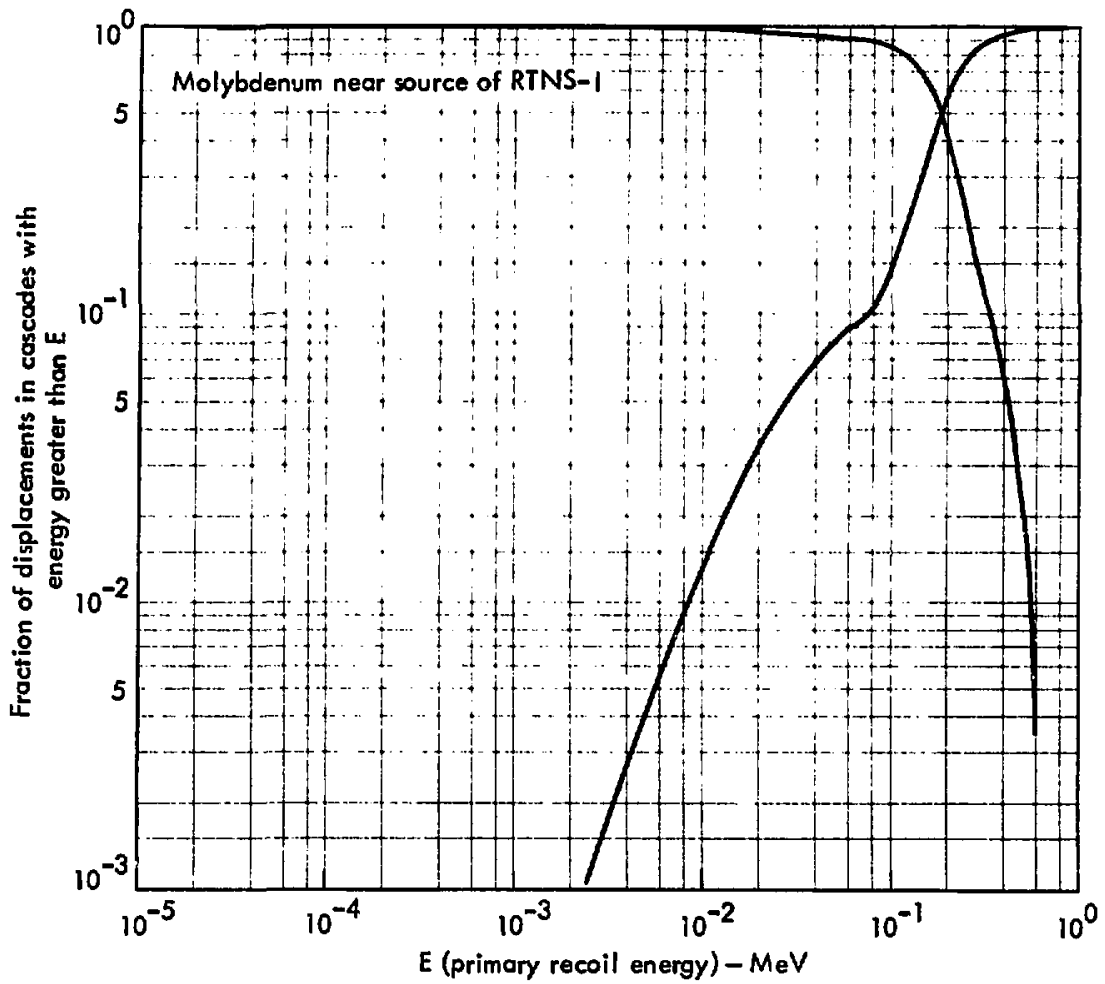

Fig. 39. The normalized integral of the damage energy ipectrum. 


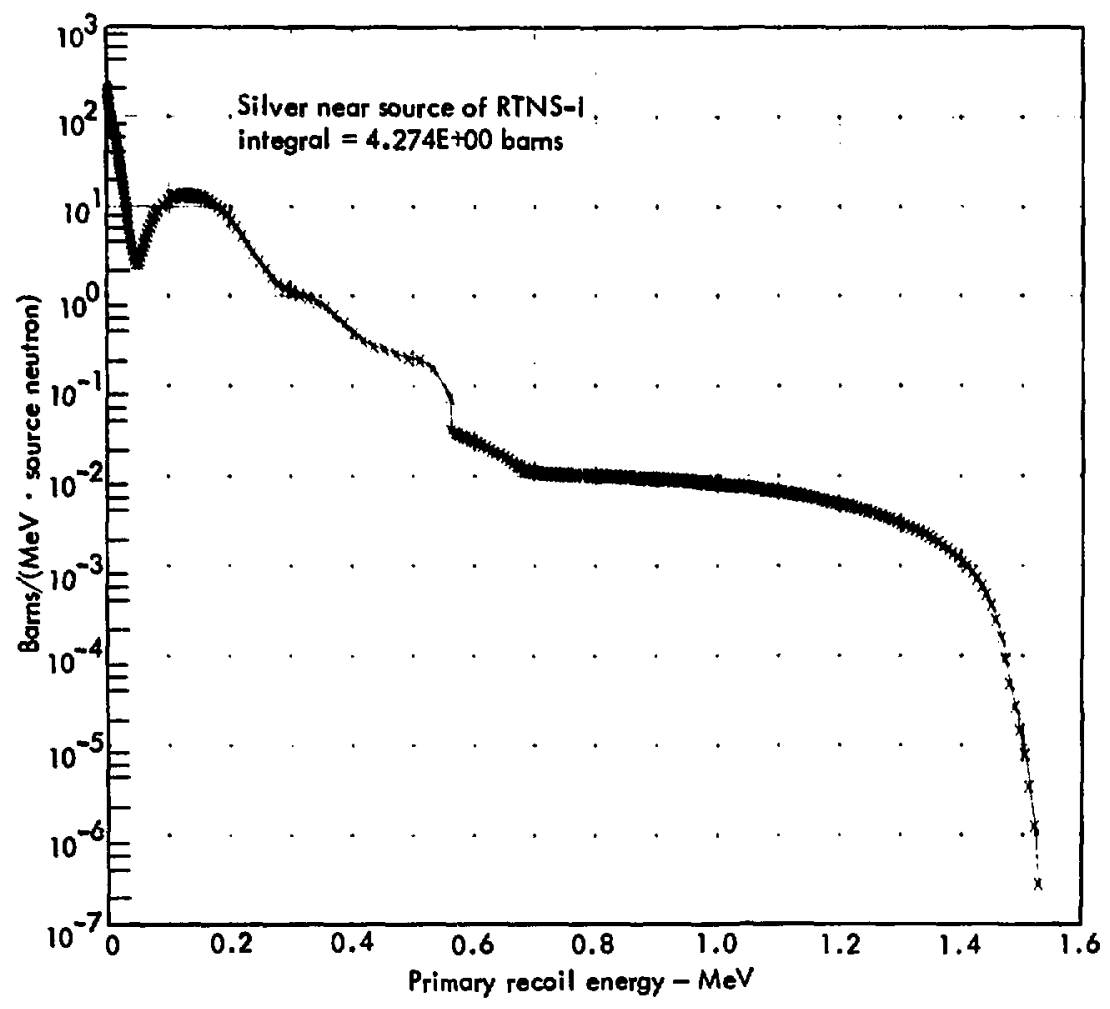

Fig. 40. The primary recoil spectrum (semi-log). 


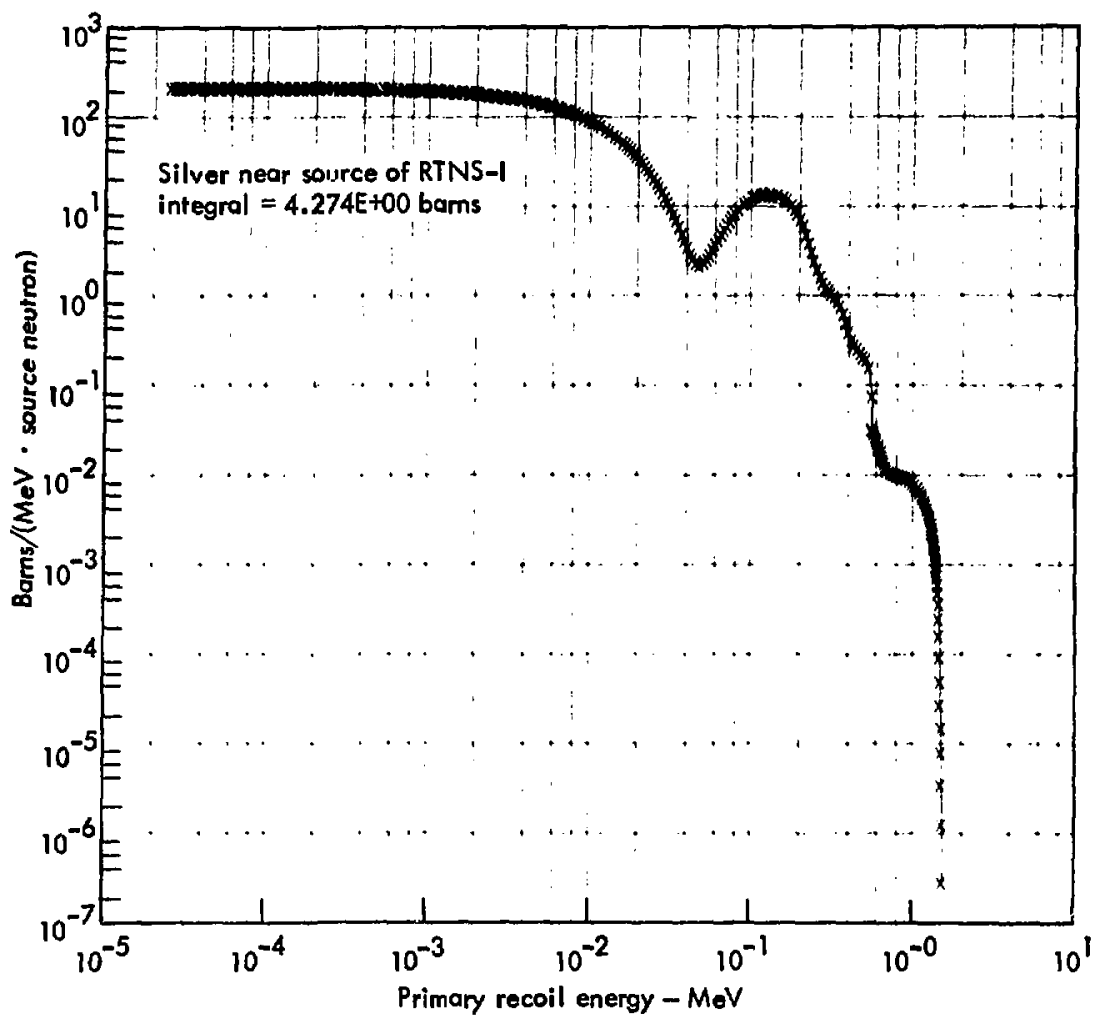

Fig. 41. The primary recoil spectrum (log-1og).

$-45-$ 


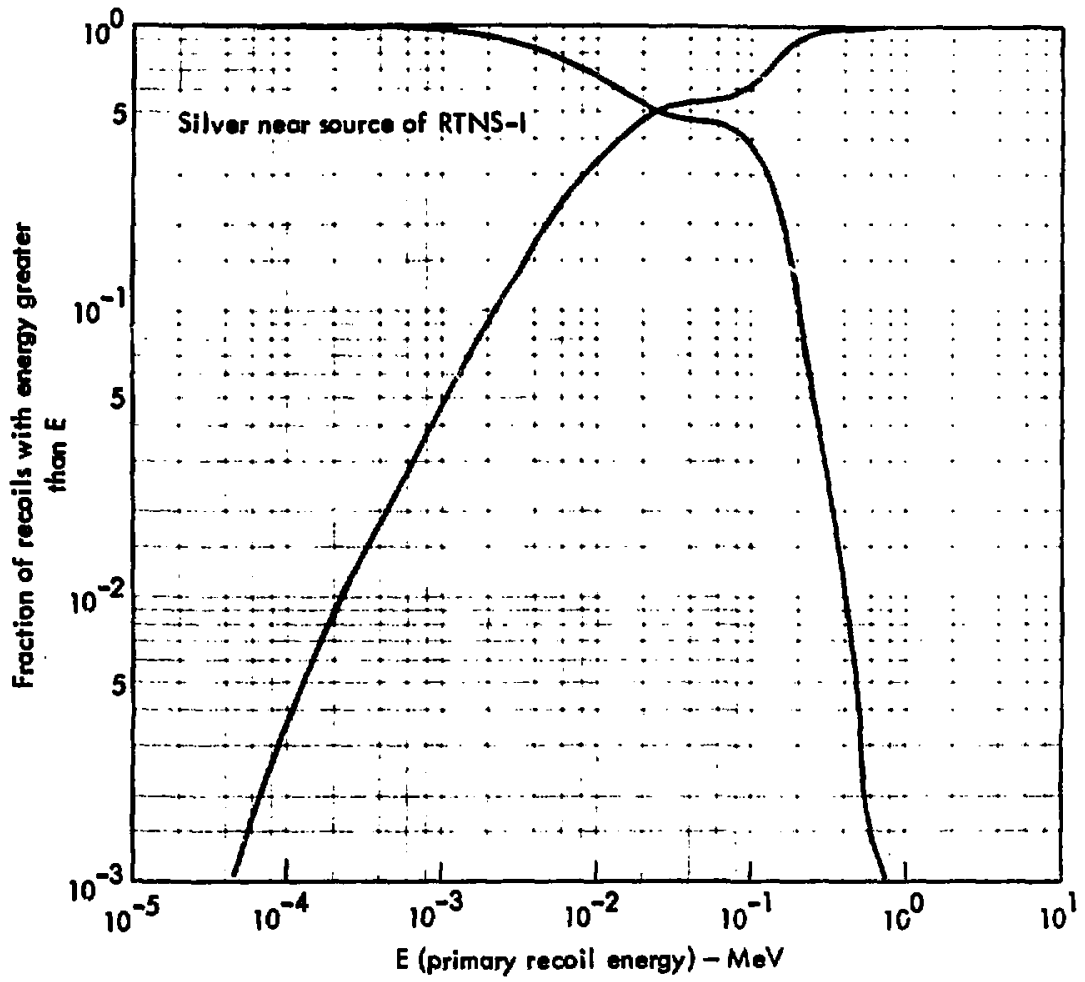

B1g. 42. The normalized integral of the recoll spectrum. 


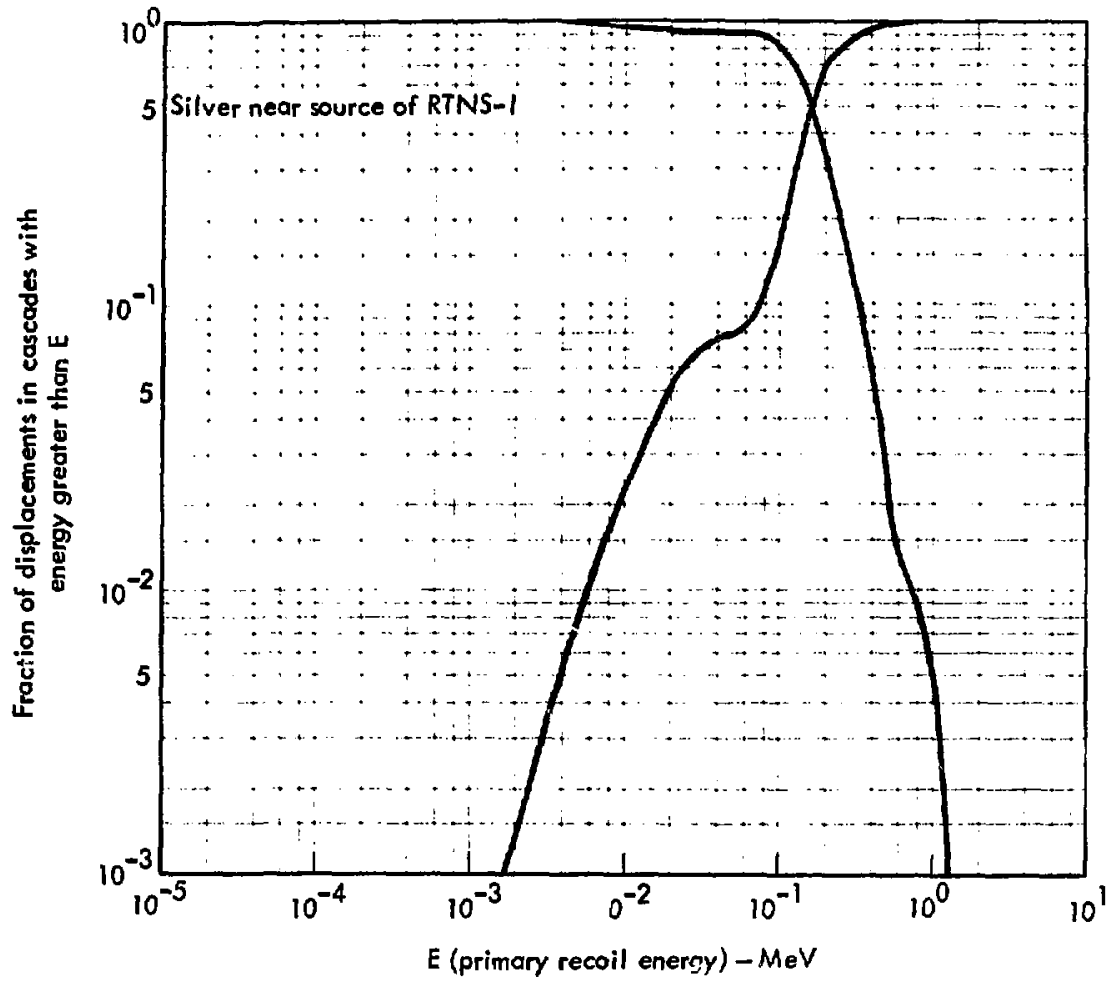

FIg. 43. The normalized integral of the damage energy spectruf. 


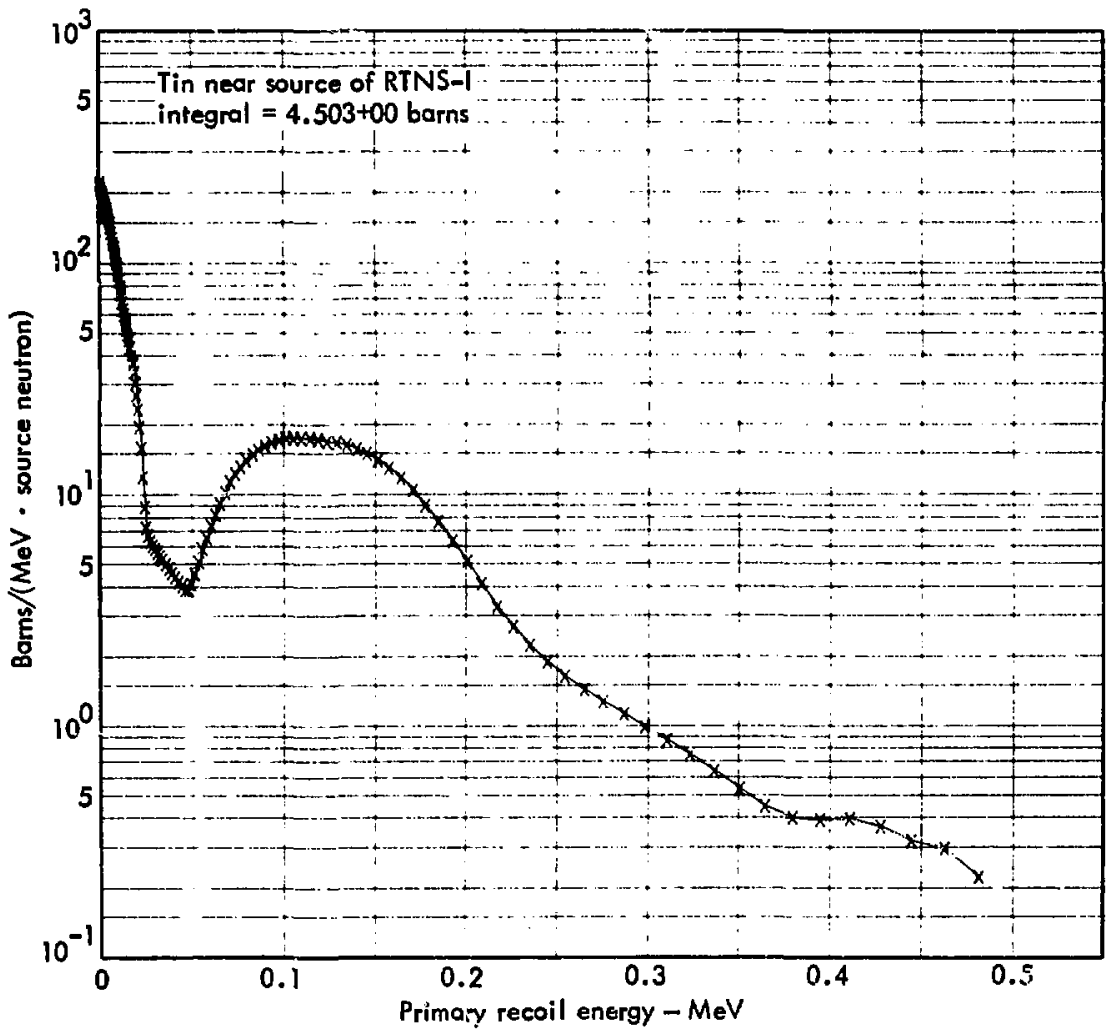

F1g. 44. The primary recoil spectrum (semi-log). 


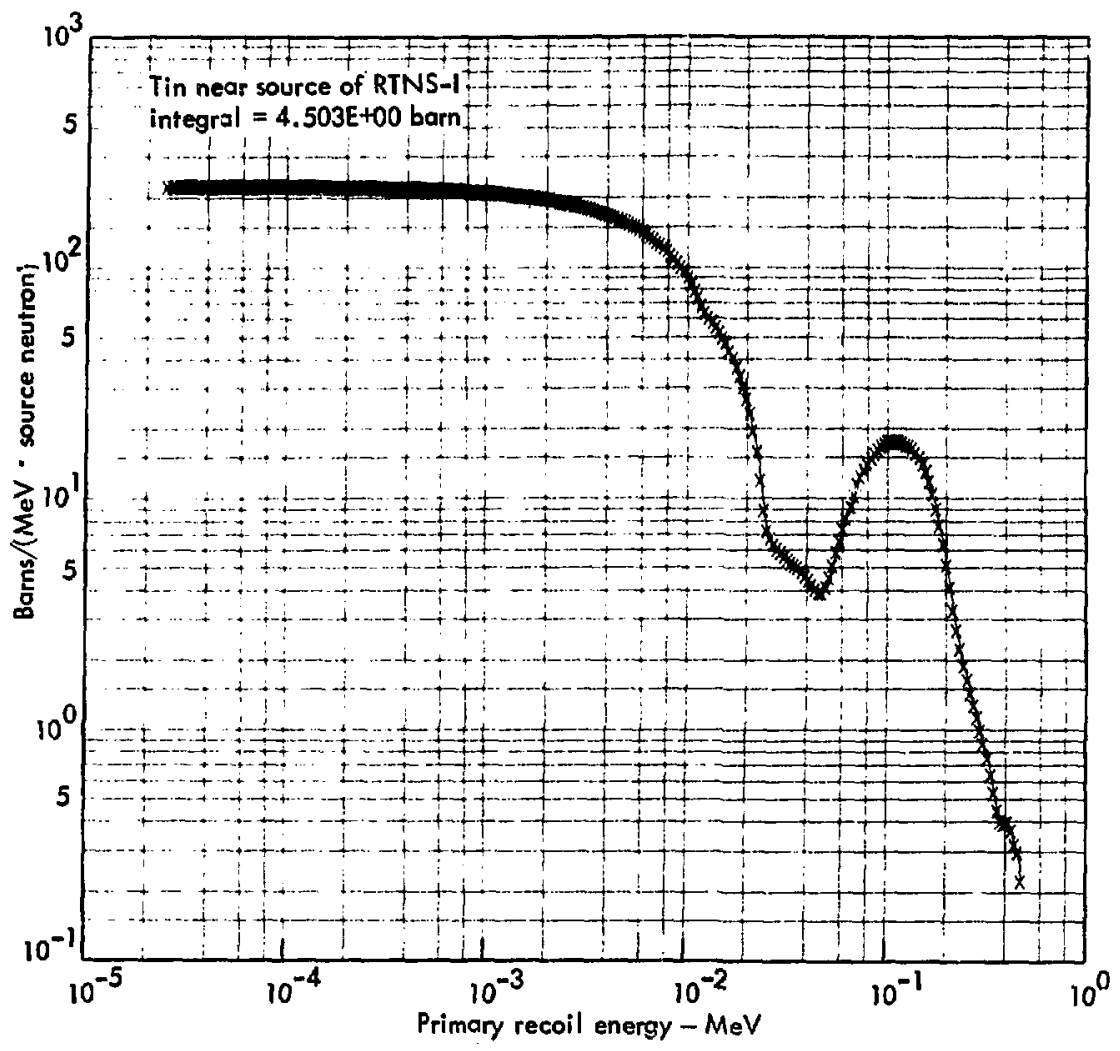

F1g. 45. The primary recotl spectrum $(\log -10 g)$. 


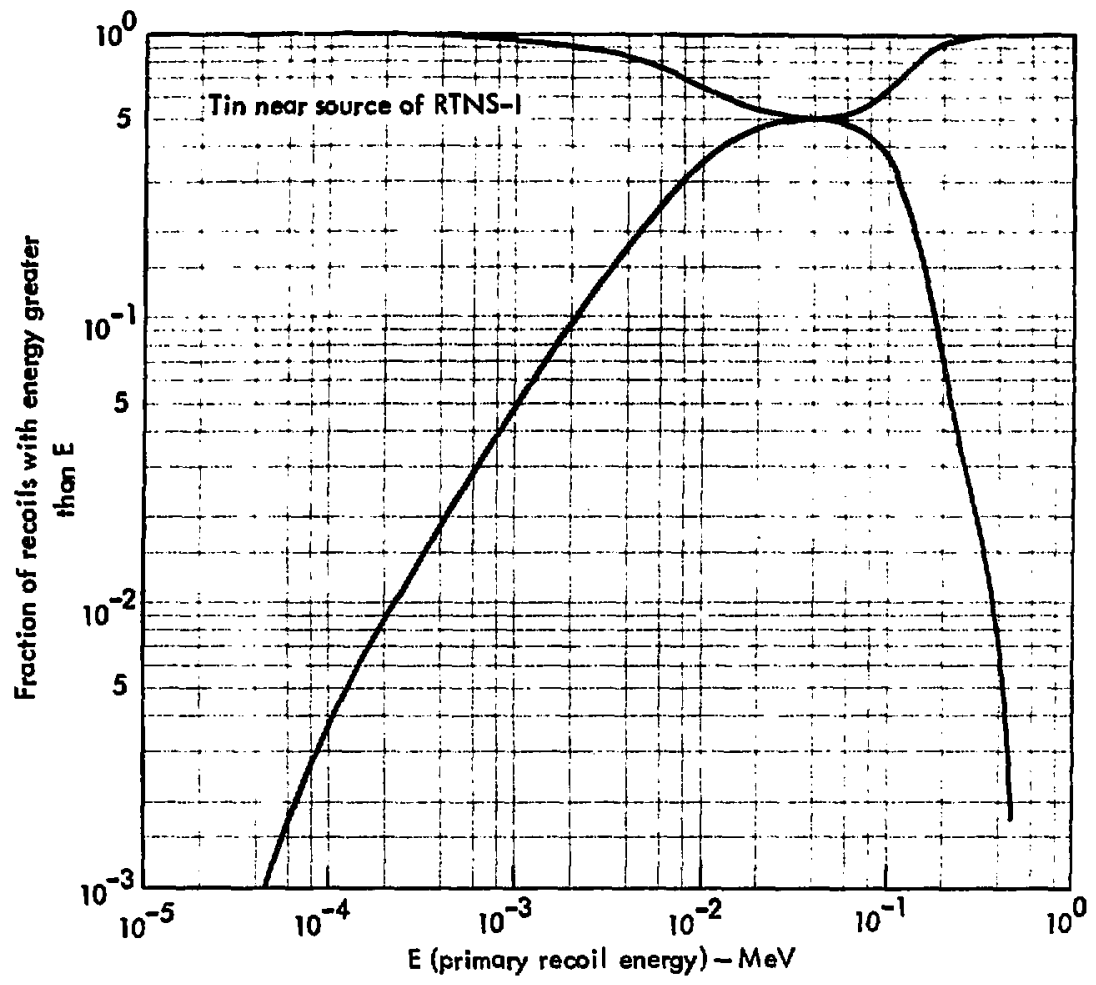

F1g. 46. The nomallzed integral of the recoll spectrum. 


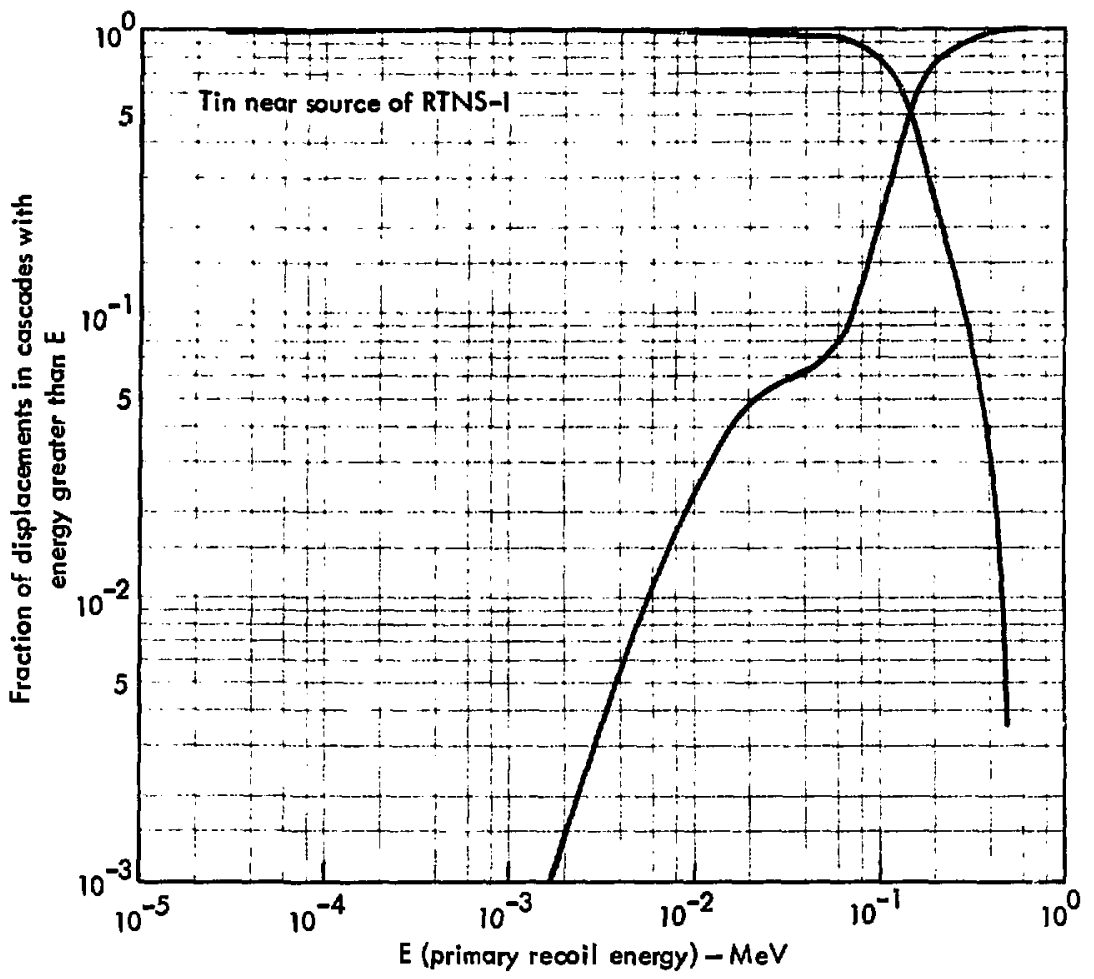

F1g. 47. The normalized integral of the damage energy spectrum. 


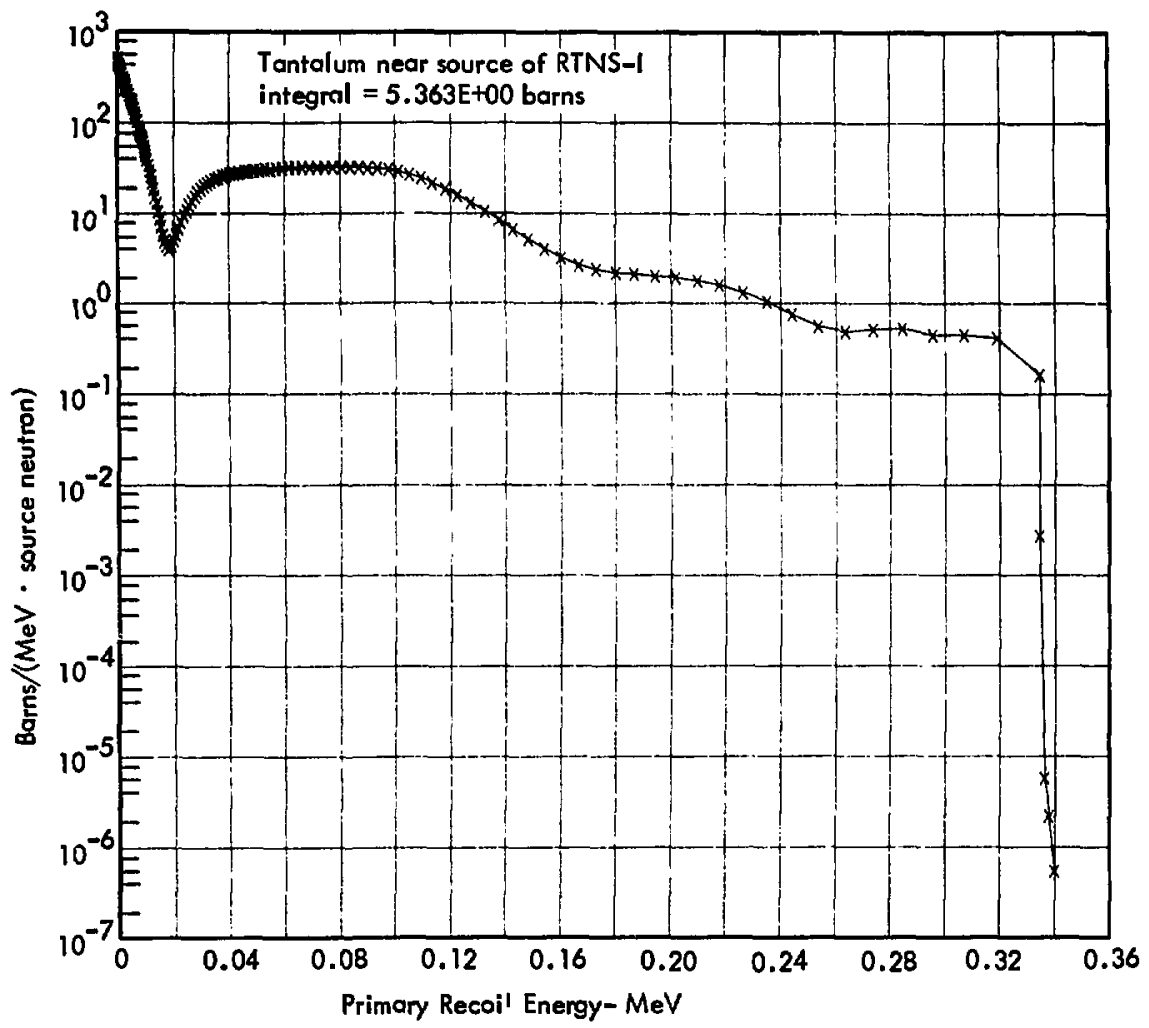

Fig. 48. The primary recoll spectrum (sem1-log). 


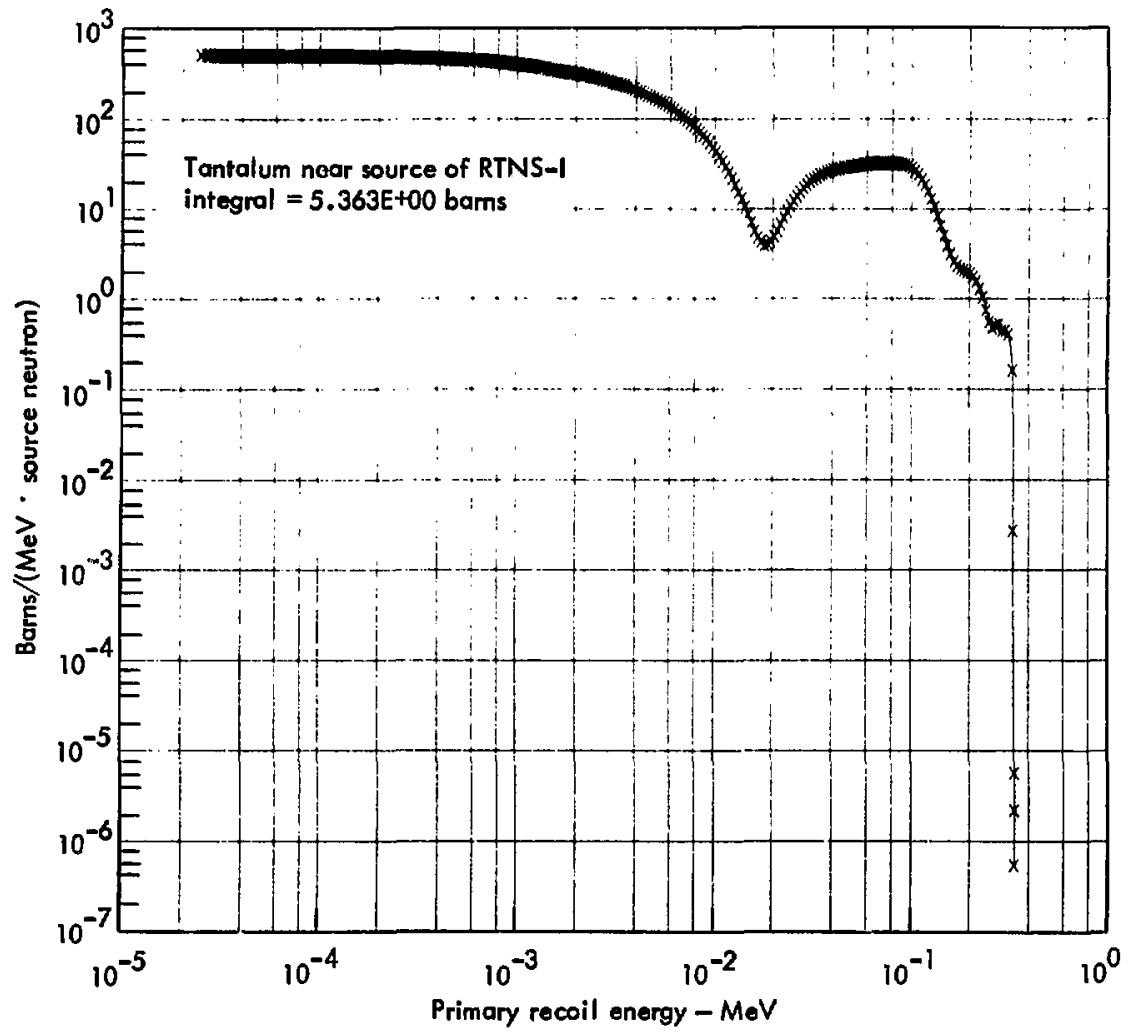

Fig. 49. The prinary recoll spectrum $(\log -\log )$. 


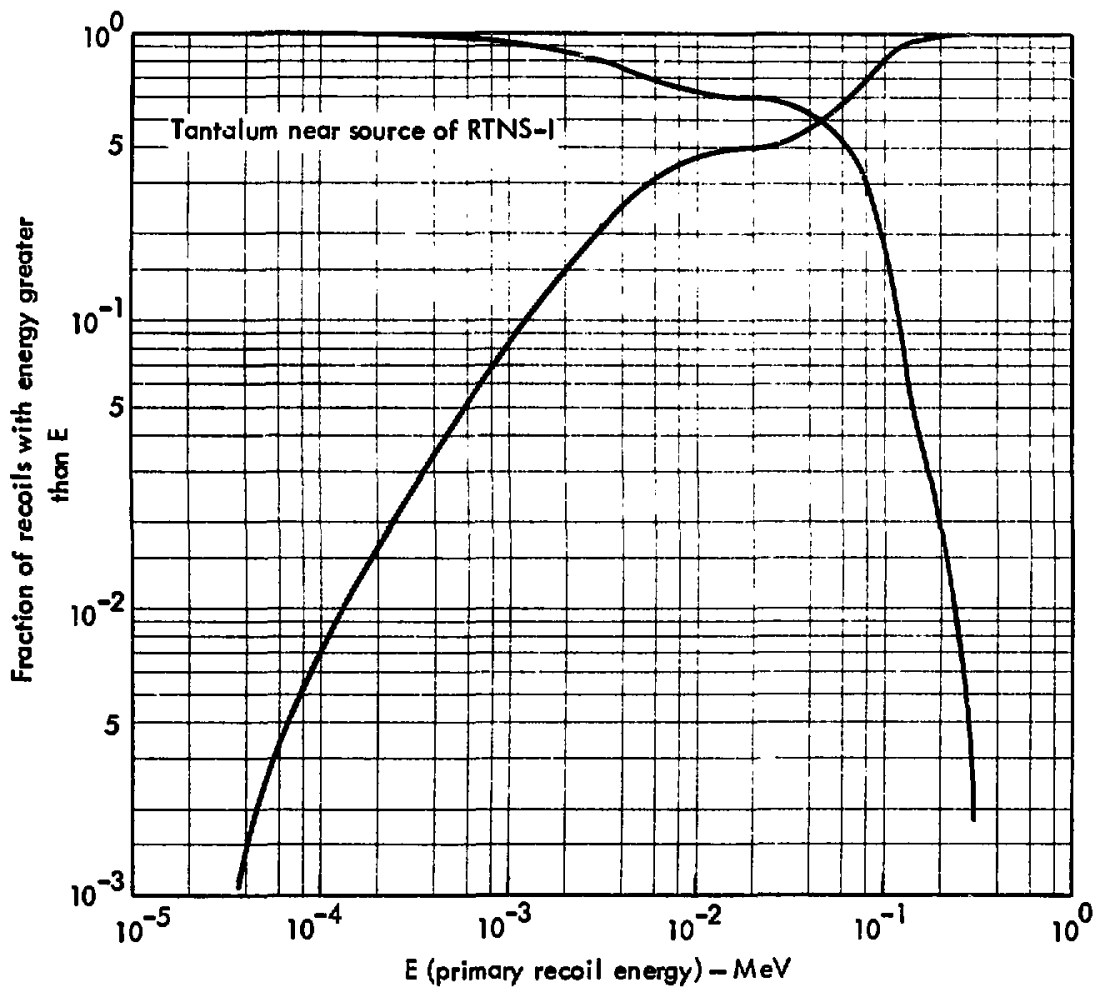

FIg. 50. The normalized integral of the recoll spectrum. 


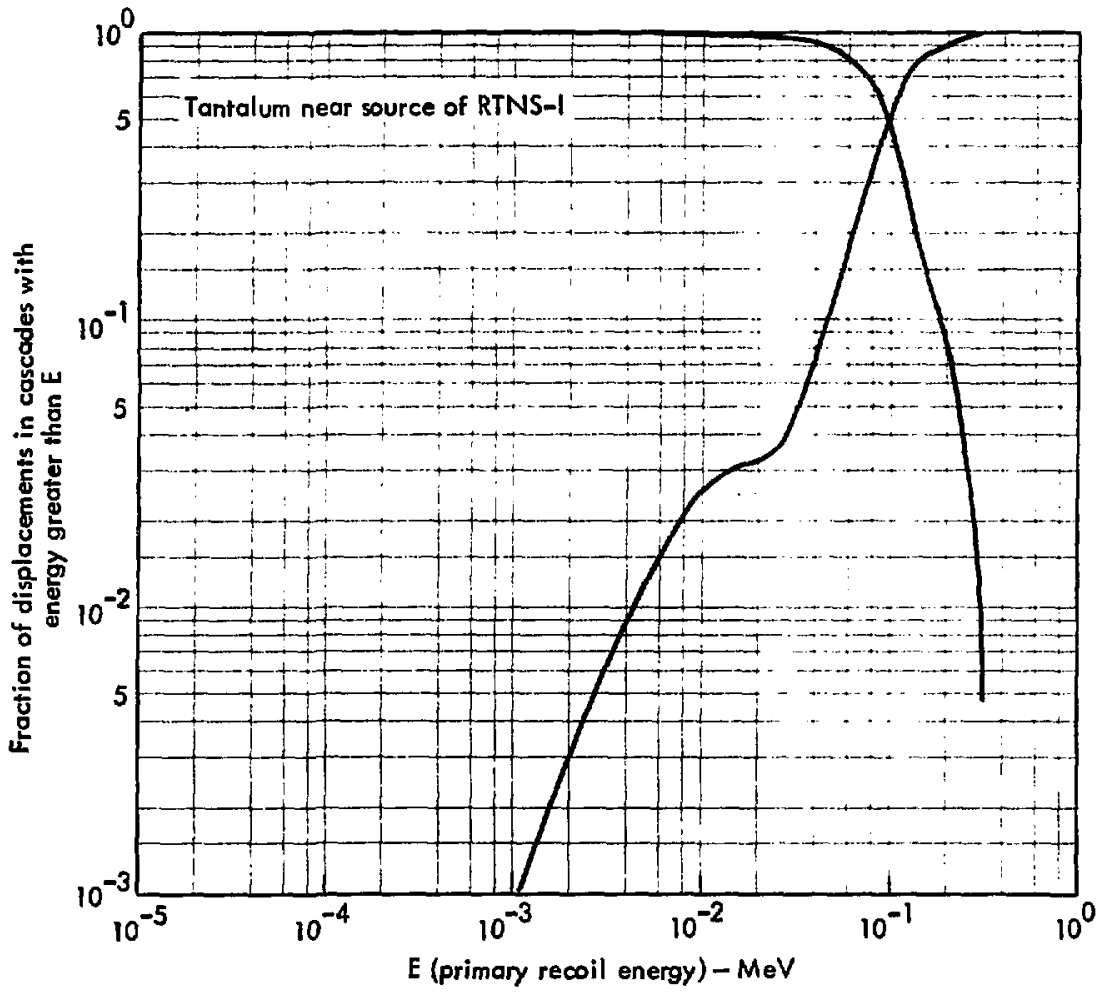

Fig. 51. The normalized integral of the damage energy spectrum. 


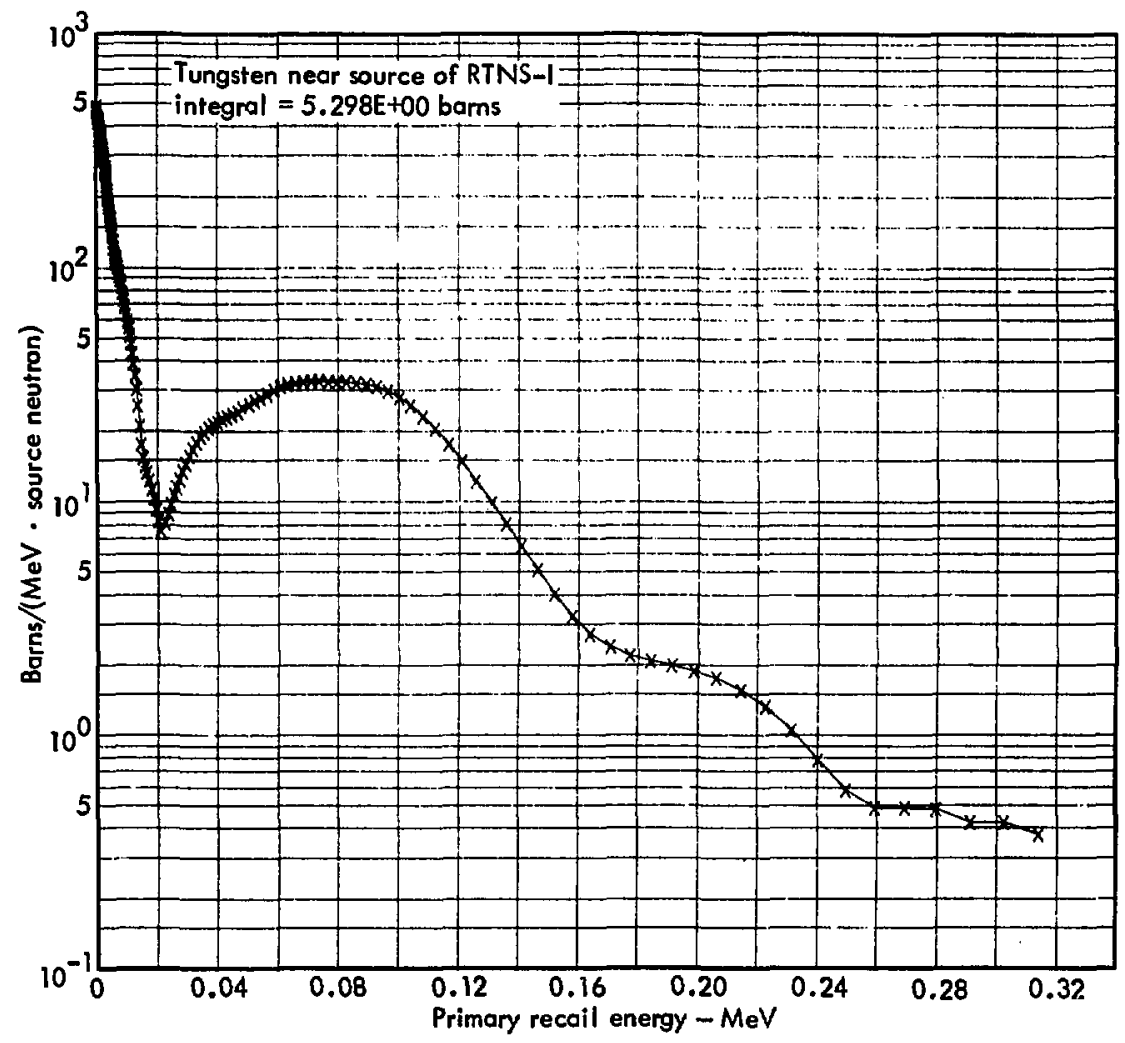

Fig. 52. The primary recoll spectrum (semi-log). 


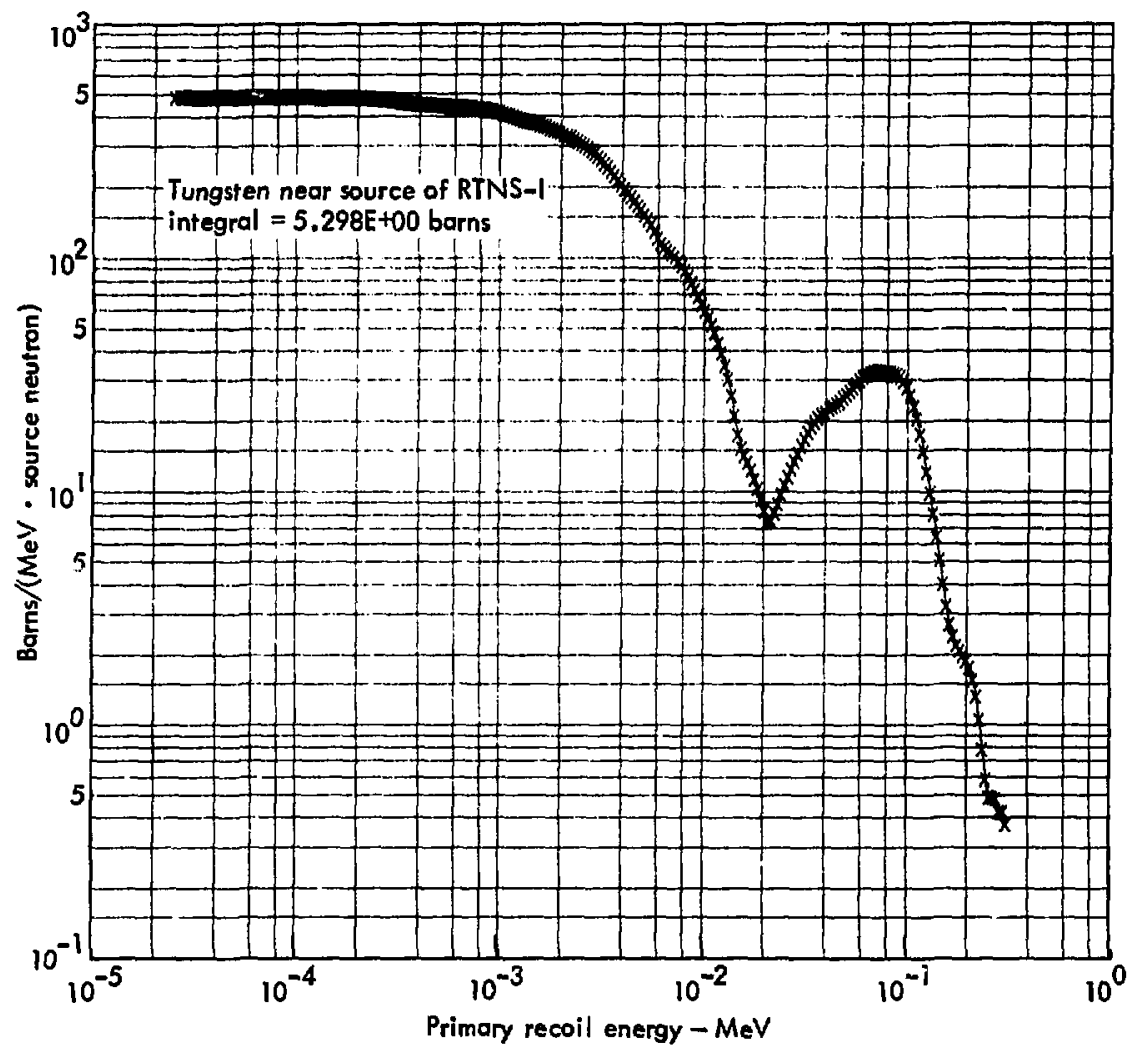

Fig. 53. The primary recoil spectrum (log-log). 


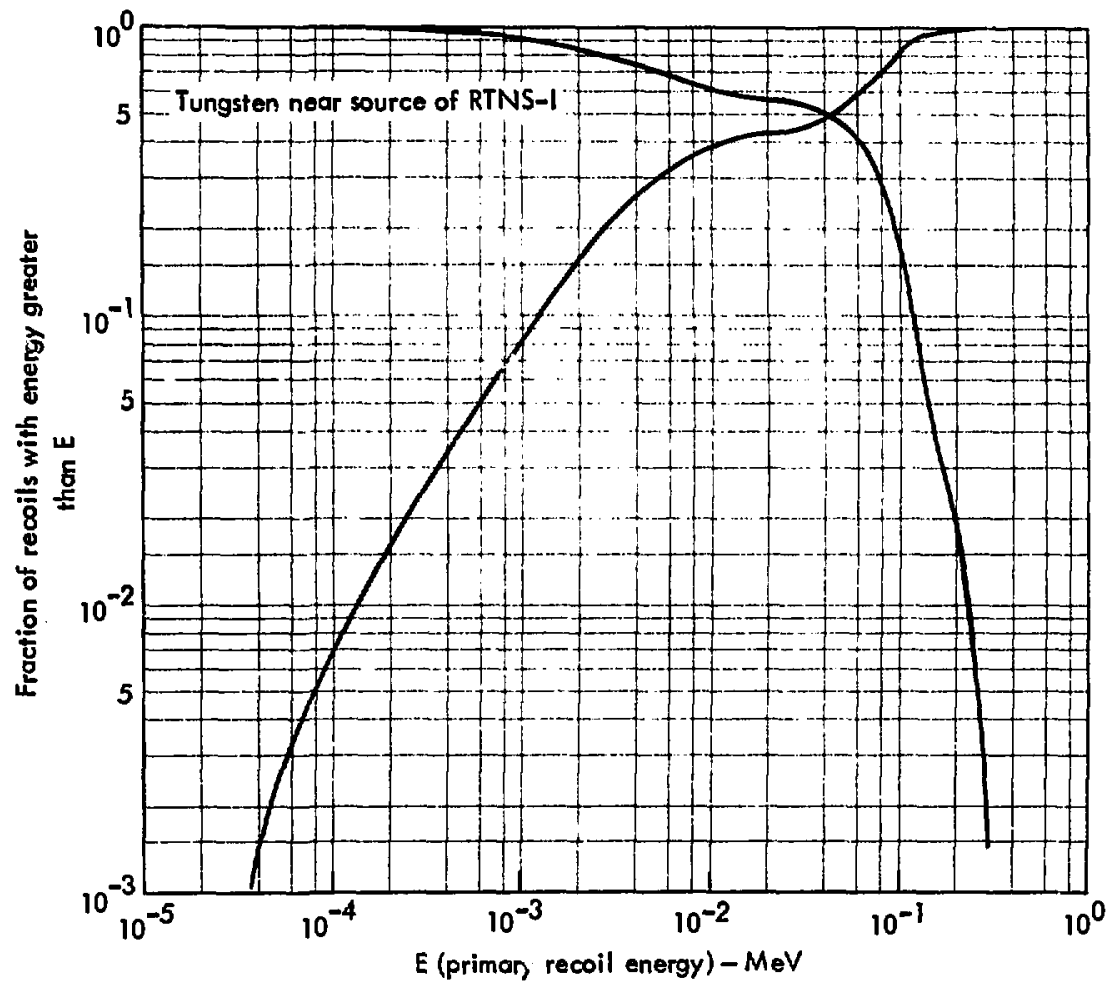

Fig. 54. The normalized integral of the recoll spectrum. 


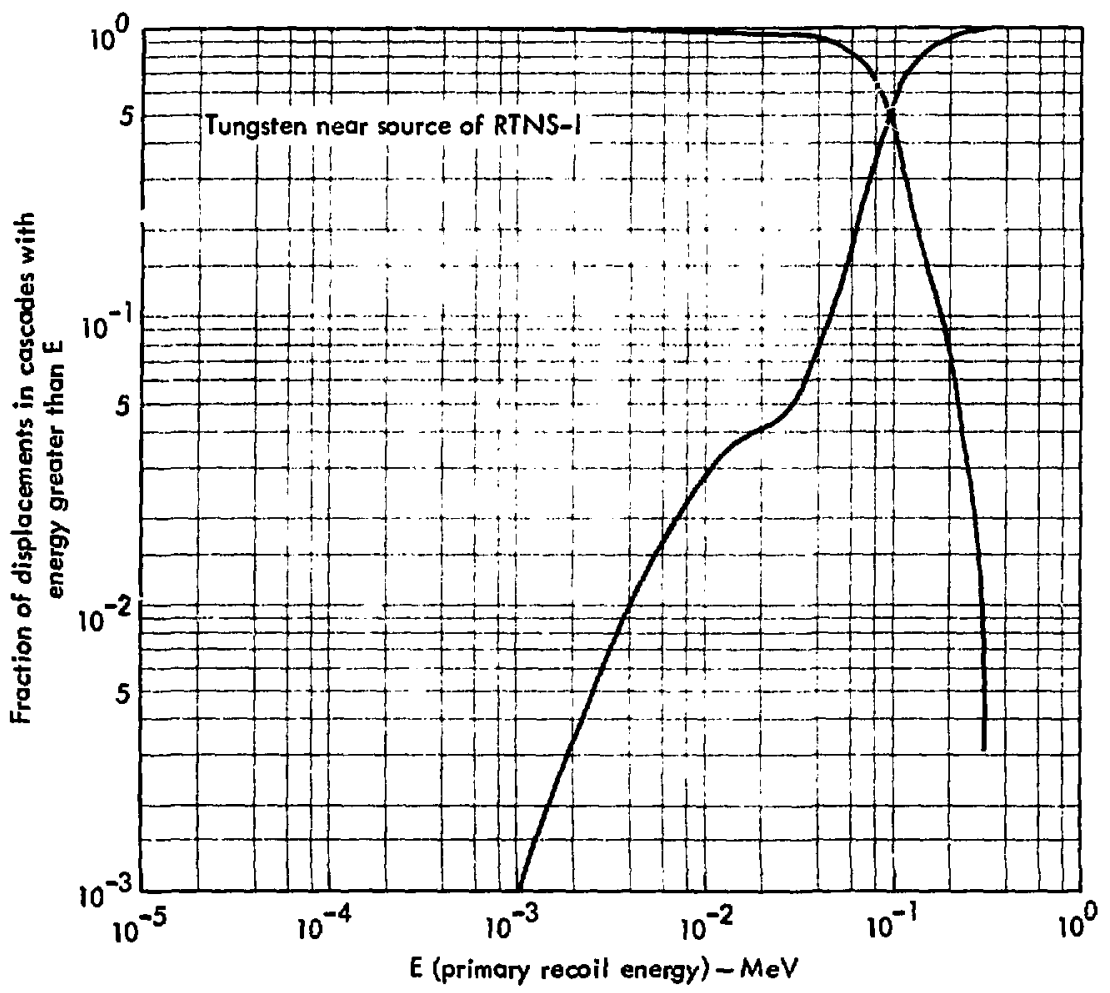

F1g. 55. The normalized integral of the damage energy spectrum. 


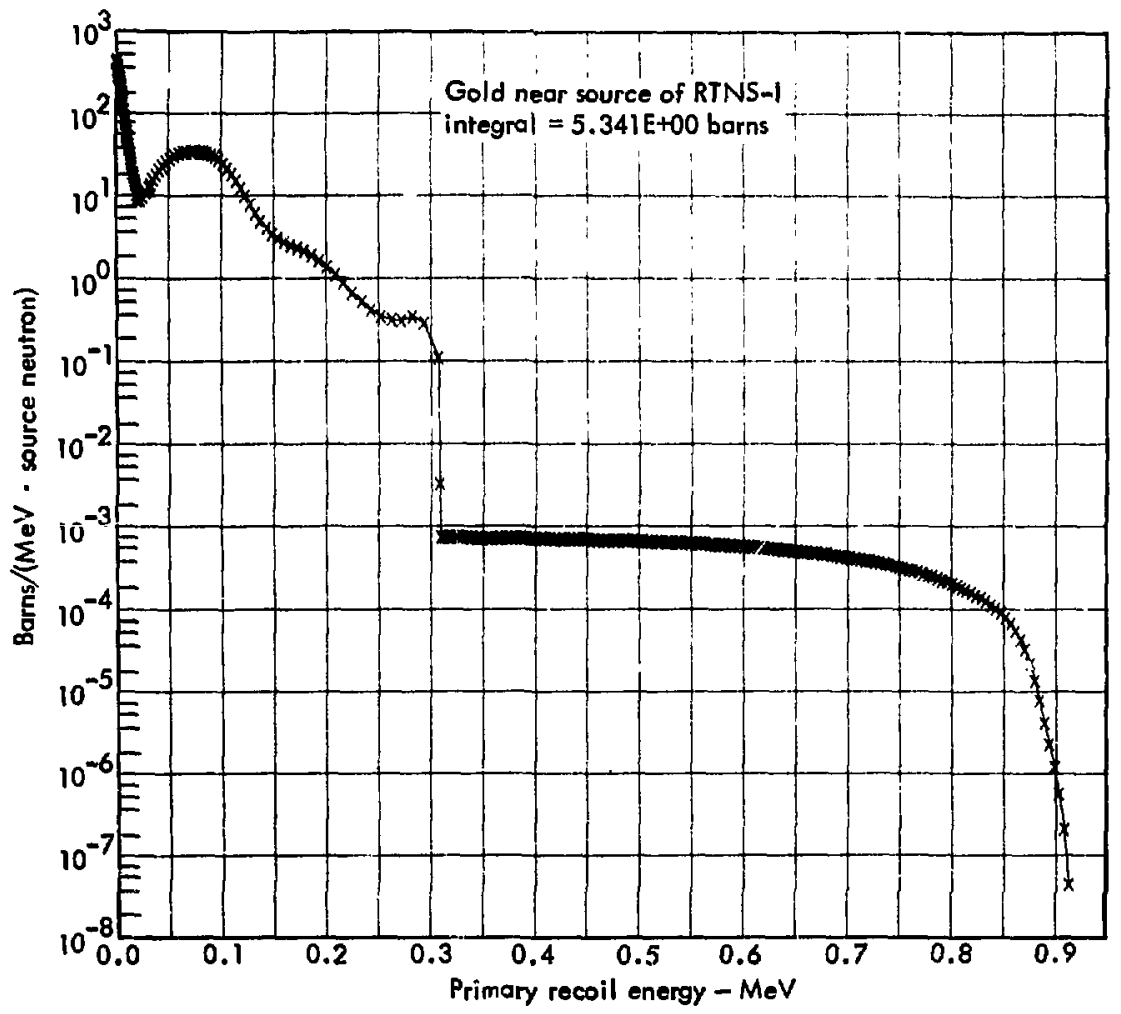

Fig. 56. The primary recoil spectrum (semi-log). 


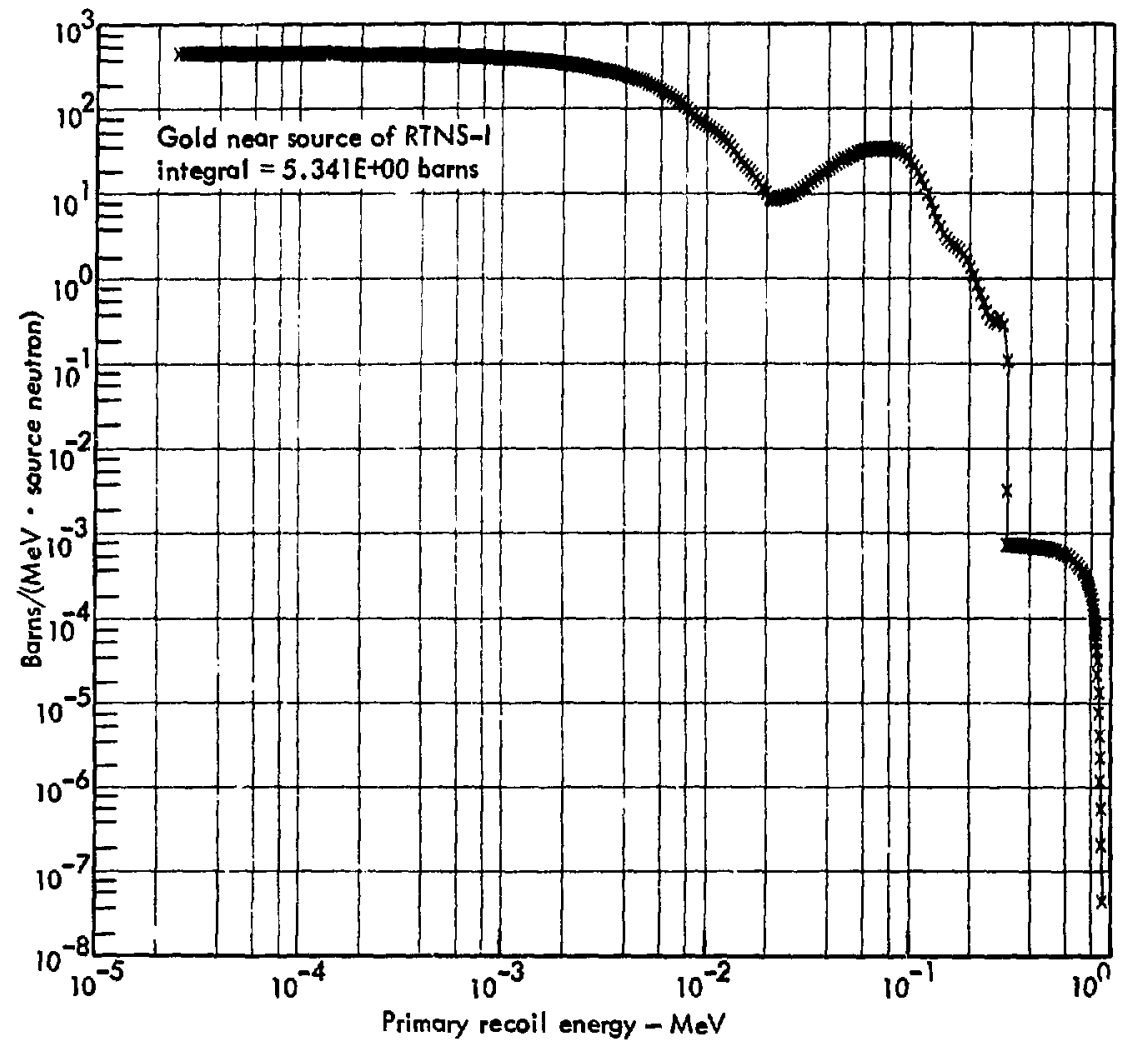

F1g. 57. The primary recoll spectrum $(\log -\log )$. 


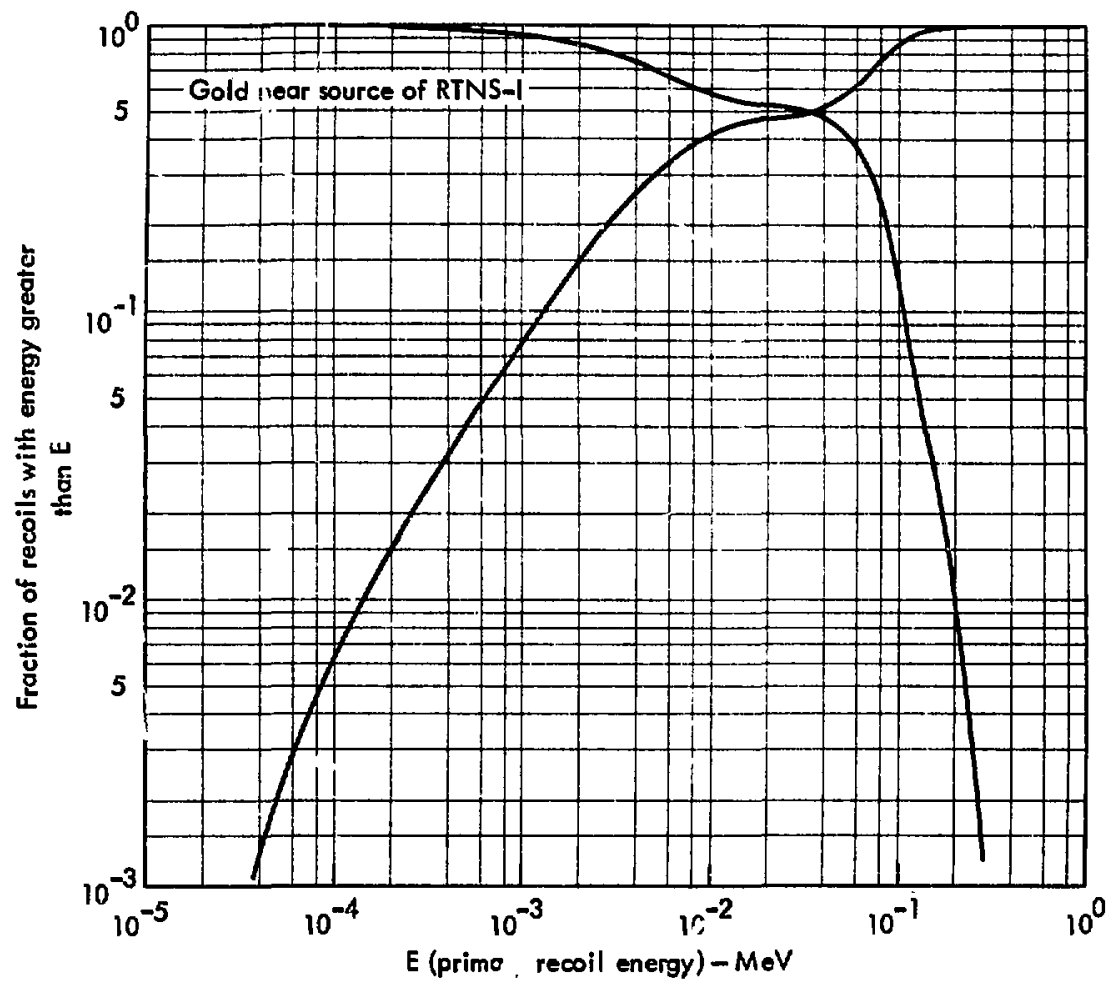

Fig. 58. The normalized integral of the recoll spectrum. 


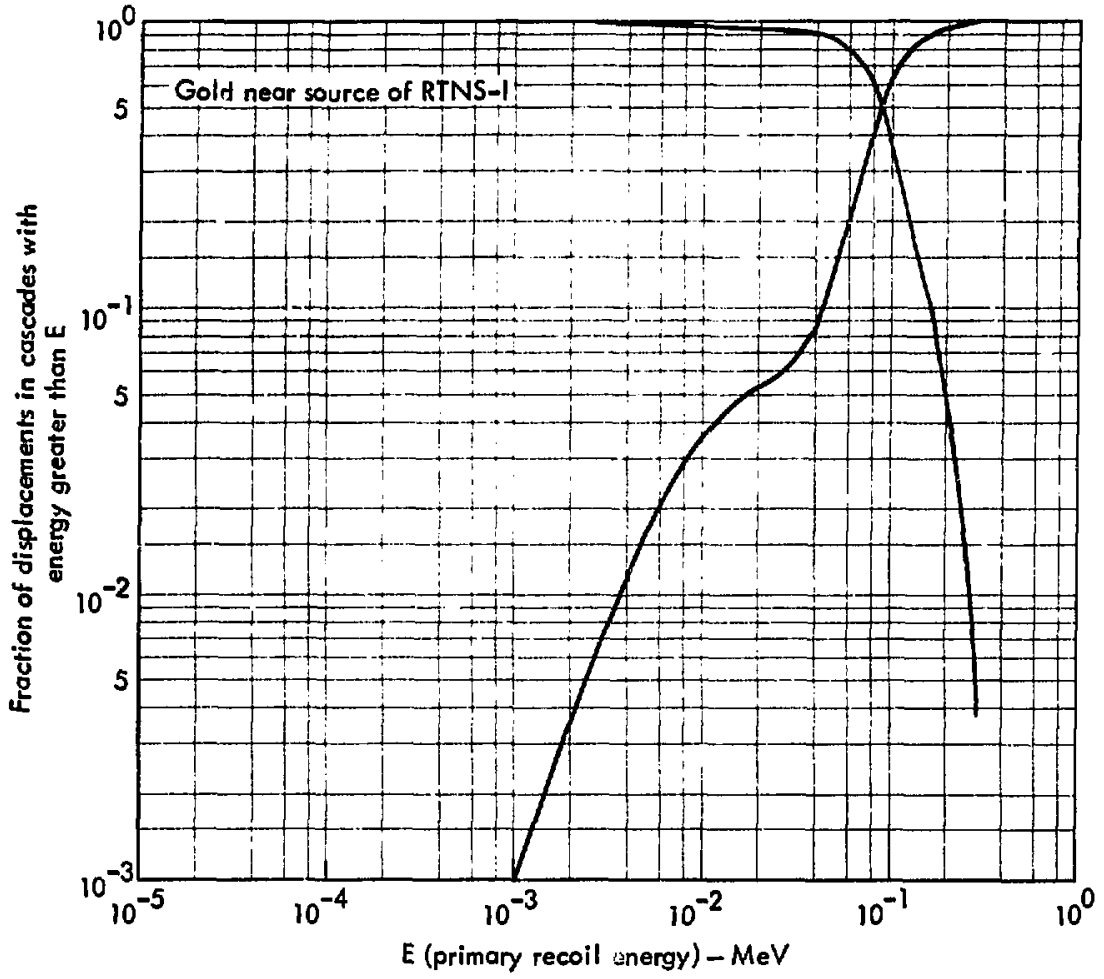

Fig. 59. The normalized integral of the damage energy spectrum. 


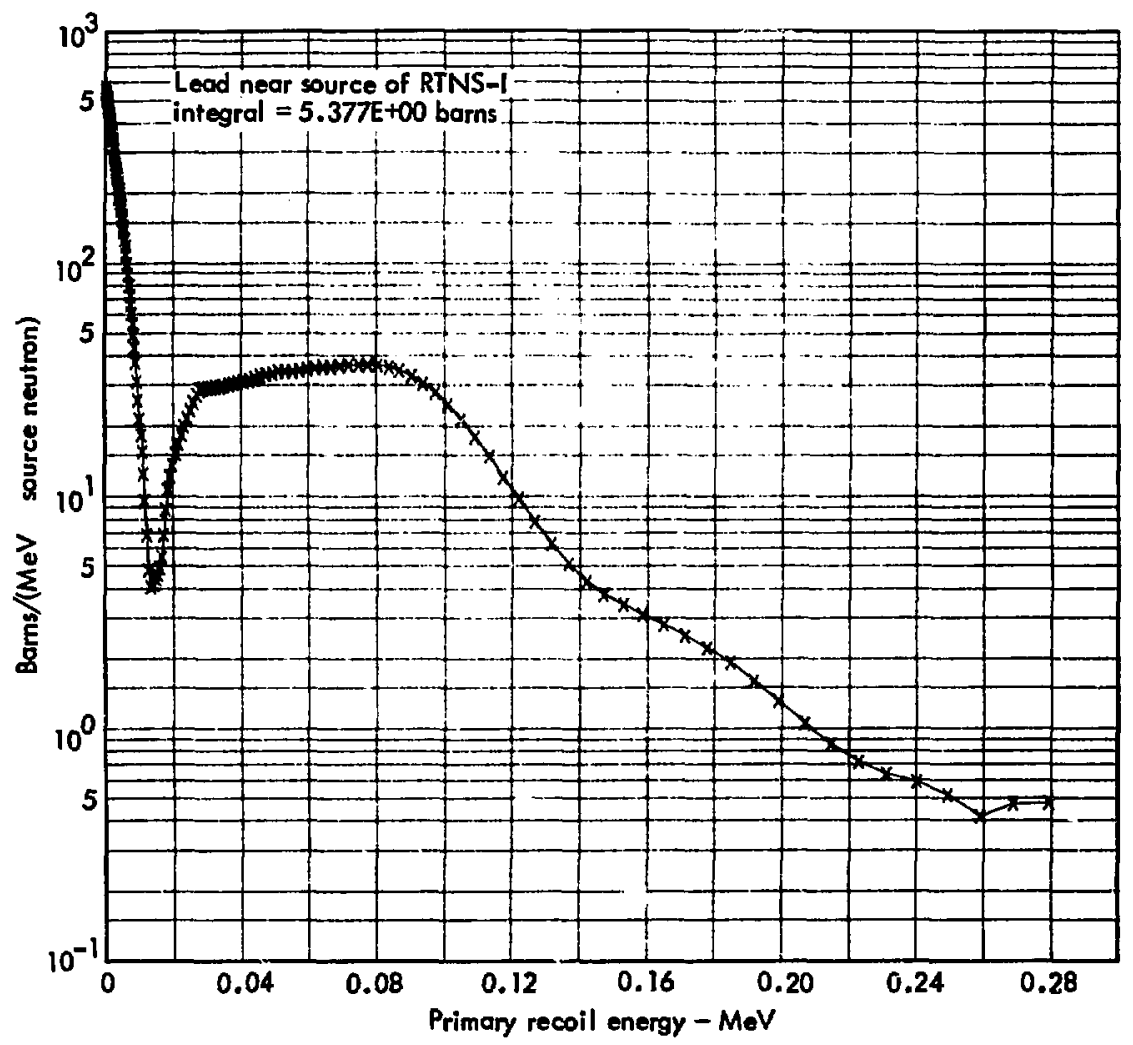

Fig. 60. The primary recoll spectrum (semi-log). 


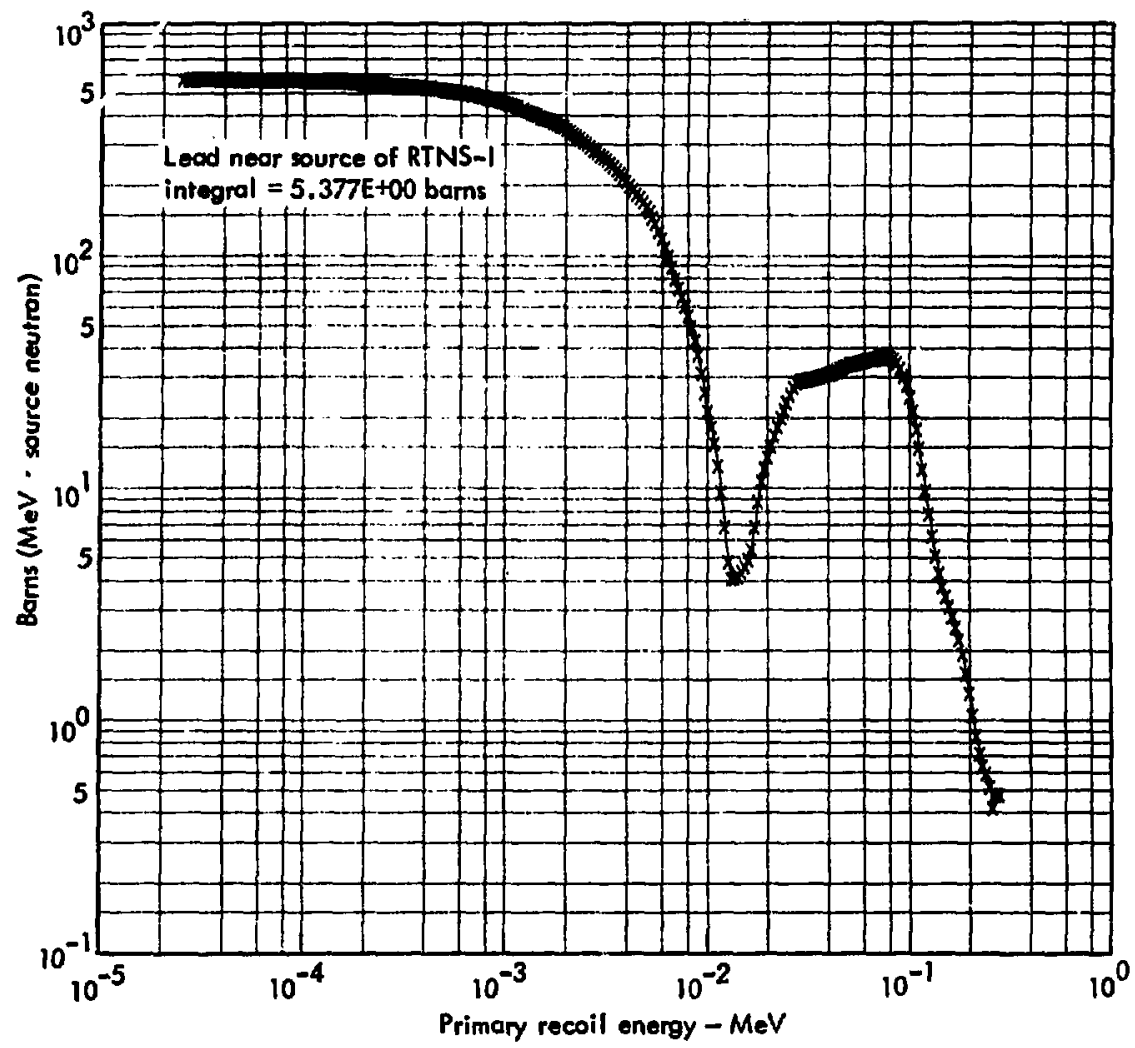

F1g. 61. The primary recoil spectrum $(\log -\log )$. 


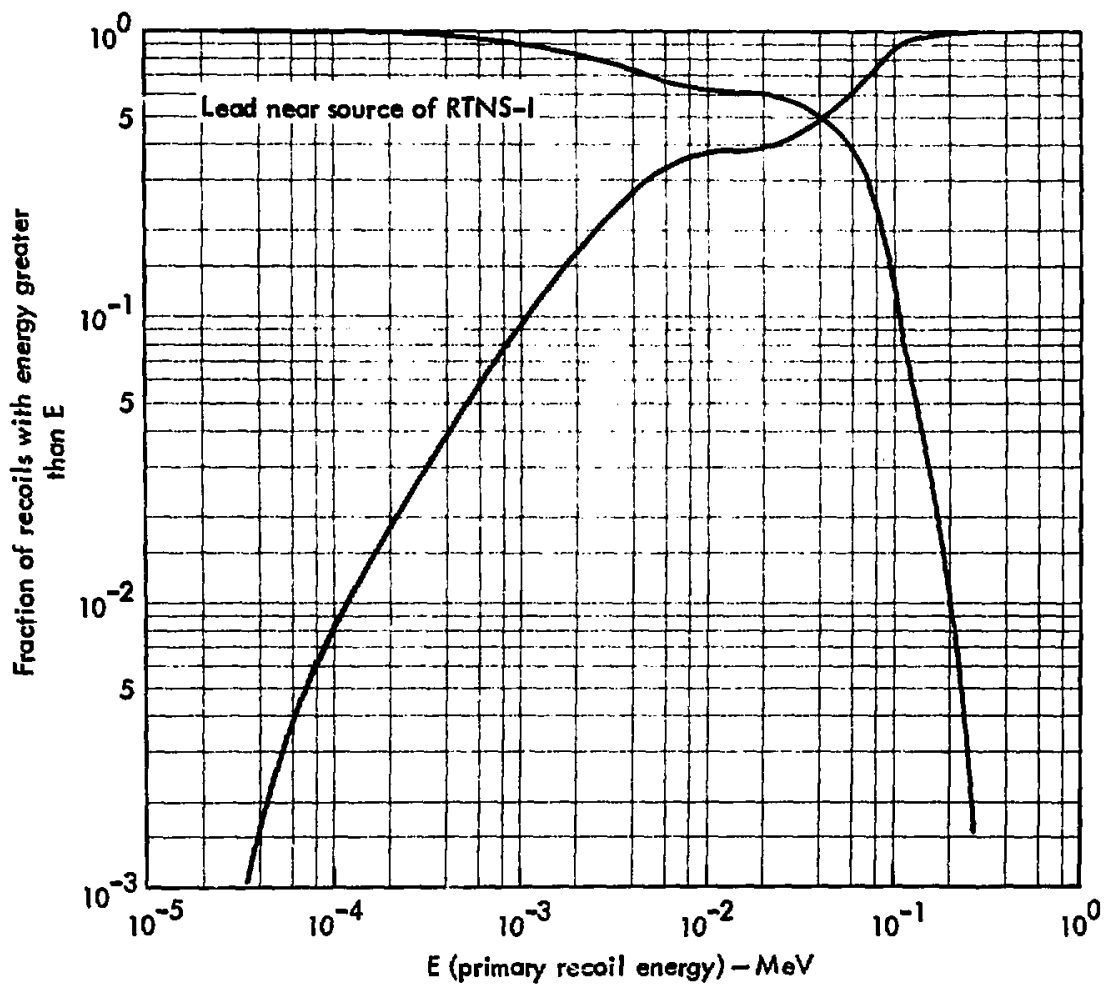

F1g. 62. The normalized Integral of the recoll spectrum. 


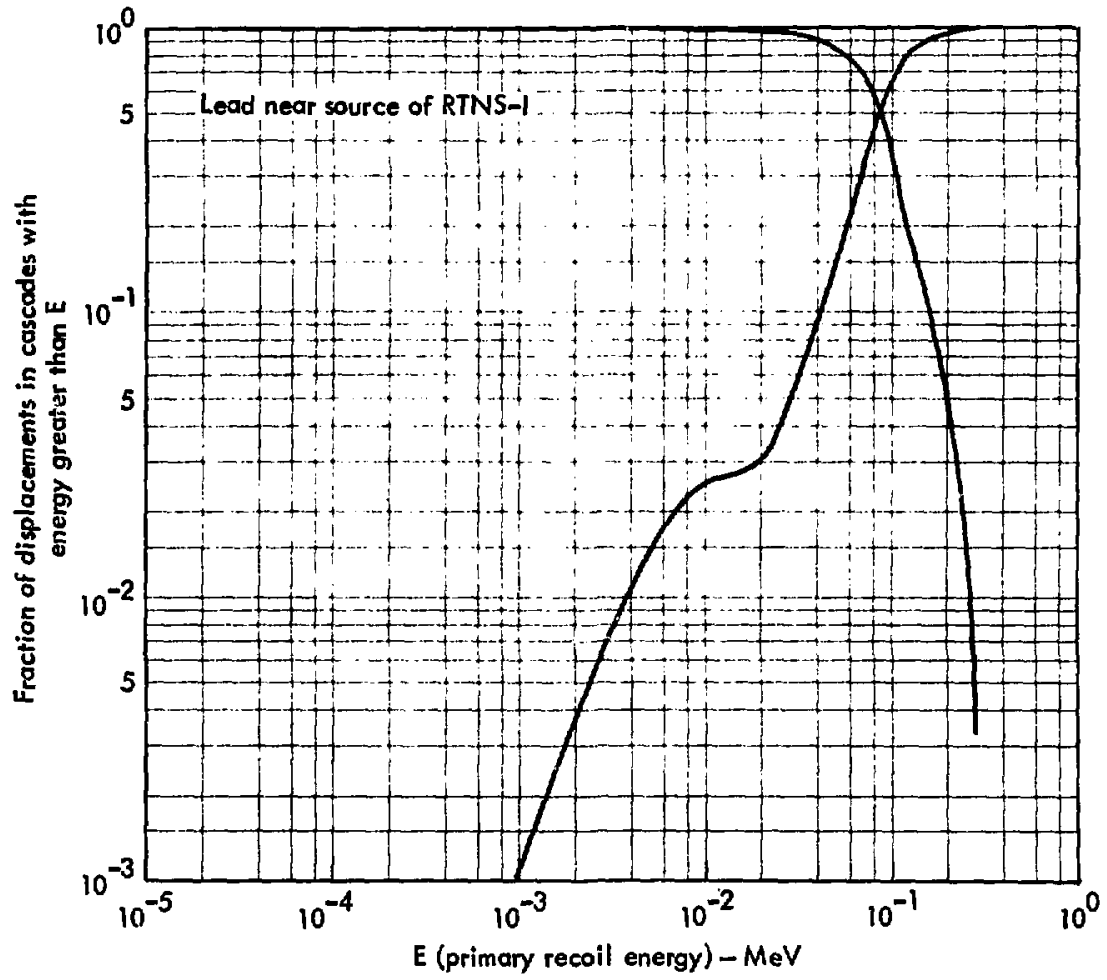

Fig. 63. The normalized integral of the damage energy spectrum. 